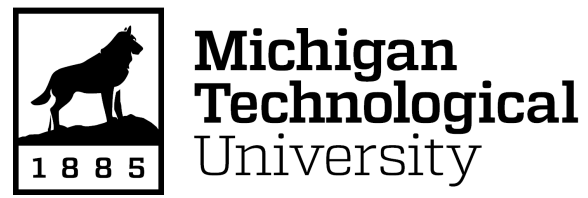

Michigan Technological University Digital Commons @ Michigan Tech

Dissertations, Master's Theses and Master's Reports

2016

\title{
AIR CHARGE ESTIMATION FOR AN SI ENGINE USING IN- CYLINDER PRESSURE SENSOR
}

Arya Yazdani

Michigan Technological University, aryay@mtu.edu

Copyright 2016 Arya Yazdani

\section{Recommended Citation}

Yazdani, Arya, "AIR CHARGE ESTIMATION FOR AN SI ENGINE USING IN-CYLINDER PRESSURE SENSOR", Open Access Master's Thesis, Michigan Technological University, 2016.

https://doi.org/10.37099/mtu.dc.etdr/226

Follow this and additional works at: https://digitalcommons.mtu.edu/etdr

8 Part of the Mechanical Engineering Commons 
AIR CHARGE ESTIMATION FOR AN SI ENGINE USING IN-CYLINDER PRESSURE SENSOR

\author{
By \\ Arya Yazdani
}

\begin{abstract}
A THESIS
Submitted in partial fulfillment of the requirements for the degree of MASTER OF SCIENCE

In Mechanical Engineering
\end{abstract}

MICHIGAN TECHNOLOGICAL UNIVERSITY

2016

(C) 2016 Arya Yazdani 
This thesis has been approved in partial fulfillment of the requirements for the Degree of MASTER OF SCIENCE in Mechanical Engineering.

Department of Mechanical Engineering-Engineering Mechanics

Thesis Advisor: Dr. Jeffrey D. Naber

Committee Member: Dr. Jeffrey B. Burl

Committee Member: $\quad$ Dr. Scott A. Miers

Committee Member: Dr. Mahdi Shahbakhti

Department Chair: Dr. William W. Predebon 


\section{Dedication}

I dedicate this thesis to my parents, Zohreh and Hashem, for their consistent spiritual support for me, while being thousand miles away during this work 


\section{Table of Contents}

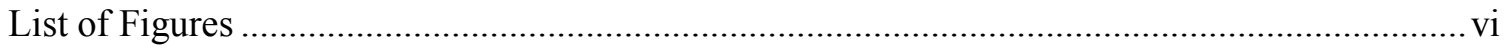

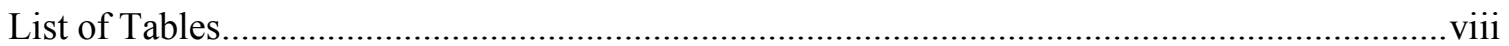

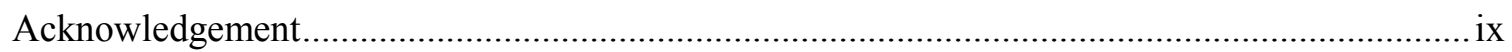

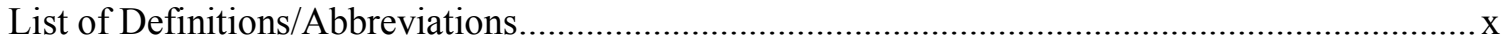

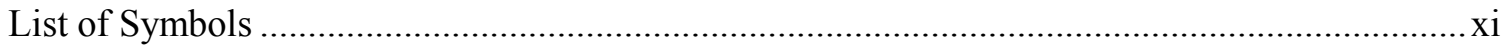

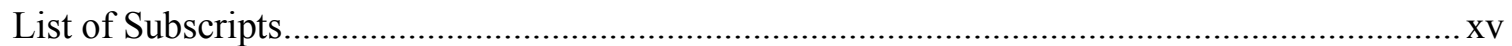

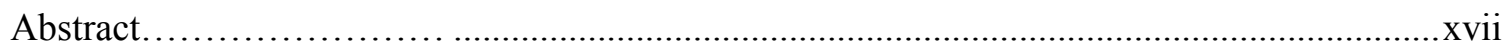

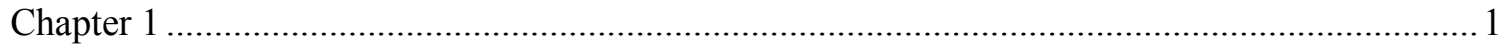

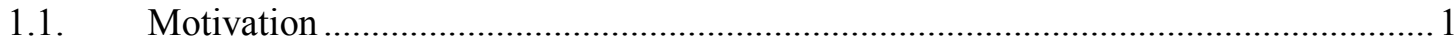

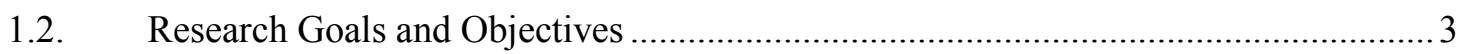

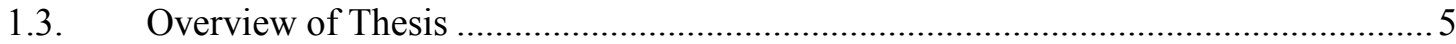

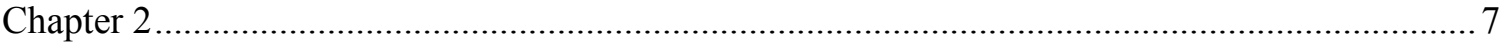

Air Charge Estimation Background and Literature Review ...................................................... 7

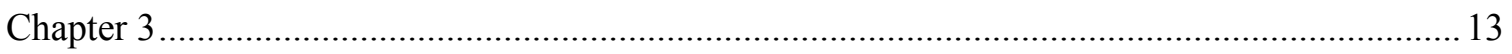

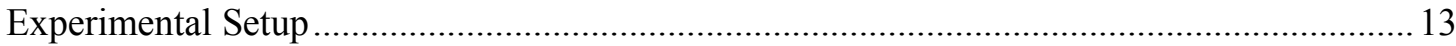

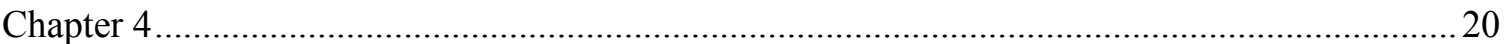

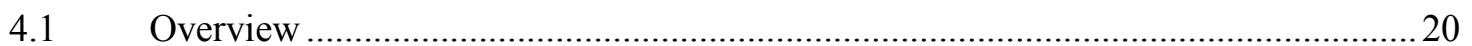

4.2. Equations Used in Air Charge Estimation Algorithm ........................................... 22

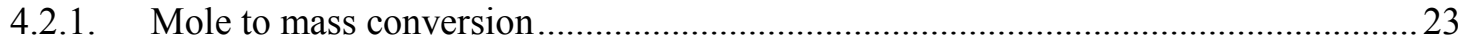

4.2.2. Water Vapor Partial Pressure Calculation.................................................................. 24

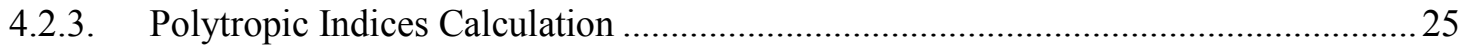

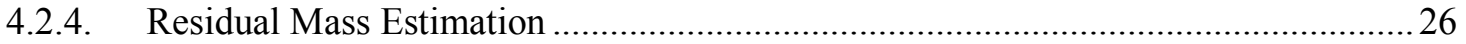

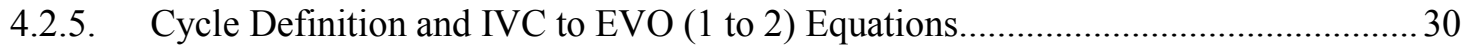

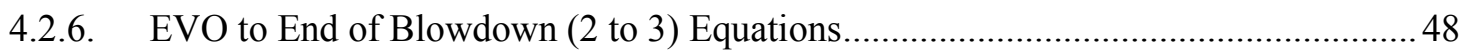

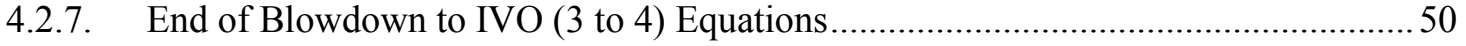

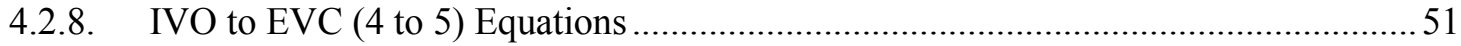

4.2.9. EVC to BDC in Compression Stroke (5' to 7) Equations............................................ 54

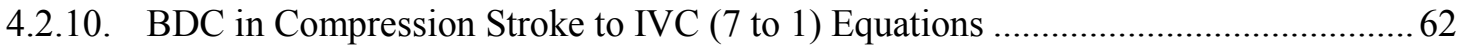

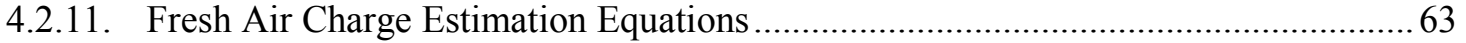




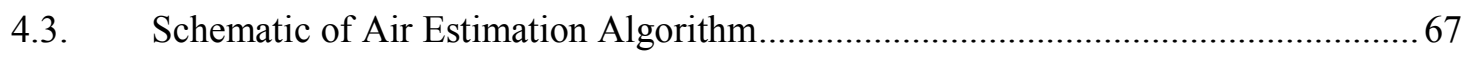

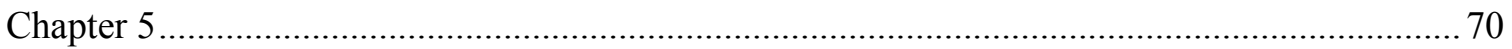

5.1 Air Charge Estimation Using Fuel and Wide-Band Sensors...................................... 71

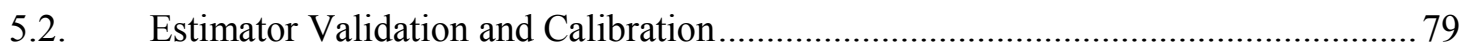

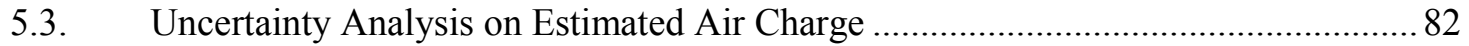

5.3.1. $\quad$ Air Charge Mass and Exhaust Temperature Uncertainties ….................................. 83

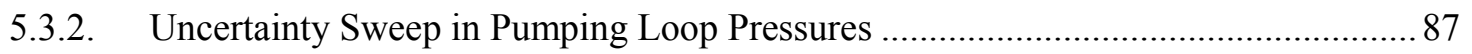

5.3.3. Air Charge Uncertainty Comparison between Different Estimators.......................... 93

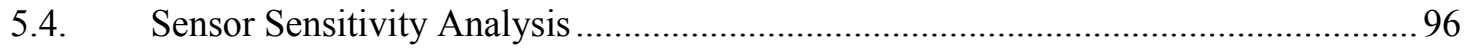

5.5. Generated Lookup Tables based on Calibration Data .............................................. 99

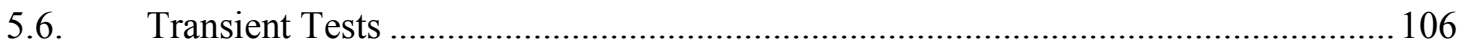

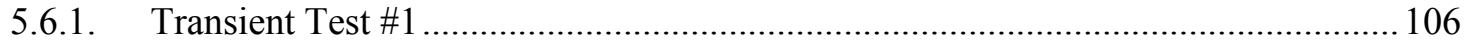

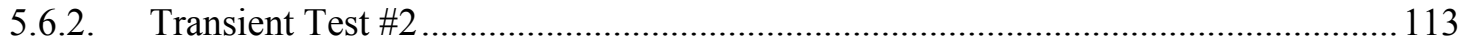

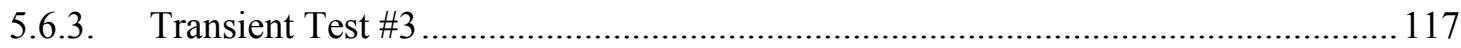

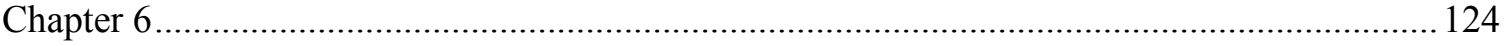

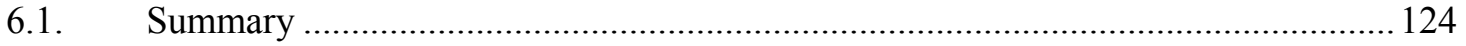

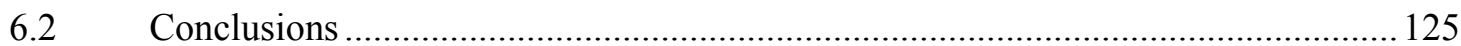

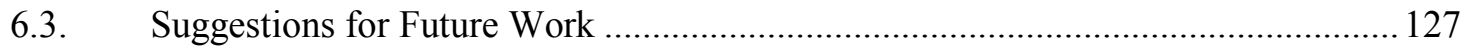

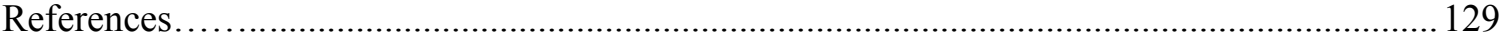

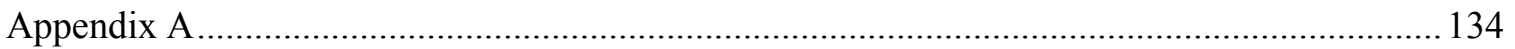

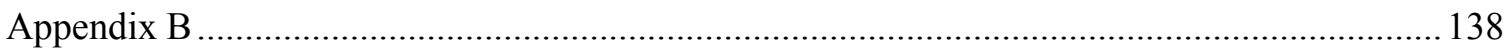

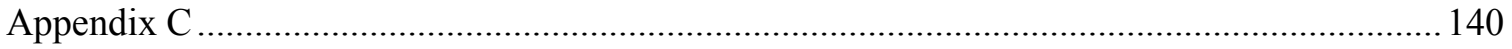

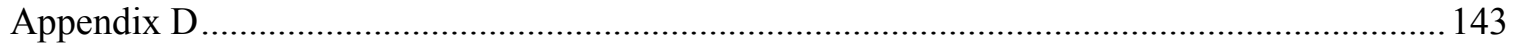




\section{List of Figures}

Figure 1- V6 3.5L Ford Ecoboost engine and EC Dynamometer available in MTU MEEM building sub-basement

Figure 2- Pipes connected to exhaust manifold (red circle indicators) with one end adjacent to exhaust valves of cylinders in bank 2

Figure 3- Six individual wide-band sensors mounted on pipes which come from exhaust manifolds of both banks. 17

Figure 4- Coriolis fuel flow meter mounted on fuel delivery system ......................................... 18

Figure 5- Laminar Flow Element (LFE) setup mounted on intake pathway to the engine............ 19 Figure 6- Pressure-Volume diagram and specific event timings for Ecoboost engine at 1500 RPM,

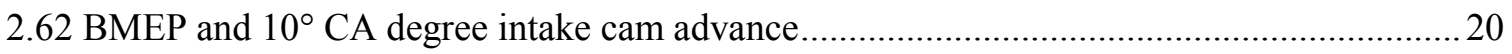

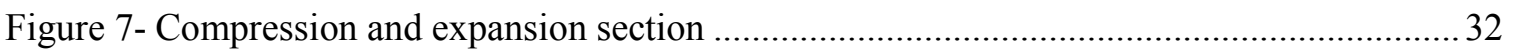

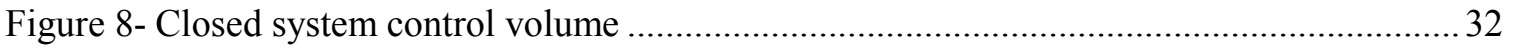

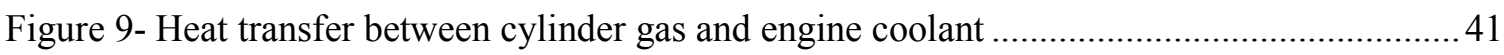

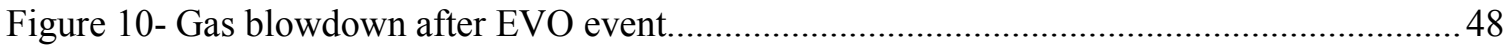

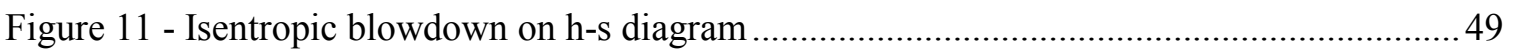

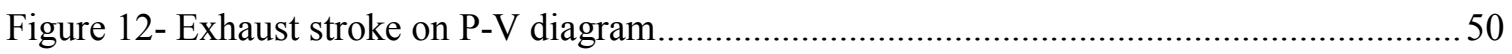

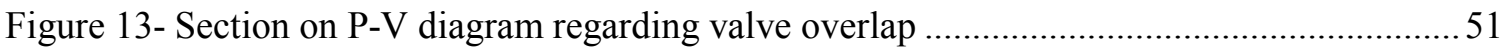

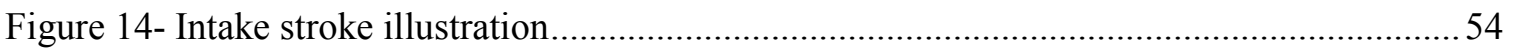

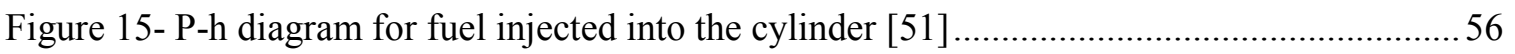

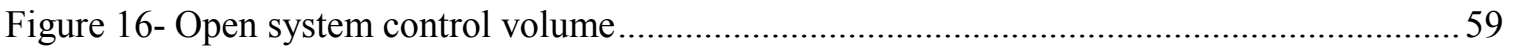

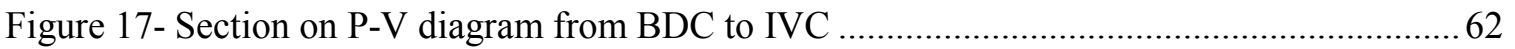

Figure 18- Air estimation algorithm using in-cylinder pressure (Method 1) ................................. 68

Figure 19- Air estimation algorithm using in-cylinder pressure (Method 2) .................................69

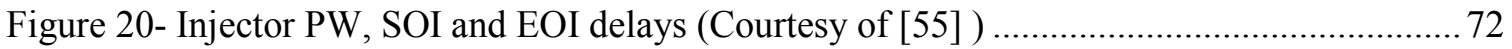

Figure 21- Total injected fuel vs. average injector pulse-width (all test conditions) ......................74

Figure 22-Total injected fuel vs. average injection differential pressure (all test conditions).......75

Figure 23- Total calculated fuel against total measured fuel (both fuel for 6 cylinders and 300 cycles)

Figure 24- Estimator relative uncertainties for different tests (pumping loop pressure uncertainty sweep).

Figure 25- Relative and absolute air charge uncertainty against uncertainty sweep in pumping loop pressures

Figure 26- Comparison between ' $\alpha$ ' values from neural network output and tabulated data for 102 Figure 27- Comparison between hconstant values from network output and tabulated data for 103 Figure 28- Comparison between ' $\alpha$ ' values from neural network output and tabulated data for 104 Figure 29- Comparison between hconstant values from neural network output and tabulated

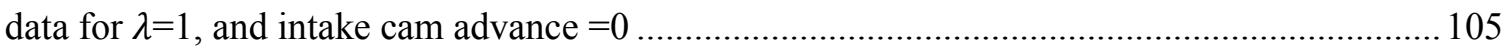

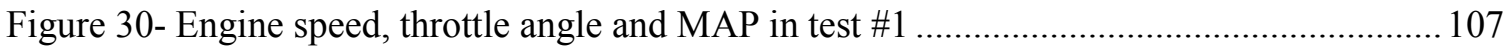

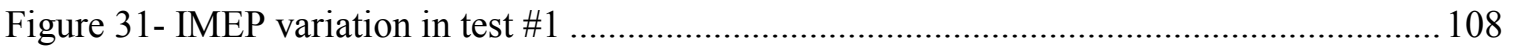

Figure 32- Lambda and cam advance angles in different banks in test \#1 ............................... 109 
Figure 33- Estimator and experimental air charge for cylinders 1, 5, and 6 in test \#1 110

Figure 34 (a) and (b)- Estimator air charge compared to experimental air charge (estimated from

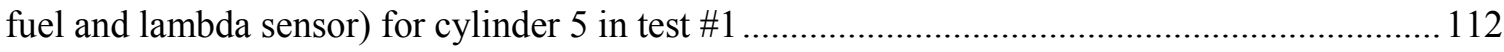

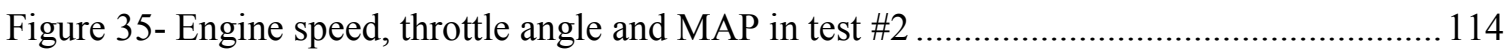

Figure 36- Lambda and cam advance angles in different banks in test \#2 ............................... 115

Figure 37- Estimator and experimental air charge for cylinders 1, 5, and 6 in test \#2 ............... 116

Figure 38- Engine speed, throttle angle and MAP in test \#3 .................................................. 117

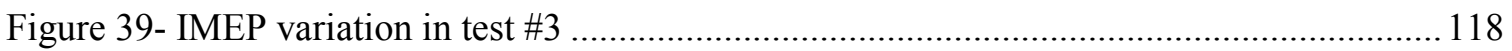

Figure 40- Lambda and cam advance angles in different banks in test \#3 ................................. 119

Figure 41- Estimator and experimental air charge for cylinders 1, 5, and 6 in test \#3 ............... 121

Figure A- 1 Relative humidity viscosity correction for air (Courtesy of [45]) ........................... 136 


\section{List of Tables}

Table 1- Comparison of different air charge estimation methods using pressure transducer ........ 11

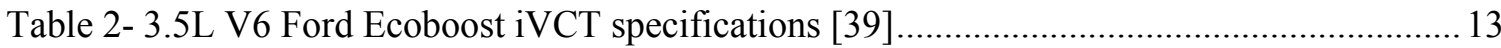

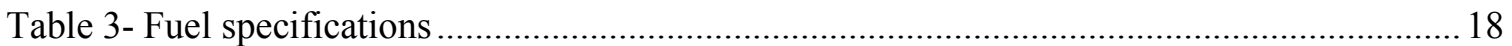

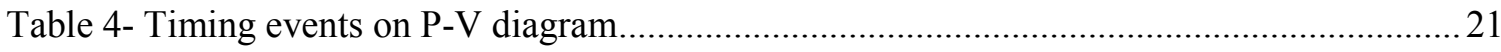

Table 5- Two different air charge estimation methods in this work based on residual gas

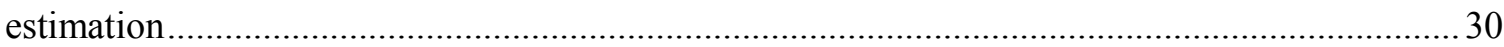

Table 6- Parameter indexing and components' mass definition used in this work.......................... 31

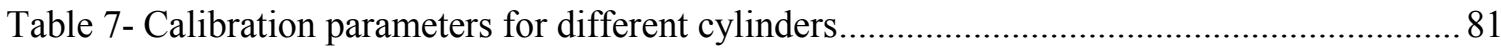

Table 8- Uncertainty in measured and model parameters data for cylinder 5 for test point 1500

RPM, 2.62 bar BMEP (3.1 bar IMEP), lambda=1, intake cam advance $=0$............................... 85

Table 9- Calculated uncertainty in estimated air charge and exhaust temperature for cylinder 5.86

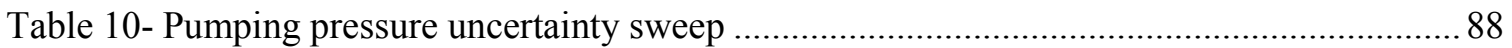

Table 11- Relative uncertainty in air charge (\%) with pumping loop pressure sweep for different

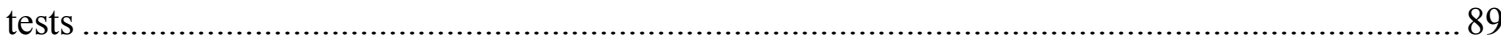

Table 12- Data for estimator in G.Colin et al., 2007-24-0049 ( [34])......................................... 93

Table 13- Uncertainty in estimated air charge for three different estimators; data for cylinder5 at test point 1500 RPM, 2.62 bar BMEP (3.1 bar IMEP), lambda=1, intake cam advance $=0$......... 95

Table 14- Effect of changing transducer gain on IMEP and estimated air charge mass................98

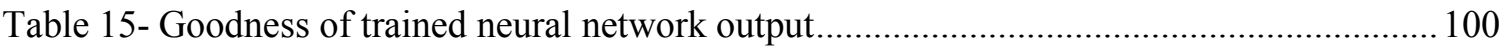

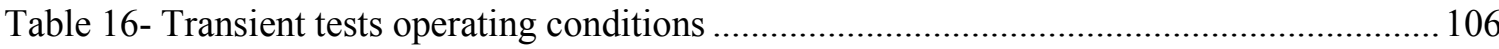

Table 17-RMSE (mg) and CV(RMSE) (\%) in transient tests for different cylinders.................. 122

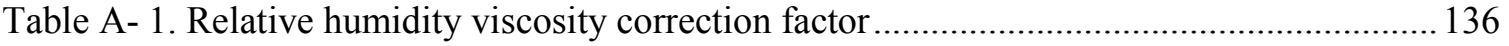

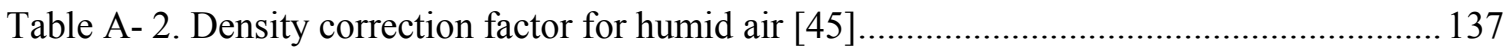

Table B- 1. Steady-state tests performed and corresponding PW, differential injection pressure,

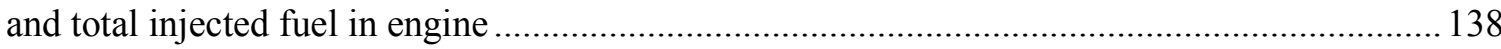

Table C- 1. Steady state test conditions and calibrated parameters .......................................... 141 


\section{Acknowledgement}

First of all, I would like to express my great appreciation to Dr. Jeffrey Naber as my advisor, for providing the opportunity to pursue my master's degree and work on this project under his supervision. I can honestly say without his support, I would not be where I am today.

For financial support, I would like to extend my appreciation to Ford Motor Company for their funding on this project. I am also thankful of Garlan Huberts, Chris Glugla, Doug McEwan and Stephen Cooper as the Ford team members, with whom I a great experience to work on this project.

I would like to thank Paul Dice for his assistance with the experimental setup in the test cell. Furthermore, I appreciate my friends Ehsan Ansari and Xin Wang who helped me with issues around running the engine and dyno and performing the tests.

I also do appreciate my friend Meysam Razmara for the time he spent to give me comments to improve the quality of this thesis. 


\section{List of Definitions/Abbreviations}

\begin{tabular}{|c|c|}
\hline AFR & Air-Fuel Ratio \\
\hline BMEP & Brake Mean Effective Pressure \\
\hline EVC & Exhaust Valve Closing \\
\hline EVO & Exhaust Valve Opening \\
\hline FAR & Fuel-Air Ratio \\
\hline FRP & Fuel Rail Pressure \\
\hline IMEP & Indicated Mean Effective Pressure \\
\hline IVC & Intake Valve Closing \\
\hline IVO & Intake Valve Opening \\
\hline LHV & Lower Heating Value \\
\hline MAP & Manifold Absolute Pressure \\
\hline MW & Molecular Weight \\
\hline PW & Pulse Width \\
\hline RGF & Residual Gas Fraction \\
\hline RH & Relative Humidity \\
\hline RMSE & Root Mean Squared Error \\
\hline SSE & Error Sum of Squares \\
\hline SSTO & Total Sum of Squares \\
\hline
\end{tabular}




\section{List of Symbols}

\begin{tabular}{|c|c|}
\hline $\bar{S}_{p}$ & Mean piston speed $\left(\frac{m}{s e c}\right)$ \\
\hline$h_{\text {constant }}$ & Heat transfer constant $\left(\frac{W}{m^{2} \cdot K}\right)$ \\
\hline$h_{f g}$ & Enthalpy of vaporization $\left(\frac{\mathrm{J}}{\mathrm{kg}}\right)$ \\
\hline$C_{1}$ & $\begin{array}{l}\text { Fox correlation constant (-) / cylinder gas velocity } \\
\text { constant (-) }\end{array}$ \\
\hline$C_{2}$ & $\begin{array}{l}\text { Fox correlation constant }(-) / \text { cylinder gas velocity } \\
\text { constant }\left(\frac{m}{K \cdot \sec }\right)\end{array}$ \\
\hline$C_{P}$ & Specific heat in constant pressure $\left(\frac{J}{\mathrm{~kg} \cdot \mathrm{K}}\right)$ \\
\hline$C_{d}$ & Injector coefficient of discharge (-) \\
\hline$C_{v}$ & Specific heat in constant volume $\left(\frac{\mathrm{J}}{\mathrm{kg} \cdot \mathrm{K}}\right)$ \\
\hline$\dot{Q}$ & Heat transfer rate $(\mathrm{W})$ \\
\hline$R^{2}$ & R-squared (-) \\
\hline$U_{X}$ & Uncertainty in measured or model variable \\
\hline$U_{Y}$ & Uncertainty in estimated variable \\
\hline$V_{c}$ & Clearance volume $\left(\mathrm{m}^{3}\right)$ \\
\hline$V_{d}$ & Displacement volume $\left(\mathrm{m}^{3}\right)$ \\
\hline$W_{\text {piston }}$ & Work done on piston $(\mathrm{J})$ \\
\hline$X_{\text {res }}$ & Residual gas fraction $(\%)$ \\
\hline
\end{tabular}




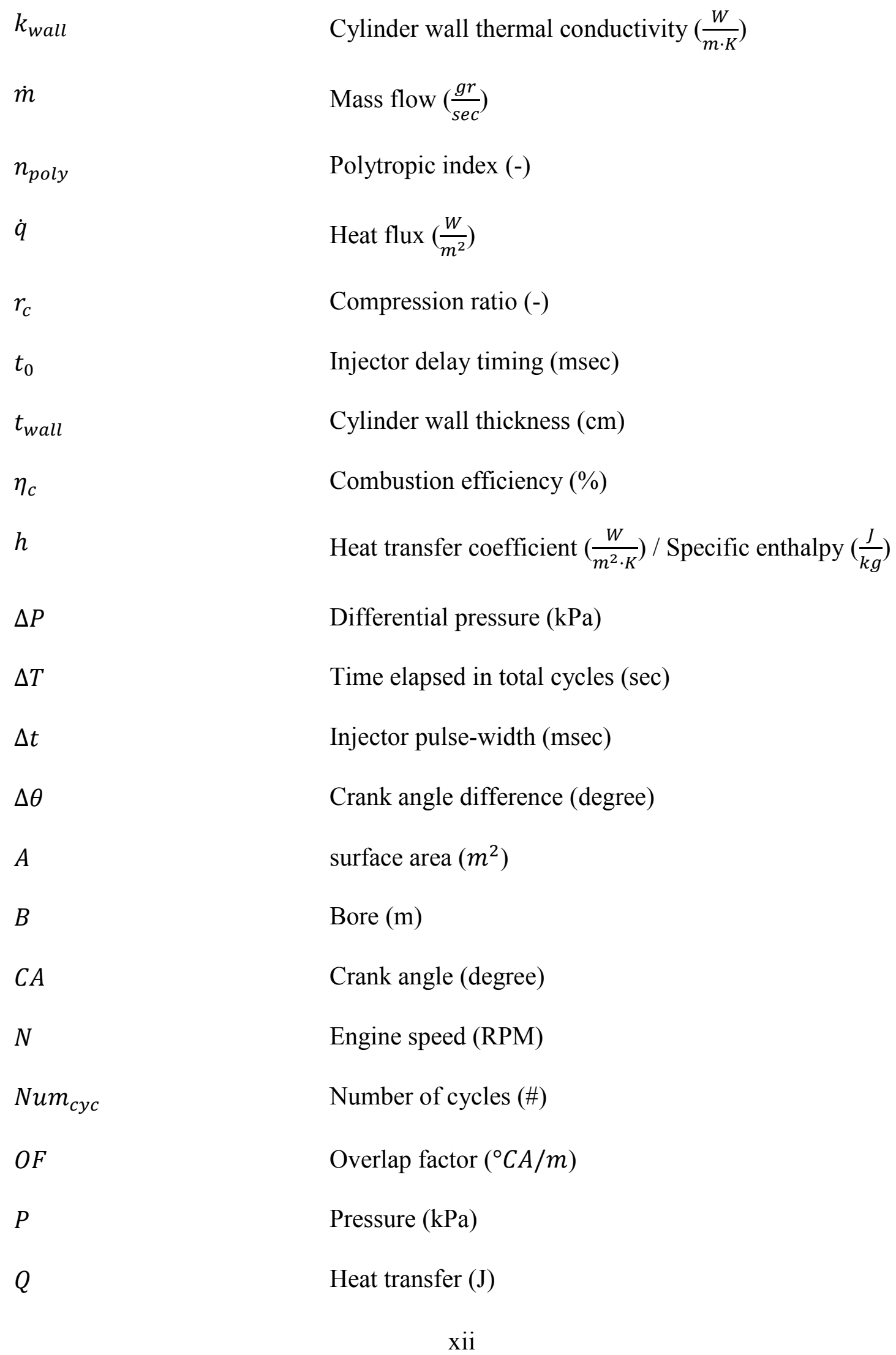


$R$

S

$T$

$U$

V/ Vol

X

$a$

$f$

$k$

$l$

$m$

$n$

$t$

w

$y$

Z

$\alpha$

$\gamma$

$\theta$
Universal gas constant $\left(\frac{\mathrm{kJ}}{\mathrm{kgmol} \cdot \mathrm{K}}\right) /$ ratio of connecting rod

to crank radius (-)

Stroke (m)

Cylinder charge temperature $(\mathrm{K})$

Internal Energy $(\mathrm{J})$

Cylinder Volume $\left(\mathrm{m}^{3}\right)$

Wrist-pin offset (mm)

Crankshaft radius (m)

Correction factor in surface area calculation (-)

Cycle index (\#)

Connecting rod length (m)

Mass (mg)

Number of moles $(\mathrm{kmol})$

Time (sec)

average cylinder gas velocity $(\mathrm{m} / \mathrm{sec})$

Mole fraction (\%) /

Fuel fraction vaporized before IVC (\%)

Fuel fraction going into air (\%)

Residual estimator parameter $\left({ }^{\circ} \mathrm{CA} / \mathrm{m}\right)$

Specific heat ratio (-)

Crank angle $\left({ }^{\circ} \mathrm{CA}\right)$ 
$\lambda$

$\rho$

$\omega$

$\phi$
Lambda (-)

Density $\left(\frac{k g}{m^{3}}\right)$

Absolute humidity (-)

Equivalence ratio (-) 


\section{List of Subscripts}

\begin{tabular}{|c|c|}
\hline $\mathrm{H}_{2} \mathrm{O}$, vapor & Water vapor \\
\hline air & Fresh air \\
\hline air, res & Air and residual altogether \\
\hline$c$ & Cylinder \\
\hline$c h$ & Cylinder head \\
\hline$e$ & Exhaust \\
\hline exh & Exhaust \\
\hline$g$ & Gas \\
\hline$i$ & Cylinder component index/intake \\
\hline$j$ & Different sections from IVC to EVO \\
\hline $\max$ & Maximum pressure point \\
\hline$p$ & Piston crown \\
\hline poly & Polytropic \\
\hline$r$ & Reference \\
\hline ref & Reference \\
\hline res & Residual gas \\
\hline sat & Saturation \\
\hline stoich & Stoichiometric \\
\hline tot & Total \\
\hline
\end{tabular}


transfer

W
Heat transfer

Wall 


\begin{abstract}
An accurate estimation of cycle by cycle in-cylinder mass and the composition of the combustion chamber charge is required for engine control strategies to meet stringent pollution emission and fuel consumption regulations. Estimation of fresh charge and residual gas masses is beneficial in terms of fuel efficiency, tailpipe emissions, engine performance, for engine control strategies. Air-flow meter, which is mounted in the intake air circuit, can be utilized in a closed-loop strategy to control air charge. However, air flow meter has a response delay; moreover dynamics of intake manifold and pipes must be taken into consideration to improve the estimation of air charge and accurate feedback in transients. As an alternative to air flow meter, in-cylinder pressure sensors can be utilized to directly measure cylinder pressure, based on which, the amount of air charge can be estimated without the requirement to model the dynamics of the manifold.
\end{abstract}

In this work, an air charge estimation algorithm is proposed, which uses cylinder pressure trace data at specific cycle events, and by applying thermodynamics and heat transfer relationships, estimates individual cylinder air charge for each cycle in different test conditions. A residual gas estimator, which can be applied online, is also incorporated in the algorithm to estimate residual gas mass for each cycle. Estimator output is validated and calibrated based on experimental setup air charge, which is calculated from the amount of injected fuel in each cylinder and individual wide-band sensor data.

Uncertainty propagation analysis is performed to investigate the uncertainty in estimated xvii 
air charge based on the uncertainties in measured and model parameters. This analysis reveals the information about the parameters with major contribution to the uncertainty in estimated air charge. 


\section{Chapter 1}

\section{Introduction}

\subsection{Motivation}

Internal Combustion (IC) engines are one of the major consumers of fossil fuels and contributors to air pollution [1], while being the primary source of ground transportation around the globe [1]. Other power sources in the vehicles do not seem to be currently promising. There has been good progress in production and performance technology of batteries in recent years; however, Electric Vehicles (EV's), which have the battery as the only power source, confront customer acceptance as a major role in success in the market [2]. High costs in battery production, on one hand, make these vehicles prohibitively expensive; on the other hand, low range of operation may cause reluctance to switch to EV's. Therefore automotive manufacturers are not able to fully depend their technology on electric vehicles; this results in large fraction of vehicles in following years to be powered by IC engines [3].

IC engine technologies must be improved dramatically to meet stringent fuel economy and pollution regulations. The Corporate Average Fuel Economy (CAFE) standards as regulations on fuel economy improvement for car manufacturers, have an outlook with a 
sharp rise in average MPG target from 30.1 in year 2012, to 54.5 in year 2025 (combined values for cars and light trucks) [1].

Calculation of sufficient amount of injected fuel leads to improvement in fuel economy. This can be achieved by an accurate estimation of fresh charge inducted into engine cylinder; moreover, this estimation can be beneficial in maintaining required indicated torque, controlling the Air/Fuel (A/F) ratio and meeting the tailpipe emission standards, among other targets.

Traditionally, Mass Air Flow (MAF) sensors have been used on the intake circuit of the engine to estimate the air flow into the intake manifold and a closed-loop strategy is used to control the $\mathrm{A} / \mathrm{F}$ ratio utilizing lambda sensors in the exhaust manifold [4]. However, there are several drawbacks of using MAF sensors. Firstly, there is a response delay in the measurement of air flow into the manifold. Since the air flow meter is mounted in the upstream of the intake path, to improve the air charge estimation in transients, dynamics of intake manifold and pipes must be considered [4].

Secondly, air charge in the manifold is not uniformly distributed into the cylinders; which can increase the emissions [5]. Detailed modeling of intake system is required to accurately estimate individual cylinder air charge. Furthermore, lambda sensors in the exhaust manifold have been used in production engines to control $\mathrm{A} / \mathrm{F}$ ratio with a closed-loop strategy. Due to the distance of this sensor from the cylinder, a delay in accurate lambda value feedback is expected in transients [6]. Moreover, since production engines have one 
sensor mounted in the exhaust manifold, calculation of individual lambda value from each cylinder may require additional computation algorithms [6].

In-cylinder pressure sensors can directly measure cylinder pressure and air charge can be estimated by using pressure data through a pressure-based air estimation strategy. This is an alternative to utilization of air flow meters and has certain advantages. One of the advantages of using in-cylinder pressure transducer data is that fresh air is estimated using pressure of each cylinder at each cycle. This approach facilitates the real-time application of pressure data to calculate the amount of individual injected fuel to control the $\mathrm{A} / \mathrm{F}$ ratio to a target value.

\subsection{Research Goals and Objectives}

This thesis is a summary of a developed algorithm to estimate the fresh air mass inducted into the engine using in-cylinder pressure sensors data with following objectives:

- Estimate each cylinder fresh air charge in each cycle with 5\% minimal and 2\% target accuracy as requested by Ford

- Estimate residual gas mass in each cylinder and cycle needed for combustion control 
- Estimate engine run-time parameters such as heat transfer amount in compression, combustion, and expansion stroke and temperature at Intake Valve Closing (IVC)

- Be utilized in steady-state and transient conditions

- Be integrated in real-time engine strategy to control the individual $\mathrm{A} / \mathrm{F}$ ratio and indicated torque to a target value in each cycle

The algorithm being developed, basically includes thermodynamic and heat transfer relationships applied to different events on individual cycle Pressure-Volume (P-V) diagram to estimate air mass. To estimate the fresh air mass at Intake Valve Closing (IVC) of a specific cycle, pressure data at IVC and pressures from the previous cycle are used. Therefore, with one iteration on the preceding cycle and using IVC pressure of the current cycle, air mass is estimated. To estimate cylinder air charge, residual gas mass must be known. Depending on how the residual mass is estimated, two different methods are studied for air estimation algorithm. Method 1 uses the Residual Gas Fraction (RGF), which can be estimated from a high fidelity correlation or engine simulation software. This value changes with engine run-time conditions. The second method (Method 2), is an online residual estimator that is incorporated into the algorithm. Considering the two main terms for residual gas mass (trapped and overlap backflow), a correlation is proposed which estimates residual mass at each cycle (rather than RGF in Method 1). 


\subsection{Overview of Thesis}

The organization of this thesis in different chapters is as follows.

In Chapter 2, a literature review and background information regarding previous research done on air charge estimation is provided. A variety of methods, including utilization of in-cylinder pressure sensors are reported in this chapter.

Chapter 3 of this report includes a description on the test cell and data acquisition setup, used for data logging and estimator validation.

In Chapter 4, equations regarding air charge estimator using two residual estimation methods are reported. A schematic of air estimation algorithm is depicted to better illustrate its details for both residual estimators at the end of this chapter.

In Chapter 5, estimator validation and calibration is performed by using experimental air charge, which is the air charge that is calculated from injected fuel and individual wide-band sensor data for each cylinder. Two parameters in the estimator, one regarding heat transfer and the other for residual estimator, are calibrated such that estimator air charge matches the experimental one (calculated from fuel and lambda). This calibration is done for a range of steady-state test conditions including different lambda and intake cam advances. Final calibration table for different tests is reported. Also in this chapter, uncertainty propagation analysis is performed to evaluate the amount of uncertainty propagated into the estimated air mass from uncertainties in the measured parameters, e.g. 
in-cylinder pressure. Moreover, by doing this analysis, the contributing parameters to the uncertainty in air charge can be identified. In another attempt, a sensitivity analysis investigating effect of change in transducer gain, offset and noise on IMEP and estimated air charge, is performed. This analysis is done to recognize the impact of error in transducer data measurement on estimator output. A neural network is trained and validated to be utilized as a lookup table for the estimator calibrated parameters. These networks show good performance inside the range of the training data, while having extrapolating issues outside this range. A couple of transient tests with intermittent load and lambda change are done and estimator air charge is compared to the experimental air charge. These tests are done within the operating region of steady-state test range (RPM, IMEP, lambda and cam advance) to avoid the extrapolation of the neural network as the lookup table.

Finally in Chapter 6, a summary of the air charge estimator is reported and conclusions regarding the performance of the estimation are drawn. Recommendations for future work, to improve estimator performance are also presented. 


\section{Chapter 2}

\section{Air Charge Estimation Background and Literature Review}

Numerous works have been done in the literature to estimate fresh air charge using different types of sensors. Following section includes a comprehensive report on the different works and strategies taken to improve air charge estimation.

A general study on the methods used to estimate the fresh air charge mass has been performed initially in this research. Different methods can be categorized in terms of sensors used for the estimation. A comparative study is done in [4] on various techniques to accurately estimate inducted air into the engine equipped with Variable Valve Timing (VVT) using different sensors. Mass Air Flow (MAF) sensor is widely utilized to estimate air flow and shows good air measurement in steady-state conditions without the effort to consider change in Volumetric Efficiency (VE) caused by engine aging or other effects [7] [8]. In transient loads, however, MAF sensor measurements may not be accurate, which is referred to as one of its drawbacks [9].

Speed-Density approach is another method which uses Manifold Absolute Pressure (MAP) sensor along with intake air temperature to estimate air charge [4]. This method requires a good calibration of VE which, in turn, needs an accurate estimation of Residual Gas 
Fraction (RGF). Examples of the methods using MAP to estimate fresh air charge can be found in [10] and [11].

Input Estimation Methods are a type of air estimation approaches where both MAP and MAF sensors are used [4]. A good calibration of VE is also crucial in these methods. Works done in [9] and [12] are examples of using this method for air estimation.

Closed-loop observer based methods take advantage of system state observers to estimate fresh air. Different categories of state observers are used in different works, among which are Luenberger-like observers, Kalman filters and Extended Kalman Filters (EKF), Sliding mode observers, and nonlinear adaptive observers. Luenberger-like observers are utilized in [10], [13], and [14] to estimate system states. Kalman filters are another group of observers used to estimate system states and air charge and are used in [15] [16] [17] [18] [19]. Extended Kalman filter is also utilized in [20], [21], [22], and [23]. Sliding mode observers can be beneficial in air charge estimation as used in [24] and [25]. And finally [23], [26], [27], [28], and [29] have taken advantage of nonlinear adaptive observers to estimate air charge into the engine.

There are several works with the aim of air charge estimation and size reduction in VE calibration tables using neural networks. One of the advantages of these networks is that they can be used for systems with high nonlinearity; however, they show poor performance in extrapolation outside the training region which is a big disadvantage. Works done in [7], 
[30], [31], and [32] are among the ones that have used neural networks for VE calibration and air charge estimation.

The next category, which is of our interest in this study, is in-cylinder pressure sensor data utilization to estimate air charge. Studies done by authors in [33], [34], [35], [36], [37] are among several works that are done to use pressure transducer data to estimate fresh air through different methodologies.

The authors in [33] have developed an iterative algorithm to estimate both residual and fresh charge masses. In addition to cylinder pressure, the intake manifold pressure and temperature are also used, which must be fast enough to yield to accurate estimations during engine transients. The approach includes two major iterative estimations: total mass and residual gas fraction. In-cylinder mixture temperature at $50 \%$ mass burned position is used to estimate total mass and residual gas fraction is calculated from IVC temperature and residual temperature.

The authors in [34] use the ideal gas law to estimate total charge at IVC, using cylinder pressure and charge temperature at this point, which can be estimated from intake and exhaust manifold temperatures and residual fraction. Polytropic index in compression stroke is computed from cylinder pressure trace measurement by using least square method and sampling a number of pressure points after IVC and before ignition. An estimated cylinder pressure is then fitted by assuming this polytropic process and is finally used in 
the ideal gas law at IVC to estimate total charge mass. Residual fraction is also estimated from the correlation used in [38]. This online air estimation algorithm is then applied in steady-state operation mode at two different engine speeds.

An air charge estimation method named as "Delta P" is studied in [35] for engine transient mode. Being computationally simple is one of the benefits of this method, which makes it suitable for online estimation; however, being sensitive to engine speed and residual gas fraction makes it difficult to utilize it for engines equipped with EGR or variable valve timing. Moreover, the uncertainty in cylinder pressure measurement is highly propagated into estimated air charge resulting in low estimation accuracy (will be shown in uncertainty analysis section of this work).

In [36], ideal gas law is used to estimate air charge by considering logged cylinder pressure and partial pressures of different components in cylinder gas mixture (i.e. air charge, fuel, residual fraction and external EGR). This approach is also capable of being used as a real-time estimation method.

Table 1 compares three different air estimation methods in the literature using cylinder pressure in addition to the estimator developed in this work. This comparison is done by considering target estimated parameters, different sensor used, online or offline applicability of the method, computation zone where pressure sensor data is used, steady- 
state or transient utilization of the estimator, and assumptions made for parameter estimations.

Table 1- Comparison of different air charge estimation methods using pressure transducer

\begin{tabular}{|c|c|c|c|c|}
\hline Method & $\begin{array}{l}\text { M. Mladek, } \\
{[33]}\end{array}$ & $\begin{array}{c}\text { G.Colin } \\
{[34]}\end{array}$ & $\begin{array}{c}\text { DeltaP } \\
{[35]}\end{array}$ & $\begin{array}{l}\text { Air Charge } \\
\text { Estimator } \\
\text { (This Work) }\end{array}$ \\
\hline 总 & $\begin{array}{l}\text { Cylinder air } \\
\text { mass } \\
\text { Residual gas } \\
\text { mass }\end{array}$ & - Cylinder air mass & - Cylinder air mass & $\begin{array}{l}\text { - Cylinder air mass } \\
\text { - Residual gas mass }\end{array}$ \\
\hline 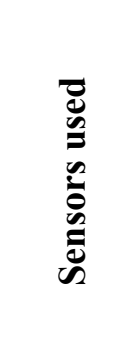 & $\begin{array}{l}\text { Cylinder } \\
\text { pressure } \\
\text { Inlet/exhaust } \\
\text { pressure } \\
\text { Intake } \\
\text { manifold } \\
\text { temperature }\end{array}$ & $\begin{array}{l}\text { Cylinder pressure } \\
\text { - Intake and } \\
\text { exhaust manifold } \\
\text { pressure } \\
\text { Temperature at } \\
\text { exhaust }\end{array}$ & Cylinder pressure & $\begin{array}{l}\text { - Cylinder pressure } \\
\text { - Manifold pressure } \\
\text { - Intake temperature } \\
\text { - Relative humidity }\end{array}$ \\
\hline & $\begin{array}{l}\text { Offline for } \\
\text { initial } \\
\text { condition } \\
\text { Online for } \\
\text { iterative } \\
\text { estimation }\end{array}$ & $\begin{array}{l}\text { Online at } 1000 \\
\text { and } 2000 \text { RPM }\end{array}$ & Offline & - Online \\
\hline 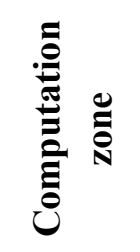 & $\begin{array}{l}\text { IVC to EVO } \\
\text { with } 0.2 \text { crank } \\
\text { angle degree } \\
\text { sampling } \\
\text { period }\end{array}$ & $\begin{array}{l}\text { IVC to a point } \\
\text { before ignition } \\
\text { with } 6 \text { crank } \\
\text { angle degree } \\
\text { sampling period }\end{array}$ & $\begin{array}{l}\text { From IVC to a point } \\
\text { before ignition }\end{array}$ & - Entire cycle \\
\hline
\end{tabular}




\begin{tabular}{|c|c|c|c|c|}
\hline 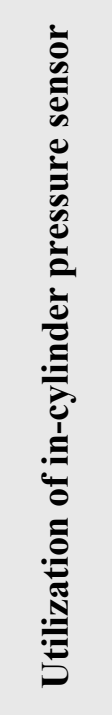 & $\begin{array}{l}\text { Burn rate } \\
\text { - Initial total } \\
\text { mass } \\
\text { - Mean } \\
\text { temperature at } \\
\text { IVC } \\
\text {-Fresh charge } \\
\text { temperature } \\
\text { Mean } \\
\text { temperature at } \\
\text { CA50 } \\
\text { Total mass } \\
\text { estimation (at } \\
\text { IVC) }\end{array}$ & $\begin{array}{l}\text { Fitting polytropic } \\
\text { curve } \\
\text { Ideal gas law to } \\
\text { estimate cylinder } \\
\text { total mass }\end{array}$ & $\begin{array}{l}\text { To calculate the } \\
\text { slope and } \mathrm{Y} \text { - } \\
\text { intercept of the line } \\
M_{\text {fresh }}=\alpha \cdot \Delta P-\beta\end{array}$ & $\begin{array}{l}\text { Pressure at } \\
\text { different timing } \\
\text { events used in } \\
\text { thermodynamic } \\
\text { and heat transfer } \\
\text { relationships }\end{array}$ \\
\hline 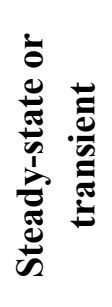 & $\begin{array}{l}\text { Steady-state } \\
\text { from 1000- } \\
4000 \text { RPM and } \\
\text { at different } \\
\text { MEP's }\end{array}$ & $\begin{array}{l}\text { Steady-state at } \\
1000 \text { and } 2000 \\
\text { RPM }\end{array}$ & $\begin{array}{l}\text { Steady-state for } \\
\text { different RPM's } \\
\text { Transient at } 4800 \\
\text { RPM and different } \\
\text { intake valve } \\
\text { transitions }\end{array}$ & $\begin{array}{l}\text { Steady-state and } \\
\text { transient }\end{array}$ \\
\hline 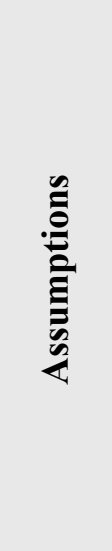 & $\begin{array}{l}\text { Using ideal gas } \\
\text { law } \\
\text { Initial } \\
\text { temperature at } \\
50 \% \text { mass } \\
\text { burnt is } \\
\text { constant } \\
\text { Residual gas } \\
\text { fraction at } \\
\text { beginning is } \\
10 \%\end{array}$ & $\begin{array}{l}\text { - Ideal gas law } \\
\text { Blow-by } \\
\text { neglected }\end{array}$ & $\begin{array}{l}\text { Ideal gas law } \\
\text { Mass conservation } \\
\text { during computation } \\
\text { zone }\end{array}$ & $\begin{array}{l}\text { Ideal gas law } \\
\text { Mass conservation } \\
\text { from IVC to EVO } \\
\text { (Blow-by } \\
\text { neglected) } \\
\text { Initial values for } \\
\text { IVC temperature } \\
370 \mathrm{~K}, \mathrm{RGF} 11 \% \text {, } \\
\text { and fuel mass } 14 \\
\text { mg }\end{array}$ \\
\hline
\end{tabular}

To the best of author's knowledge, no work has been done which estimates the air charge using the method taken in the algorithm proposed in this work. Compared to the methodologies which utilize in-cylinder pressure, this work suggests a novel method for air charge and residual gas estimation. 


\section{Chapter 3}

\section{Experimental Setup}

A 3.5L V6 twin-turbo VCT Direct-Injection (DI) Ford Ecoboost engine, located in the sub-basement floor of the Mechanical Engineering-Engineering Mechanics building at MTU, was used to run different tests and validate the air charge estimator. Engine geometry and valve event timings are shown in Table 2.

Table 2- 3.5L V6 Ford Ecoboost iVCT specifications [39]

\begin{tabular}{|c|c|}
\hline Bore & $92.5 \mathrm{~mm}$ \\
\hline Stroke & $86.7 \mathrm{~mm}$ \\
\hline Compression Ratio & $10.0: 1$ \\
\hline Connecting Rod Length & $152.68 \mathrm{~mm}$ \\
\hline Wrist-Pin Offset & $0.9 \mathrm{~mm}$ \\
\hline Intake Duration & $236 \mathrm{deg}$ \\
\hline Intake Valve Opening (IVO) & $40 \mathrm{deg}$ BTDC \\
\hline Intake Valve Closing (IVC) & $16 \mathrm{deg}$ ABDC \\
\hline Exhaust Duration & $236 \mathrm{deg}$ \\
\hline Exhaust Valve Opening (EVO) & $46 \mathrm{deg}$ BBDC \\
\hline Exhaust Valve Closing (EVC) & $10 \mathrm{deg}$ ATDC \\
\hline Firing Order & $1-4-2-5-3-6$ \\
\hline
\end{tabular}


An Eddy Current (EC) dynamometer is coupled to the engine which is controlled via National Instruments LabVIEW ${ }^{\mathrm{TM}}$ software [40] in the control room.

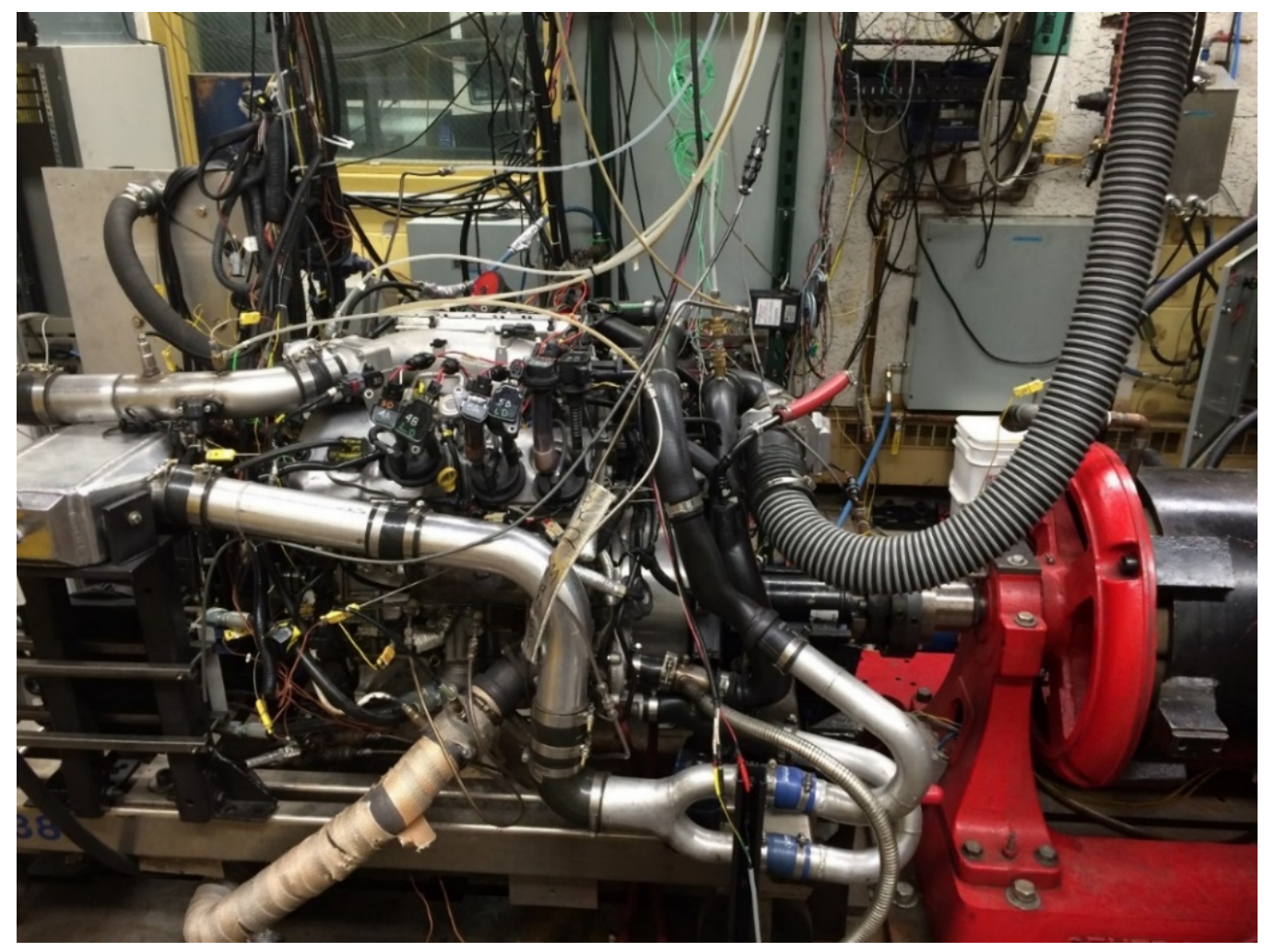

Figure 1- V6 3.5L Ford Ecoboost engine and EC Dynamometer available in MTU MEEM building sub-basement

ATI Vision ${ }^{\circledR}$ software [41] is used as the ECU interface to control engine load, air/fuel ratio, and intake cam advance, among many other engine run-time parameters. This software has data logging feature and in this research, injector pulse-width and fuel rail pressure are among the parameters which are logged to be used in calculation of the amount of injected fuel in each cylinder (to be discussed in Chapter 5). 
The engine is equipped with six in-cylinder piezoelectric Kistler ${ }^{\circledR}$ transducers [42]. Sensor type $6125 \mathrm{~A}$ is used in cylinders 3,5 , and 6; type 6125B in cylinders 1 and 4, and type $6125 \mathrm{C}$ used in cylinder 2 . The signals from the transducers are amplified and logged with high sampling rate in $\mathrm{ACAP}^{\circledR}[43]$ combustion analysis software. Among the capabilities of this software are real-time cylinder pressure and non-cylinder pressure calculations; among the cylinder pressure calculations are real-time calculation of Mean Effective Pressures (IMEP and PMEP), burn rate, combustion phasing, and polytropics; and noncylinder calculations including cylinder volume and engine speed (from encoder signal). For ACAP combustion calculations, the time stamp resolution is set to $25.6 \mu \mathrm{sec}$ (default) and maximum number of cycles is 685 .

In addition to the two wide-band sensors (lambda sensors) on each bank, which are found on the production engines, six individual wide-band sensors are attached to the pipes which come from within the exhaust manifold immediately after each cylinder exhaust valves. These pipes were added with the purpose of monitoring and logging the individual air/fuel ratio of each cylinder. These data are also logged by ACAP $^{\circledR}$. 


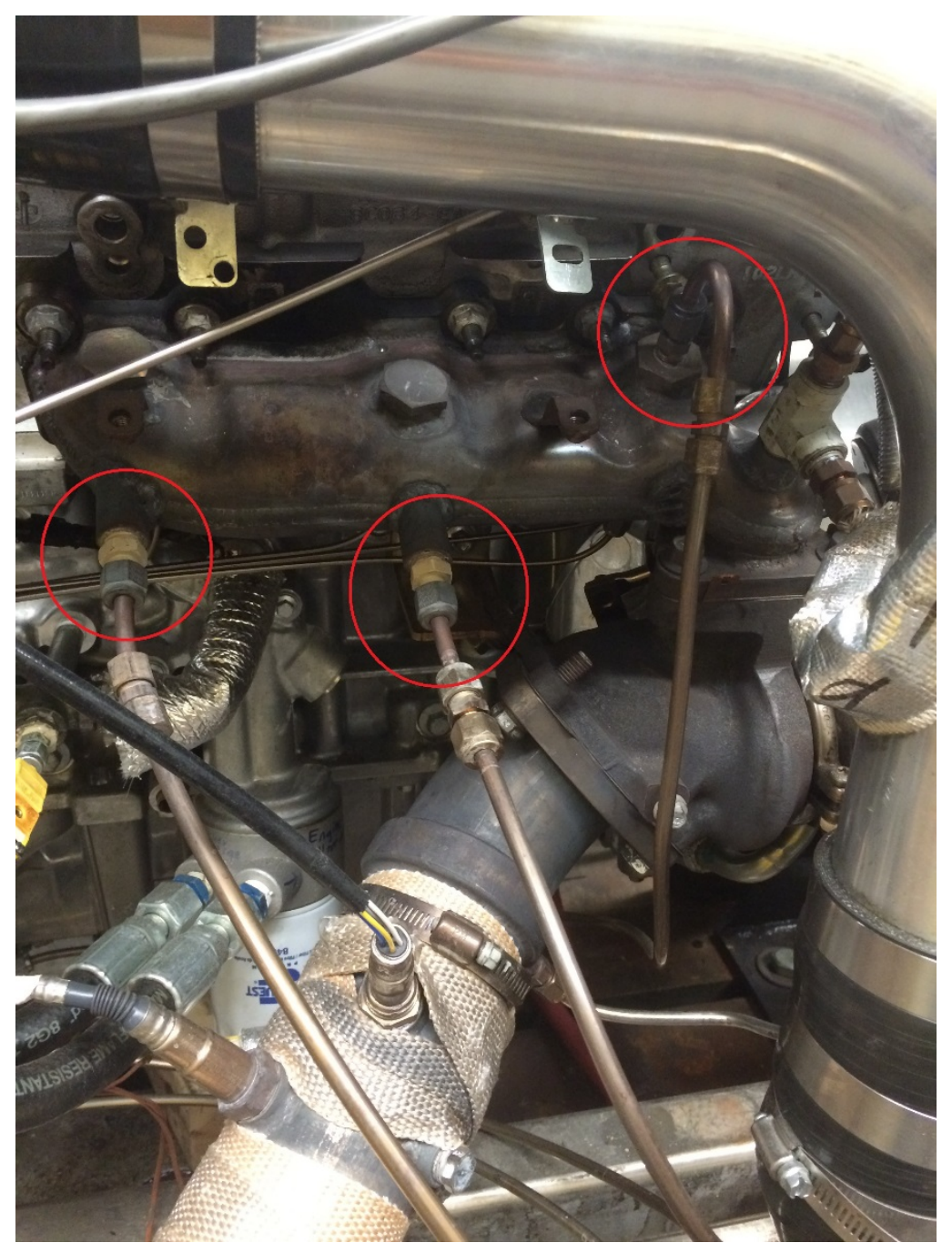

Figure 2- Pipes connected to exhaust manifold (red circle indicators) with one end adjacent to exhaust valves of cylinders in bank 2 


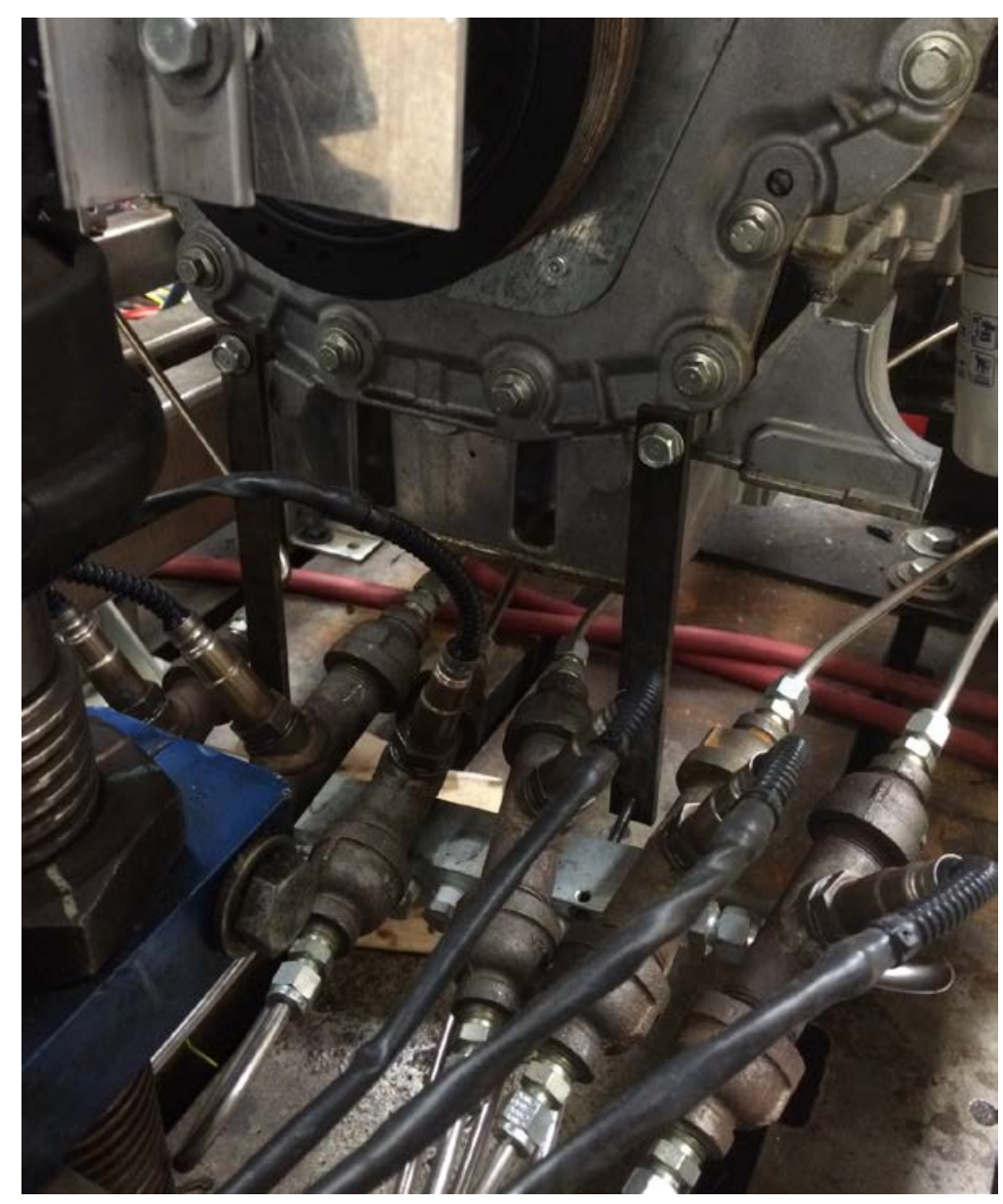

Figure 3- Six individual wide-band sensors mounted on pipes which come from exhaust manifolds of both banks

A Micro Motion ${ }^{\circledR}$ ELITE $^{\circledR}$ Coriolis [44] flow and density meter is assembled on the fuel delivery pipe to accurately measure the fuel flow into the engine, as it is seen in Figure 4 . Since air charge estimation will be calibrated and validated based on accurate fuel measurements, the fuel meter data is also logged with high sampling rate in ACAP. Fuel specifications are shown in Table 3. 
Table 3- Fuel specifications

\begin{tabular}{|c|c|}
\hline Fuel Type & Gasoline E10 (PON 87) \\
\hline Composition & $90 \%$ gasoline, 10\% ethanol \\
\hline Density $\left[\frac{\mathrm{kg}}{\mathrm{m}^{3}}\right]$ & 757.4 \\
\hline Stoichiometric Air-Fuel Ratio (AFR) [-] & 14.06 \\
\hline Lower Heating Value (LHV) $\left[\frac{\mathrm{MJ}}{\mathrm{kg}}\right]$ & 41.64 \\
\hline
\end{tabular}

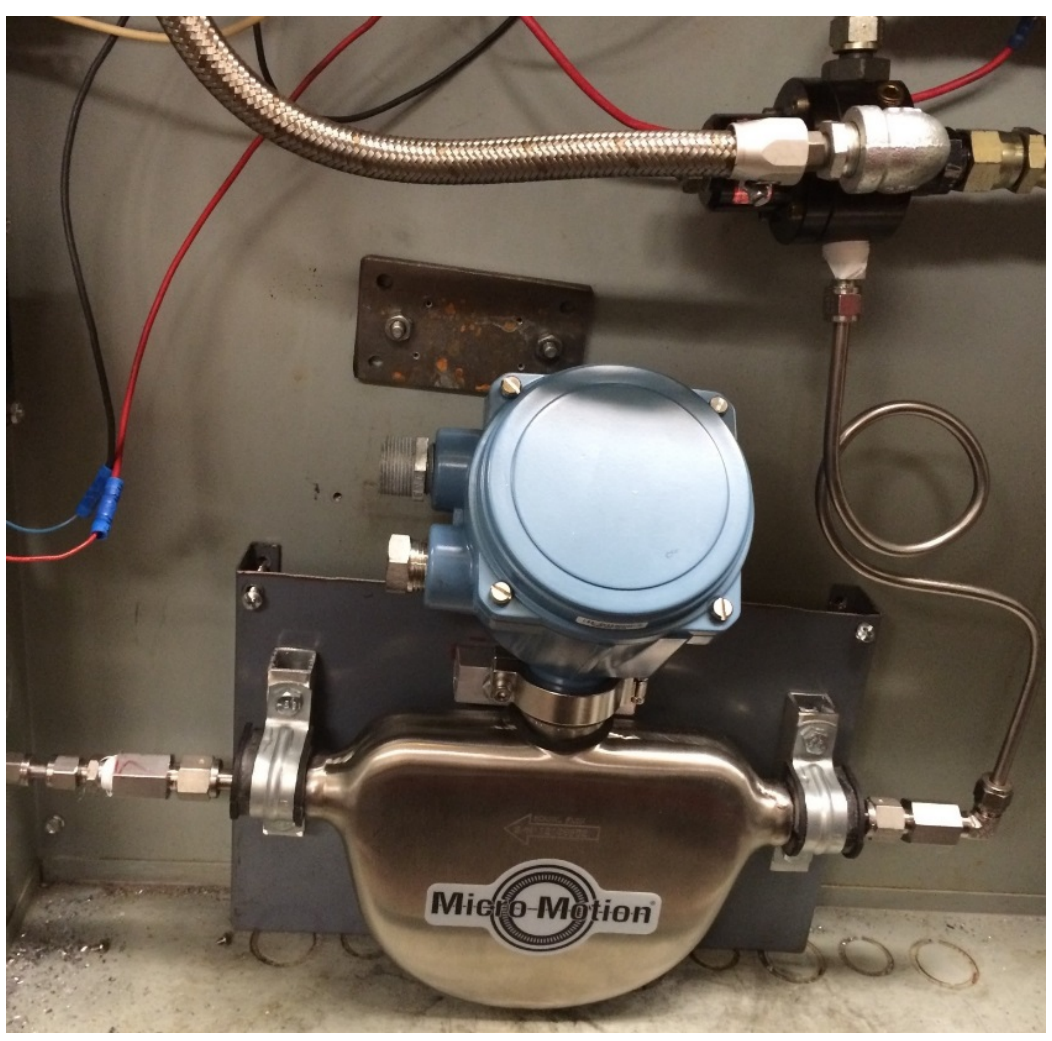

Figure 4- Coriolis fuel flow meter mounted on fuel delivery system 
As a conventional method to measure the air flow into the engine, a Laminar Flow Element (LFE) manufactured by Meriam ${ }^{\mathrm{TM}}$ [45] (model \# 50MC2-4) is mounted in the upstream of the air intake path (Figure 5). The air measurements are going to be monitored and logged into LabVIEW ${ }^{\mathrm{TM}}$ control panel. The correction coefficients and the formulas provided by Meriam which are used in LabVIEW SubVI are reported separately in Appendix A.

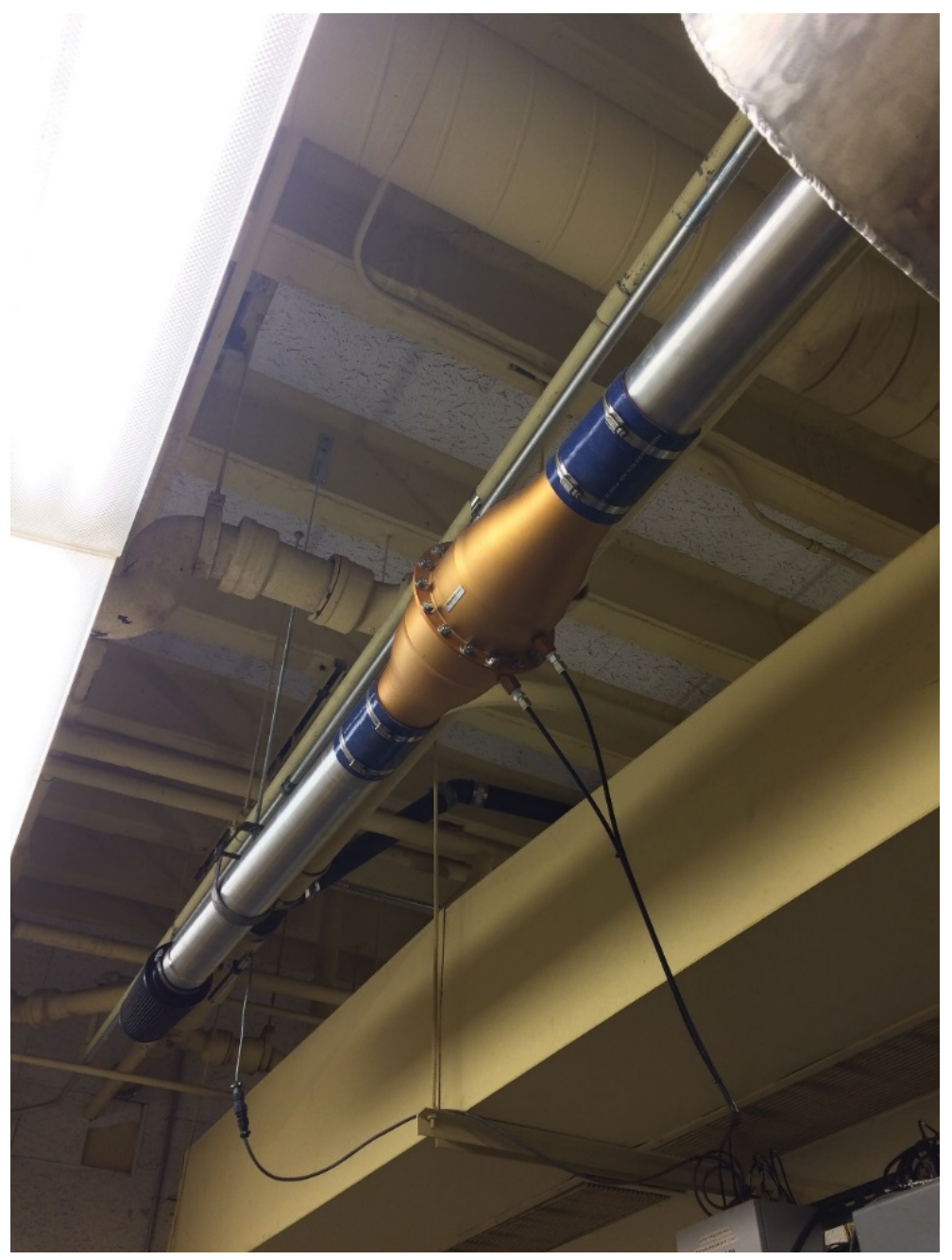

Figure 5- Laminar Flow Element (LFE) setup mounted on intake pathway to the engine 


\section{Chapter 4}

\section{Air Charge Estimator Algorithm and Equations}

\subsection{Overview}

Cylinder pressure trace through the cycle can be used to estimate individual cylinder fresh air charge. This estimation can be done by considering cylinder mixture transitions from different thermodynamic states in addition to heat transfer occurring between these states. Pressure trace for an operating condition of $1500 \mathrm{RPM}, 2.62 \mathrm{BMEP}$ and $10^{\circ} \mathrm{CA}$ degree intake cam advance is shown in Figure 6 for better illustration of specific timing events. Specific points on P-V diagram related to events are summarized and explained in Table 4.

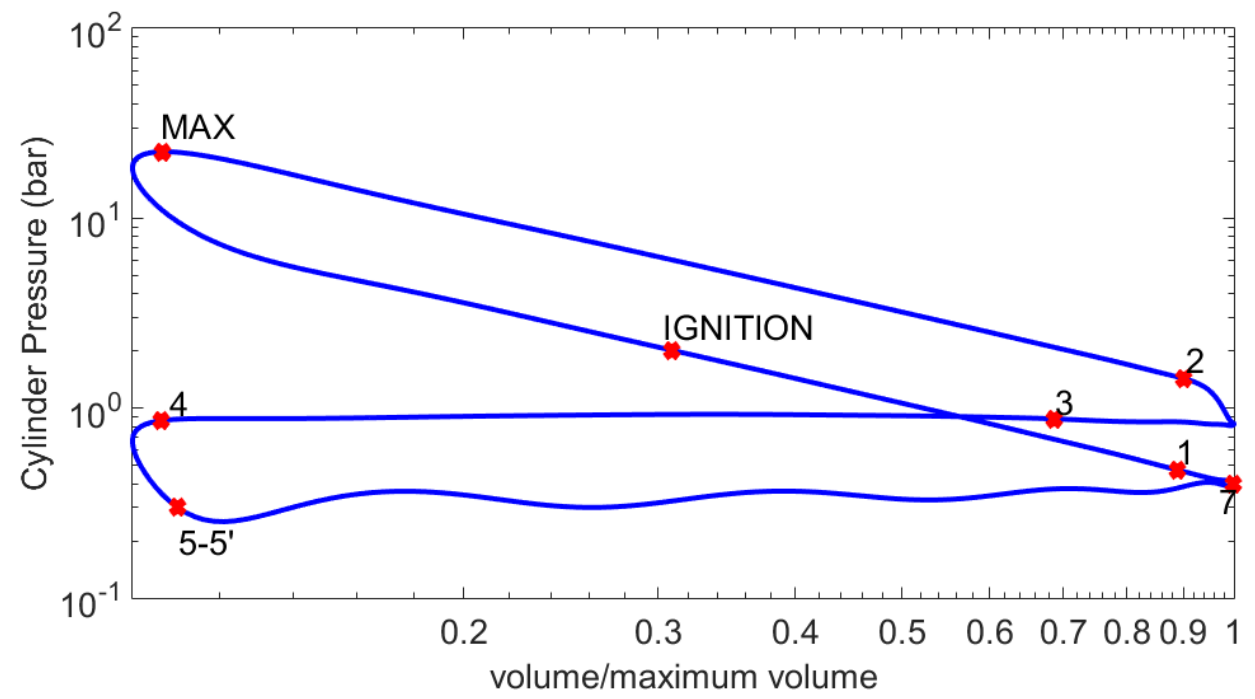

Figure 6- Pressure-Volume diagram and specific event timings for Ecoboost engine at 1500 RPM, 2.62 BMEP and $10^{\circ} \mathrm{CA}$ degree intake cam advance 
Table 4- Timing events on P-V diagram

\begin{tabular}{|c|c|c|}
\hline Point & Event & Explanation \\
\hline 1 & IVC & Intake Valve Closing \\
\hline IGNITION & Ignition timing & The point with start of spark discharge \\
\hline MAX & Maximum pressure & $\begin{array}{c}\text { The point on the diagram where cylinder } \\
\text { pressure has its maximum value }\end{array}$ \\
\hline 2 & $\mathrm{EVO}$ & Exhaust Valve Opening \\
\hline 3 & End of Blowdown & $\begin{array}{l}\text { Pressure and temperature of this point are } \\
\text { used as exhaust pressure and temperature }\end{array}$ \\
\hline 4 & IVO & Intake Valve Opening \\
\hline $5-5^{\prime}$ & $\begin{array}{l}\text { Exhaust Valve Closing } \\
\text { (EVC) }\end{array}$ & $\begin{array}{l}\text { Point } 5 \text { is considered as EVC. Point } 5^{\prime} \text { is } \\
\text { the point in the intake stroke regarding } \\
\text { start of fresh air induction into the } \\
\text { cylinder }\end{array}$ \\
\hline 7 & $\begin{array}{c}\text { BDC in compression } \\
\text { stroke }\end{array}$ & $\begin{array}{l}\text { The point in compression stroke where } \\
\text { cylinder pressure rise due to compression } \\
\text { is detectible. Here it is assumed that this } \\
\text { point coincides with BDC in the } \\
\text { beginning of compression stroke. }\end{array}$ \\
\hline
\end{tabular}

The air charge estimation algorithm includes different relationships that hold for different sections of engine run-time on the $\mathrm{P}-\mathrm{V}$ diagram; estimator calculations are performed in a step-by-step procedure on and in between the points mentioned in Table 4. One main relationship, by which total cylinder charge at IVC is estimated, is the ideal gas law applied to the trapped cylinder charge at IVC of each cycle; by having cylinder pressure, volume and temperature, total moles in the cylinder is calculated using: 


$$
P V=n_{t o t} R T
$$

in which,

$n_{\text {tot }}$ is the total moles of components trapped in the cylinder at IVC and $R$ is the universal gas constant of $8.3144598 \frac{\mathrm{kJ}}{\mathrm{kgmol} \cdot \mathrm{K}}$.

In this equation $P$ is cylinder pressure measured at IVC and $V$ is cylinder volume, at the same point; this volume is calculated using engine geometry. Parameter $T$ is the temperature of cylinder mixture at IVC, which cannot be measured directly and has to be estimated. One of the targets in this work, is to estimate this temperature using engine cylinder pressure at different points on the P-V diagram, based upon fresh air and residual masses. Therefore, estimation of the temperature at IVC can lead us to measurement of total moles at IVC and ultimately fresh air charge moles (mass).

\subsection{Equations Used in Air Charge Estimation Algorithm}

In this section, major equations, which are used to estimate fresh air charge are described. The $\mathrm{P}-\mathrm{V}$ diagram is broken into different sections and relevant equations and conditions in each section are explained. Sections 4.2.1 to 4.2.3 are allocated to general equations used for conversion between mass and moles, water vapor pressure estimation, and polytropic indices calculation, respectively. In section 4.2.4 the methods to estimate residual gas mass 
are discussed. Thermodynamic and heat transfer relationships applied to different sections depicted on P-V diagram, are discussed in detail in sections 4.2.5 to 4.2.11.

\subsubsection{Mole to mass conversion}

Using thermodynamic relationships will result in estimation of total moles of cylinder charge; hence for better physical interpretation, mole to mass conversion is done using following equation:

$$
n_{i}=\frac{m_{i}}{M W_{i}}
$$

here $n, m$, and $M W$ denote number of moles, mass and molecular weight, respectively. The index ' $i$ ' refers to different components which exist in the cylinder charge at different points; these components are fresh air, residual gas (burnt gas), fuel and water vapor. It should be noted that, in this thesis, effect of external EGR to the cylinder charge is not studied.

Mole fraction $\left(y_{i}\right)$ which is number of moles of each component $\left(n_{i}\right)$ divided by the total number of moles $\left(n_{t o t}\right)$ is calculated as:

$$
y_{i}=\frac{n_{i}}{n_{\text {tot }}}=\frac{n_{i}}{n_{\text {air }}+n_{\text {res }}+n_{\text {fuel }}+n_{H_{2} O, \text { vapor }}}
$$


All through this work, $n_{\text {air }}, n_{\text {res }}, n_{\text {fuel }}$, and $n_{\mathrm{H}_{2} \mathrm{O} \text {,vapor }}$ denote moles of fresh air, residual gas, fuel and water vapor, respectively.

\subsubsection{Water Vapor Partial Pressure Calculation}

Water vapor mass is calculated and accounted for in total mass at IVC to have a more accurate fresh charge estimation. This calculation is done by knowing ambient temperature and relative humidity using:

$$
P_{H_{2} \mathrm{O}, \text { vapor }}=R H \cdot P_{\text {sat@ }} T_{\text {ambient }}
$$

$P_{H_{2} \text { O,vapor }}$ is partial pressure of water vapor (water vapor pressure), $R H$ is relative humidity and $P_{\text {sat@ }} T_{\text {ambient }}$ is water vapor saturation pressure at ambient temperature $\left(T_{\text {ambient }}\right)$.

Absolute (or specific) humidity is defined as the ratio of the water vapor mass to dry air mass [46]:

$$
\omega=\frac{m_{H_{2} \mathrm{O}, \text { vapor }}}{m_{\text {air }}}
$$


Water vapor mass ( $\left.m_{\mathrm{H}_{2} \mathrm{O}, \text { vapor }}\right)$ at IVC is calculated using ideal gas law incorporating water vapor pressure, cylinder volume and IVC temperature; this calculation will be discussed in following sections.

\subsubsection{Polytropic Indices Calculation}

Polytropic indices in compression and expansion are calculated from cylinder pressure and volume in following formula [47]:

$$
n_{\text {poly }}=\frac{\ln \left(P_{2}\right)-\ln \left(P_{1}\right)}{\ln \left(V_{2}\right)-\ln \left(V_{1}\right)}
$$

Compression polytropic is calculated by taking pressure and volume of two points on P-V diagram in compression stroke; same calculation in expansion stroke can lead to calculation of expansion polytropic.

Crank Angle (CA) equal to -180 degree refers to BDC in compression stroke and 180 degree is the measurement for $\mathrm{BDC}$ after expansion. Encoder CA measurement is equal to 0 CA degree at TDC of combustion, and this measurement scale is used uniformly through this work. 
In this work, to calculate compression polytropic, pressure and volume corresponding to $-120 \mathrm{CA}$ degree and -60 CA degree are chosen. Also to calculate expansion polytropic index, two points regarding 60 and $120 \mathrm{CA}$ degree are selected. These crank angles are set in $\mathrm{ACAP}^{\circledR}$ combustion analysis software [43] to calculate polytropics. In the estimator algorithm, compression polytropic index will be used in one calculation which will be described later.

\subsubsection{Residual Mass Estimation}

Several works have been done to estimate Residual Gas Fraction (RGF), among which are [48], [49], [50] and [33]. The RGF is defined as:

$$
X_{r e s}=\frac{m_{r e s}}{m_{a i r}+m_{r e s}}
$$

where $m_{\text {res }}$ and $m_{\text {air }}$ denote residual and air mass, trapped in the cylinder at IVC, respectively.

The equation above is a correlation between residual and air mass; so to know the amount of air charge and residual mass another equation is needed which is: 


$$
m_{\text {tot }}=m_{\text {air }}+m_{\text {res }}+m_{\text {fuel }}+m_{H_{2} \text { O,vapor }}=m_{\text {air }}\left(1+\frac{X_{\text {res }}}{1-X_{\text {res }}}+F A R+\omega\right)
$$

in which,

$m_{f u e l}$ is the fuel mass injected in each cycle, $F A R$ is Fuel-Air Ratio, and $\omega$ is absolute humidity (Eq. (4-5)).

Fuel mass is also correlated to $m_{\text {air }}$ via the formula defining lambda $(\lambda)$ :

$$
\frac{\frac{m_{\text {air }}}{m_{\text {fuel }}}}{A F R_{\text {stoich }}}=\lambda
$$

$A F R_{\text {stoich }}$ is the stoichiometric air-fuel ratio. Through this work this value is 14.06 which is the value for E10 fuel (Table 3).

$m_{\mathrm{H}_{2} \mathrm{O}, \text { vapor }}$ can also be calculated as discussed before. Therefore by having the total mass at IVC $\left(m_{\text {tot }}\right)$, which was obtained from ideal gas law, the values for air and residual mass are calculated.

One of the common methods to estimate $X_{r e s}$ is the one given in [48]. The main correlation is as follows: 


$$
X_{r e s}=C_{1} \frac{O F}{N} \cdot\left(\frac{P_{i}}{P_{e}}\right)^{-0.87} \sqrt{\left|P_{e}-P_{i}\right|}+C_{2} \cdot \phi \cdot \frac{\left(P_{i} / P_{e}\right)^{-0.74}}{r_{c}}
$$

in which:

$C_{1}$ and $C_{2}$ are non-dimensional constants,

$O F$ is overlap factor in $\left[{ }^{\circ} \mathrm{CA} / \mathrm{m}\right]$,

$N$ is engine speed in [revolution per second],

$P_{i}$ and $P_{e}$ are intake and exhaust system pressure in [bar],

$\phi$ and $r_{c}$ are fuel/air equivalence and compression ratio, respectively.

This correlation is consisted of two main residual gas components. The first term corresponds to backflow of burnt gas from exhaust port to the cylinder and second term is related to the trapped mass in the cylinder at IVO and prior to valve overlap flow.

Estimating RGF for engines equipped with variable valve timing is feasible through using high fidelity correlations which include volumetric efficiency and calibrations to calculate the value for OF for different engine operating points.

In this work, two different methodologies are taken to deal with residual fraction estimation and ultimately the estimation of air charge. Method 1 is using values of $X_{\text {res }}$, which are obtained from the RGF estimation correlations. Method 2, which is proposed in this work, 
is a new method to estimate residual mass $\left(m_{\text {res }}\right)$ form the estimated parameters in the air charge algorithm. This correlation holds the same format as the one in Eq. (4-10) as follows:

$$
m_{\text {res }}=\alpha \cdot\left(\frac{P_{i}}{P_{e}}\right)^{-0.87} \cdot \frac{\sqrt{\left|P_{e}-P_{i}\right|}}{N}+m_{I V O}=m_{\text {overlap }}+m_{I V O}
$$

The first term is representing backflow (overlap) residual component and second term $\left(m_{I V O}\right)$ represents the trapped residual mass. In this equation, $\alpha$ is the parameter that needs to be calibrated for different engine run-time conditions and will be discussed in following sections.

Table 5 shows comparison of Method 1 and Method 2. 
Table 5- Two different air charge estimation methods in this work based on residual gas estimation

\begin{tabular}{|l|l|}
\hline $\begin{array}{c}\text { Method 1: Including High Fidelity } \\
\text { Correlation for Residual Gas Fraction }\end{array}$ & \multicolumn{1}{|c|}{$\begin{array}{c}\text { Method 2 : Including Online } \\
\text { Estimator for Residual Mass }\end{array}$} \\
\hline $\begin{array}{l}\text { Estimation of temperature at IVC for } \\
\text { each cycle by using in-cylinder pressures } \\
\text { at specific points from previous cycle }\end{array}$ & $\begin{array}{l}\text { Estimation of temperature at IVC for } \\
\text { each cycle by using in-cylinder pressures } \\
\text { at specific points from previous cycle }\end{array}$ \\
\hline $\begin{array}{l}\text { Estimated IVC temperature and } \\
\text { measured pressure to estimate total } \\
\text { charge (ideal gas law) }\end{array}$ & $\begin{array}{l}\text { Estimated IVC temperature and } \\
\text { measured pressure to estimate total } \\
\text { charge (ideal gas law) }\end{array}$ \\
\hline $\begin{array}{l}\text { Table data for residual fraction at } \\
\text { different speed, load, intake and exhaust } \\
\text { cam advance. Fresh air and residual mass } \\
\text { correlated through: } m_{\text {res }}\end{array}$ & $\begin{array}{l}\text { Integrated residual mass estimator in the } \\
\text { algorithm }\end{array}$ \\
$X_{\text {res }}=\frac{m_{\text {res }}+m_{\text {air }}}{m_{\text {and }}}$ & \\
\hline $\begin{array}{l}\text { Fresh air estimation using total mass at } \\
\text { IVC and } X_{\text {res }} \text { correlation }\end{array}$ & $\begin{array}{l}\text { Fresh air estimation using total mass at } \\
\text { IVC and } m_{\text {res }} \text { (residual mass) }\end{array}$ \\
\hline
\end{tabular}

\subsubsection{Cycle Definition and IVC to EVO (1 to 2) Equations}

In this work, IVC is considered as the start point of each cycle. Index ' $k$ ' is used to indicate each cycle in the iterative approach of the estimator; e.g. $k=1$ indicates first cycle. As it is seen Table 6, in the estimation of masses of different cylinder components, the value shown for each mass at each cycle corresponds the value of that parameter at IVC of that cycle; therefore, e.g., $m_{\text {air }}(k)$ denotes fresh air mass which is existing at IVC of cycle ' $k$ '. It is obvious that this amount of air is inducted in intake stroke of cycle ' $k-1$ ' (Note again 
beginning of each cycle is IVC). Other components' mass definition can be found in the same table.

Table 6- Parameter indexing and components' mass definition used in this work

\begin{tabular}{|c|c|}
\hline Parameter & Definition \\
\hline$k$ & Cycle index \\
\hline$m_{\text {air }}(k)$ & Air mass at IVC in cycle ' $\mathrm{k}$ ' (inducted in cycle ' $\mathrm{k}-1$ ') \\
\hline$m_{\text {res }}(k)$ & Residual mass at IVC in cycle 'k' \\
\hline$m_{\text {fuel }}(k)$ & (sum of trapped and overlap mass from cycle 'k-1') \\
\hline$m_{\mathrm{H}_{2} \text { O,vapor }}(k)$ & Water vapor mass at IVC in cycle ' $\mathrm{k}$ ' \\
& (inducted in cycle 'k-1') \\
\hline
\end{tabular}

Estimation of air mass at cycle $k\left(m_{\text {air }}(k)\right)$ in air charge estimation algorithm, is done as follows:

$m_{\text {air }}(k)$ is estimated using the data from previous cycle $(k-1)$ in a step-by-step procedure and beginning from IVC of cycle $(k-1)$. Thermodynamic and heat transfer relationships in different engine run-time sections (illustrated on P-V diagram) are taken into consideration in the step-by-step procedure. 
All the calculations done in cycle ' $k-1$ ' to estimate $m_{\text {air }}(k)$ are shown in following lines. First section is IVC (1) to EVO (2) which follows:

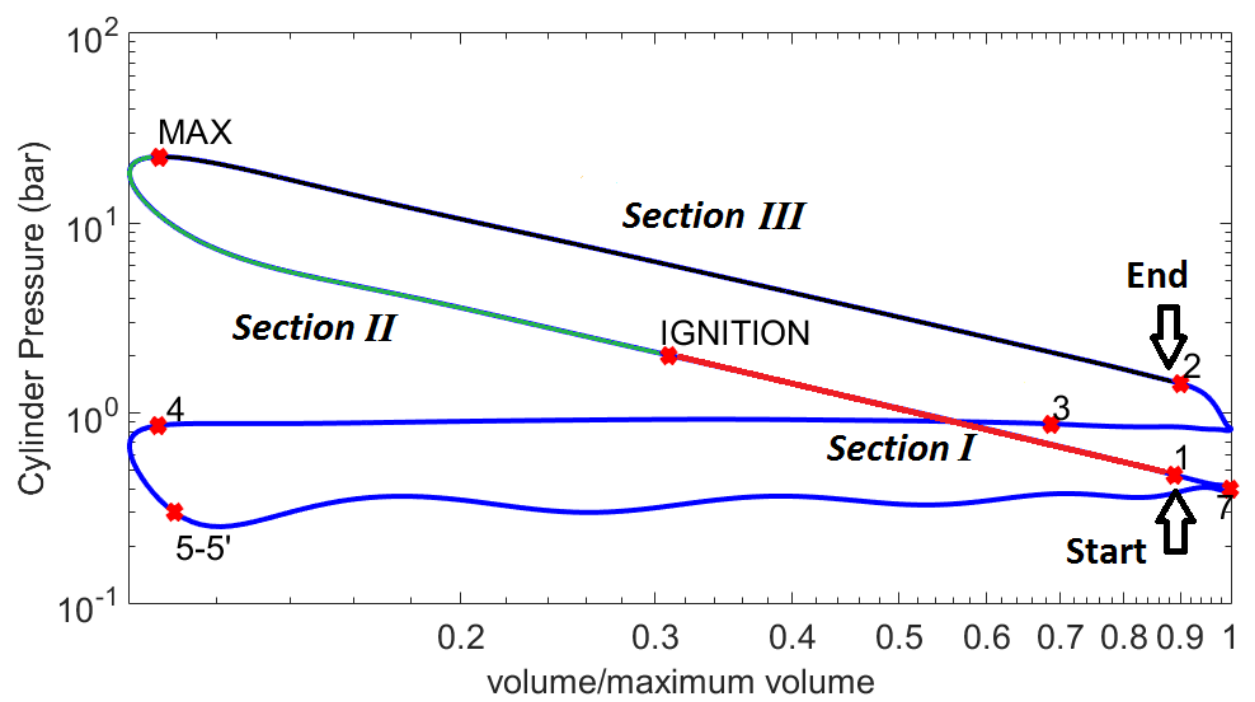

Figure 7-Compression and expansion section

This is the region which includes compression, combustion and expansion. The major equation in this region is first thermodynamics law for a closed system (blow-by neglected):

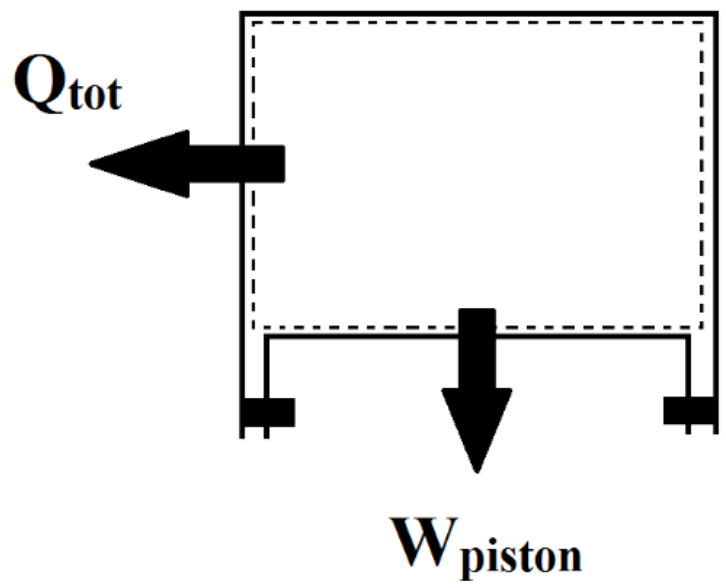

Figure 8-Closed system control volume 


$$
\begin{aligned}
\eta_{c} \cdot m_{\text {fuel }}(k-1) \cdot L H V_{\text {fuel }} & \\
& =Q_{\text {tot }}(k-1)+W_{\text {piston }}(k-1)+U_{E V O}(k-1)-U_{I V C}(k-1) \\
& +Q_{\text {charge cooling }, I V C}(k-1)
\end{aligned}
$$

The left hand side in this equation is the energy released by combustion. Here $\eta_{c}$ denotes combustion efficiency and a value of 0.97 is assumed for it in this work. However it could also be tabulated or calibrated for different engine run-time conditions. The corresponding value of fuel Lower Heating Value $\left(L H V_{\text {fuel }}\right)$, is $41.64[\mathrm{MJ} / \mathrm{kg}]$ (Table 3).

$m_{\text {fuel }}(k-1)$, as explained previously, is the injected fuel mass existing at IVC of cycle ' $k-1$ '; It is noted that the injection takes place in intake stroke although the engine is equipped with Direct Injection (DI) technology with capability of injection in compression stroke (stratified injection). Hence $m_{f u e l}(k-1)$ is the mass of fuel which is injected in intake stroke in previous cycle $(k-2)$. An assumption of $14 \mathrm{mg}$ for initial fuel mass is made for the calculation of first cycle $\left(m_{\text {air }}(1)\right)$ estimation). This value is a rough estimation of injected fuel for test point 1500 RPM, 2.62 bar, intake advance $=0$ and $\lambda=1$. Apparently injected fuel changes at different test points but this value (14 $\mathrm{mg}$ ) is merely used as an initial value to start the estimation for different test conditions, for the sake of simplicity. 
On the right hand side, $Q_{\text {tot }}(k-1)$ denotes total heat transfer occurring from IVC (1) to EVO (2). $W_{\text {piston }}(k-1)$ is work done on piston and $Q_{\text {charge cooling,IVC }}(k-1)$ is a percentage of charge cooling effect, which happens after IVC. Charge cooling will be discussed in the section including intake stroke (4.2.9) .Cylinder mixture internal energies at IVC and EVO are denoted by $U_{I V C}(k-1)$ and $U_{E V O}(k-1)$, respectively.

$$
\begin{gathered}
U_{I V C}(k-1)=m_{t o t}(k-1) \cdot C_{v, I V C}(k-1) \cdot\left(T_{I V C}(k-1)-T_{r e f}\right) \\
U_{E V O}(k-1)=m_{t o t}(k-1) \cdot C_{v, E V O}(k-1) \cdot\left(T_{E V O}(k-1)-T_{r e f}\right)
\end{gathered}
$$

Here $T_{r e f}$ is temperature at a reference point and is equal to $298 \mathrm{~K}$. Also specific heat in constant volume $\left(C_{v}\right)$ at IVC is defined based on four components as:

$$
C_{v, I V C}(k-1)=\sum y_{i, I V C}(k-1) \cdot C_{v, i}
$$

Considering four different components existing at IVC (here $y_{i, I V C}(k-1)$ denotes each component's mole fraction at IVC in cycle $k-1$ ), Following values are assumed for different $C_{v, i}$ 's at $400 \mathrm{~K}$ (assumed IVC temperature) and are obtained from EES software [51]: 


$$
\begin{aligned}
& C_{v, \text { air }}=726.2 \frac{\mathrm{J}}{\mathrm{kg} \cdot \mathrm{K}} \\
& C_{v, \text { res }}=726.2 \frac{\mathrm{J}}{\mathrm{kg} \cdot \mathrm{K}} \\
& C_{v, \mathrm{H}_{2} \text { O,vapor }}=1499 \frac{\mathrm{J}}{\mathrm{kg} \cdot \mathrm{K}} \\
& C_{v, \text { fuel }}=2049 \frac{\mathrm{J}}{\mathrm{kg} \cdot \mathrm{K}}
\end{aligned}
$$

The value for $C_{v, E V O}(k-1)$ is selected equal to $887.3\left[\frac{\mathrm{J}}{\mathrm{kg} \cdot \mathrm{K}}\right]$ (constant value at each cycle), which is $C_{v}$ of air (assuming air and burnt gas have approximately equal $C_{v}$ 's) at assumed temperature at EVO equal to $1200 \mathrm{~K}$ ( [52] section 4.7.2).

Two other terms on the right hand side of Eq. (4-12), are work done in the cycle and total heat transfer. $W_{\text {piston }}(k-1)$ is defined as:

$$
W_{\text {piston }}(k-1)=\operatorname{IMEP} P_{g}(k-1) \cdot V_{d}
$$

Where $V_{d}$ is cylinder displacement volume and $\operatorname{IMEP}_{g}(k-1)$ is the gross IMEP (the one calculated in compression and expansion strokes) which is calculated based on pressure trace and cylinder volume as:

$$
\operatorname{IMEP} P_{g}(k-1)=\frac{\int_{-180 C A}^{180 C A} P(k-1) \cdot d V}{V_{d}}=\frac{\sum P \cdot \Delta V}{V_{d}}
$$


Crank Angle (CA) is equal to zero in TDC of firing as mentioned in section 4.2.3.

The most significant calculation process is dedicated to estimation of heat transfer in the region from IVC (1) to EVO (2). Total heat transfer is calculated from following relationship:

$$
Q_{t o t}(k-1)=\int_{I V C}^{E V O} \dot{Q} d t
$$

To handle this calculation with less computation effort, this region is split to three different sections where different heat transfer behavior is expected to happen (as seen in Figure 7):

Section I is from IVC to ignition point (1 to IGNITON), Section II is from ignition point to maximum pressure point (IGNITION to MAX) and, Section III is from maximum pressure point to EVO (MAX to 2).

The general equation used to estimate heat transfer rate $(\dot{Q})$ between cylinder gas and engine coolant is:

$$
\dot{Q}(k-1)=h_{\text {tot }}(k-1) \cdot A_{\text {transfer }}(k-1) \cdot\left(T(k-1)-T_{\text {coolant }}\right)
$$


in which,

$h_{\text {tot }}(k-1)$ is the total heat transfer coefficient, $A_{\text {transfer }}(k-1)$ is the heat transfer surface area, $T(k-1)$ is cylinder gas temperature, and $T_{\text {coolant }}$ is engine coolant temperature. In following lines the calculation of each of these parameters is explained.

$T_{\text {coolant }}$ is assumed to be constant and equal to $80^{\circ} \mathrm{C}(353 \mathrm{~K}) . T(k-1)$ is calculated as the average temperature on each section as:

$$
\begin{gathered}
T_{I}(k-1)=\frac{T_{I V C}(k-1)+T_{\text {ignition }}(k-1)}{2} \\
T_{I I}(k-1)=\frac{T_{\text {ignition }}(k-1)+T_{\max }(k-1)}{2} \\
T_{I I I}(k-1)=\frac{T_{\max }(k-1)+T_{E V O}(k-1)}{2}
\end{gathered}
$$

$T_{I}, T_{I I}$, and $T_{I I I}$ denote cylinder gas average temperature in sections I, II, and III, respectively. 
Considering mass conservation and ideal gas law between IVC (1) and the ignition, maximum, and EVO (2) points, temperature at each of these points, to be used in heat transfer estimation, is as follow:

$$
\begin{gathered}
T_{\text {ignition }}(k-1)=\frac{P_{\text {ignition }}(k-1) \cdot \operatorname{Vol}_{\text {ignition }}(k-1)}{P_{I V C}(k-1) \cdot \operatorname{Vol}_{I V C}(k-1)} \cdot T_{I V C}(k-1) \\
T_{\text {max }}(k-1)=\frac{P_{\max }(k-1) \cdot \operatorname{Vol}_{\max }(k-1)}{P_{I V C}(k-1) \cdot \operatorname{Vol}_{I V C}(k-1)} \cdot T_{I V C}(k-1) \\
T_{E V O}(k-1)=\frac{P_{E V O}(k-1) \cdot \operatorname{Vol}_{E V O}(k-1)}{P_{I V C}(k-1) \cdot \operatorname{Vol}_{I V C}(k-1)} \cdot T_{I V C}(k-1)
\end{gathered}
$$

in equations above $\mathrm{Vol}$ is the cylinder volume and $P$ is cylinder pressure.

Cylinder volume is calculated from [52] (equation 2.6). Wrist-pin offset is also added to the eqaution:

$$
V o l=V_{c} \cdot\left[1+0.5 \cdot\left(r_{c}-1\right) \cdot\left(R+1-\cos (\theta)-\left(\sqrt{R^{2}-\left(\sin (\theta)+\frac{X}{a}\right)^{2}}\right)\right)\right]
$$


Here $V_{c}$ is clearance volume, $r_{c}$ is compression ratio, $X$ is wrist-pin offset (added to the equation above), $\theta$ is encoder crank angle, and $R$ is ratio of connecting rod $(l)$ length to crankshaft radius $(a)$ :

$$
R=\frac{l}{a}
$$

To calcualte the heat transfer surface, the engine geometry based equation from [52] (equation 2.8 ) is used. Also here, wrist-pin offset is used in the calcualtion:

$$
A_{\text {transfer }}=A_{c h}+A_{p}+\pi \cdot B \cdot \frac{S}{2} \cdot\left[R+1-\cos (\theta)-\sqrt{R^{2}-\left(\sin (\theta)+\frac{X}{a}\right)^{2}}\right]
$$

where,

$B$ is cylinder bore, and $S$ is stroke. $A_{p}$ and $A_{c h}$ are defined in equations (4-29) and (4-30), respectively.

$A_{p}$ is piston crown surface area, which is calculated by:

$$
A_{p}=f_{p} \cdot \pi \cdot \frac{B^{2}}{4}
$$

where, $f_{p}$ is piston surface correction factor which is ratio of piston surface area to projected piston area. In this work, it is assumed that $f_{p}$ is equal to 1 . 
$A_{c h}$ is cylinder head surface area (pentroof chamber surface), which is proportional to piston surface area and is caluculated by including the correction factor $f_{c h}$. This correction factor is ratio of actual cylinder head surface to projected area. The value for $f_{c h}$ is assumed to be 1.15 in this work.

$$
A_{c h}=f_{c h} \cdot A_{p}
$$

It is noted here that, the assumption for $f_{p}$ and $f_{c h}$ will be compensated by a calibration parameter (multiplier in Woschni's correlation) in total heat transfer estimation from IVC to EVO.

Parameter $\theta$ indicates crank angle and holds the average value of each section, therefore $A_{\text {transfer,I }}$ corresponds to $\theta_{I}$ which is the CA mean value between IVC (1) and ignition point. $A_{\text {transfer,II }}$ corresponds to $\theta_{I I}$ (average of CA at ignition and max pressure point) and $A_{\text {transfer,III }}$ is related to $\theta_{I I I}$ (average of CA at max pressure point and EVO (2)).

As it is seen in Figure 9, heat transfer from cylinder gas to engine coolant is considered in three different regions: 


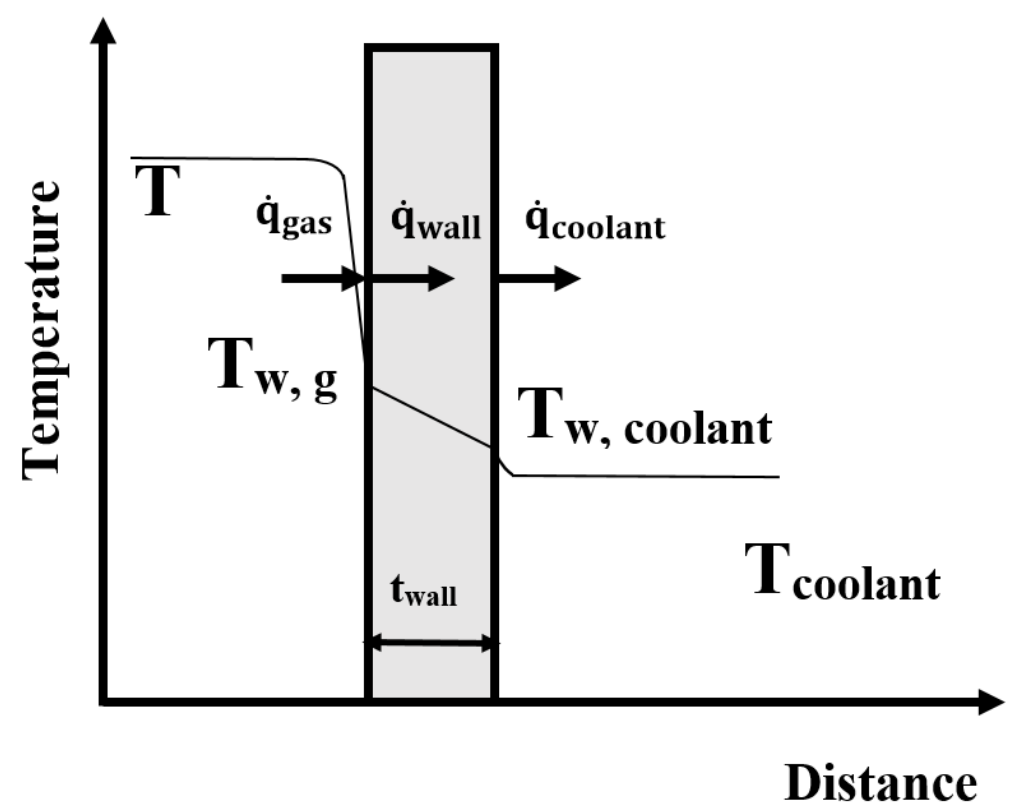

Figure 9- Heat transfer between cylinder gas and engine coolant

1) from cylinder gas to cylinder wall on gas side; heat transfer mode is considered convection (radiation is neglected),

2) through cylinder wall via conduction,

3) from cylinder wall on coolant side to coolant via convection.

Detailed discussion regarding modes of heat transfer can be found under section 12.2.4 in [52].

The rates of heat fluxes $\left(\dot{q}=\frac{\dot{Q}}{A}\right)$ is equal for 3 areas:

$$
\dot{q}_{g a s}=\dot{q}_{\text {wall }}=\dot{q}_{\text {coolant }}=\dot{q}
$$


where:

$$
\dot{q}_{g a s}=h_{c} \cdot\left(T-T_{w, g}\right)
$$

$h_{c}$ is cylinder gas heat transfer coefficient, $T$ is cylinder gas temperature, and $T_{w, g}$ is temperature of cylinder wall on gas side.

$$
\dot{q}_{w a l l}=\frac{k_{w a l l} \cdot\left(T_{w, g}-T_{w, \text { coolant }}\right)}{t_{w a l l}}
$$

$k_{w a l l}$ is cylinder wall thermal conductivity; the value of $205\left[\frac{\mathrm{W}}{\mathrm{m} \cdot \mathrm{K}}\right]$ is selected for cylinder aliuminum wall. $t_{w a l l}$ is wall thickness and the value is selected to be $0.01 \mathrm{~m}(1 \mathrm{~cm}) . T_{w, g}$ and $T_{w, \text { coolant }}$ are wall temperature on gas and coolant side, respectively.

$$
\dot{q}_{\text {coolant }}=h_{\text {coolant }} \cdot\left(T_{w, \text { coolant }}-T_{\text {coolant }}\right)
$$

$h_{\text {coolant }}$ is engine coolant heat transfer coefficient with value of $7500\left[\frac{\mathrm{W}}{\mathrm{m}^{2} \cdot \mathrm{K}}\right]$ and $T_{\text {coolant }}$ is engine coolant temperature. 
By doing algebraic calculations on Eq. (4-32), (4-33), and (4-34), equation below is obtained:

$$
\dot{q}_{j}(k-1)=\frac{h_{c, j}(k-1) \cdot k_{\text {wall }} \cdot h_{\text {coolant }}}{k_{\text {wall }} \cdot h_{\text {coolant }}+t_{w a l l} \cdot h_{c, j}(k-1) \cdot h_{\text {coolant }}+h_{c, j}(k-1) \cdot k_{\text {wall }}} \cdot\left(T_{j}(k-1)-T_{\text {coolant }}\right)
$$

in which, ' $j$ ' is the index for different sections of heat transfer calculation, which are IVC to ignition (section I), ignition to maximum pressure point (section II), and maximum pressure point to EVO (section III). This equation is rewritten as Eq. (4-19).

Also total heat transfer coefficient for different sections $\left(h_{t o t, j}\right)$ is defined as:

$$
h_{\text {tot }, j}(k-1)=\frac{h_{c, j}(k-1) \cdot k_{\text {wall }} \cdot h_{\text {coolant }}}{k_{\text {wall }} \cdot h_{\text {coolant }}+t_{\text {wall }} \cdot h_{c, j}(k-1) \cdot h_{\text {coolant }}+h_{c, j}(k-1) \cdot k_{\text {wall }}}
$$

Parameter $h_{c, j}(k-1)$ is cylinder gas heat transfer coefficient in each section at cycle ' $k-1$ ' and is estimated using Woschni's correlation as follows:

$$
h_{c, j}(k-1)=h_{\text {constant }}(k-1) \cdot B^{-0.2} \cdot P_{j}(k-1)^{0.8} \cdot T_{j}(k-1)^{-0.55} \cdot w_{j}(k-1)^{0.8}
$$


In this correlation $h_{\text {constant }}(k-1)$ is a constant multiplier (will be named heat transfer constant from now on) in each cycle, which is going to be calibrated for different engine run-time conditions in following sections. Therefore its value may differ cycle by cycle in a transient test. $B$ denotes bore, $T_{j}(k-1)$ is cylinder gas temperature and $w_{j}(k-1)$ is average cylinder gas velocity calculated from:

$$
w_{j}(k-1)=C_{1} \cdot \bar{S}_{p}(k-1)+C_{2} \cdot \frac{V_{d} \cdot T_{r}(k-1)}{P_{r}(k-1) \cdot V_{r}(k-1)}\left(P_{j}(k-1)-P_{j, \text { motoring }}(k-1)\right)
$$

In this correlation, $C_{1}$ is selected to be equal to $2.28[-]$ and $C_{2}$ is $3.24 \times 10^{-3}\left[\frac{\mathrm{m}}{\mathrm{K} \cdot \mathrm{sec}}\right]$ ( [52] equation 12.18). Other parameters are also defined as:

$$
\bar{S}_{p}(k-1)=2 \cdot S \cdot \frac{N(k-1)}{60}
$$

$\bar{S}_{p}(k-1)$ is mean piston speed in $\left[\frac{m}{s e c}\right], S$ is engine stroke in $[\mathrm{m}]$ and $N(k-1)$ is engine speed in $[\mathrm{RPM}]$ (changes cycle by cycle with speed transience). $V_{d}$ is displaced volume, $T_{r}(k-1), P_{r}(k-1)$, and $V_{r}(k-1)$ are reference values for cylinder temperature, pressure and volume; the reference point is selected to be IVC in this work. Also $P_{j}(k-1)$ denotes cylinder pressure in each of the three sections from IVC to EVO. The average value is also defined for each section, therefore: 


$$
\begin{gathered}
P_{I}(k-1)=\frac{P_{I V C}(k-1)+P_{\text {ignition }}(k-1)}{2} \\
P_{I I}(k-1)=\frac{P_{\text {ignition }}(k-1)+P_{\max }(k-1)}{2} \\
P_{I I I}(k-1)=\frac{P_{\max }(k-1)+P_{E V O}(k-1)}{2}
\end{gathered}
$$

$P_{j, \text { motoring }}(k-1)$ is motoring in-cylinder pressure at the same crank angle as $P_{j}(k-1)$ :

$$
\begin{gathered}
P_{I, \text { motoring }}(k-1)=\frac{P_{I V C, \text { motoring }}(k-1)+P_{\text {ignition,motoring }}(k-1)}{2} \\
P_{I I, \text { motoring }}(k-1)=\frac{P_{\text {ignition,motoring }}(k-1)+P_{\text {max }, \text { motoring }}(k-1)}{2} \\
P_{I I, \text { motoring }}(k-1)=\frac{P_{\text {max }, \text { motoring }}(k-1)+P_{E V O, \text { motoring }}(k-1)}{2}
\end{gathered}
$$

The motoring values for IVC and ignition point are also defined as: 


$$
P_{I V C, \text { motoring }}(k-1)=P_{I V C}(k-1)
$$

$$
P_{\text {ignition, motoring }}(k-1)=P_{\text {ignition }}(k-1)
$$

Motoring pressure at maximum pressure point is calculated from IVC pressure and polytropic equation:

$$
P_{\text {max }, \text { motoring }}(k-1)=P_{I V C}(k-1) \cdot\left(\frac{V_{o l_{I V C}}(k-1)}{V_{C}}\right)^{1.35}
$$

where,

$V_{c}$ is clearance volume and compression polytropic coefficient of 1.35 is assumed for this process.

Motoring pressure at EVO is also calculated from maximum point motoring pressure using polytropic equation and assuming expansion coefficient of 1.36 (Note: in motoring, expansion polytropic coefficient is slightly greater than the compression one). 


$$
P_{\text {EVo }, \text { motoring }}(k-1)=P_{\text {max }, \text { motoring }}(k-1) \cdot\left(\frac{V_{c}}{V_{o l_{E V O}}(k-1)}\right)^{1.36}
$$

Now based on our calculations Eq. (4-19) can be solved and $\dot{Q}_{j}(k-1)$ is estimated. To calculate the heat transfer energy $(Q(k-1))$ in different sections, the following conversions are done:

$$
\begin{gathered}
Q_{I}(k-1)=\dot{Q}_{I}(k-1) \cdot \frac{\Delta \theta_{I}(k-1)}{N(k-1)} \\
Q_{I I}(k-1)=\dot{Q}_{I I}(k-1) \cdot \frac{\Delta \theta_{I I}(k-1)}{N(k-1)} \\
Q_{I I I}(k-1)=\dot{Q}_{I I I}(k-1) \cdot \frac{\Delta \theta_{I I I}(k-1)}{N(k-1)}
\end{gathered}
$$

In these equations, $N(k-1)$ is engine speed in $\left[\frac{\text { degree }}{\text { sec }}\right] . \Delta \theta_{I}(k-1)$ denotes $\mathrm{CA}$ difference between IVC and ignition point, $\Delta \theta_{I I}(k-1)$ is CA difference between ignition and maximum pressure point, and $\Delta \theta_{I I I}(k-1)$ is equal to CA difference between $\mathrm{EVO}$ and maximum pressure point.

Therefore total heat transfer calculation is done by: 


$$
Q_{t o t}(k-1)=Q_{I}(k-1)+Q_{I I}(k-1)+Q_{I I I}(k-1)
$$

Now all the terms in Eq. (4-12) are calculated (except charge cooling term, which will be mentioned in intake stroke section) and temperature at EVO is estimated.

\subsubsection{EVO to End of Blowdown (2 to 3) Equations}

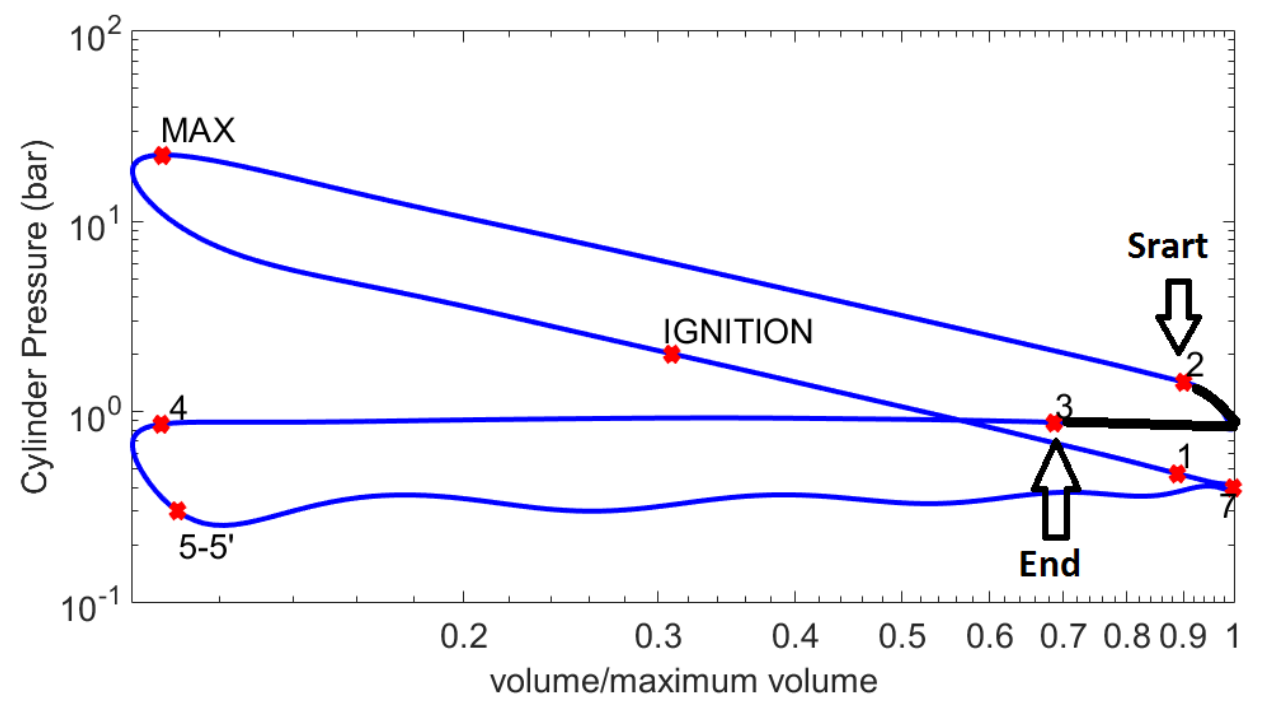

Figure 10- Gas blowdown after EVO event

When the exhaust valve opens (point 2), an isentropic blowdown from pressure at EVO to the exhaust stroke pressure (point 3) happens which is illustrated in Figure 11. 


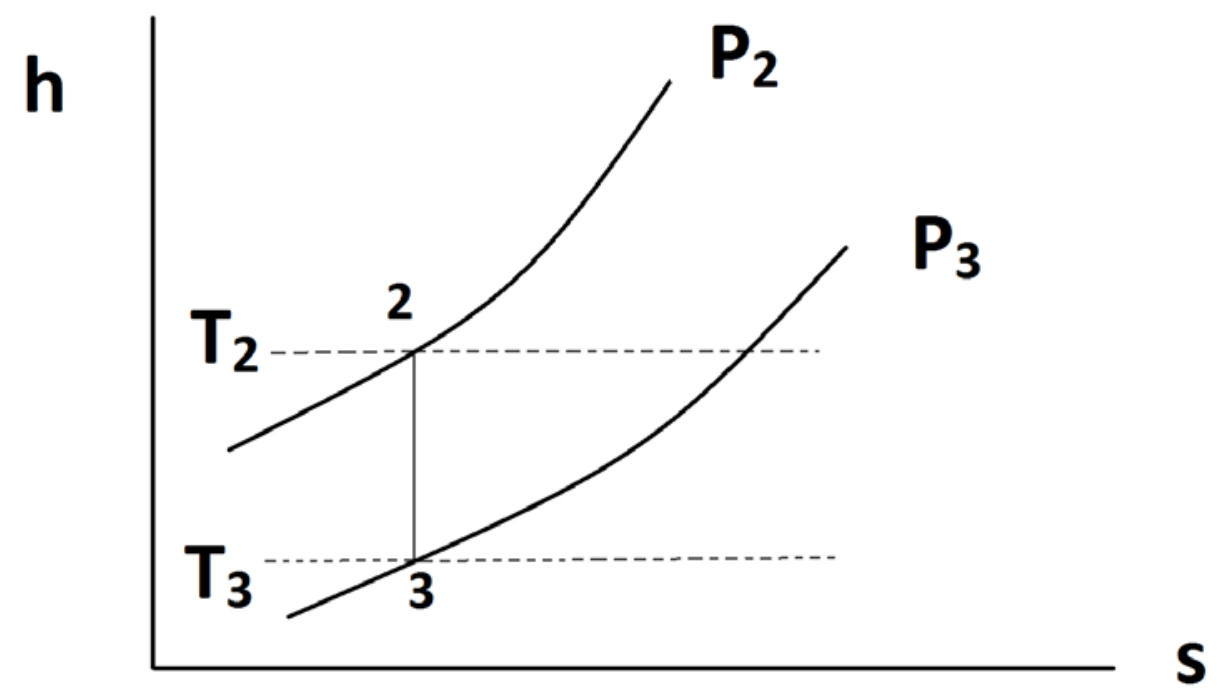

Figure 11 - Isentropic blowdown on h-s diagram

Pressure at point 3 is interpreted as exhaust pressure shown as $P_{\text {exh }}$ and temperature of this point will be referred to as exhaust temperature $\left(T_{\text {exh }}\right)$. This is the temperature of the gases in the cylinder during the exhaust stroke and is estimated using isentropic expansion equation:

$$
\frac{P_{e x h}(k-1)}{P_{E V O}(k-1)}=\left(\frac{T_{e x h}(k-1)}{T_{E V O}(k-1)}\right) \frac{\gamma_{E V O}}{\gamma_{E V O}-1}
$$

In this work, end of blowdown point, is assigned to $260 \mathrm{CA}$ degree ( $\left.80^{\circ} \mathrm{CA} \mathrm{ABDC}\right)$. The value of $\gamma_{E V O}$ is assumed 1.324 , which is air specific ratio at $1200 \mathrm{~K}$ ( [52] figure 4-18). So at the end of this section $T_{\text {exh }}$ is available. 


\subsubsection{End of Blowdown to IVO (3 to 4) Equations}

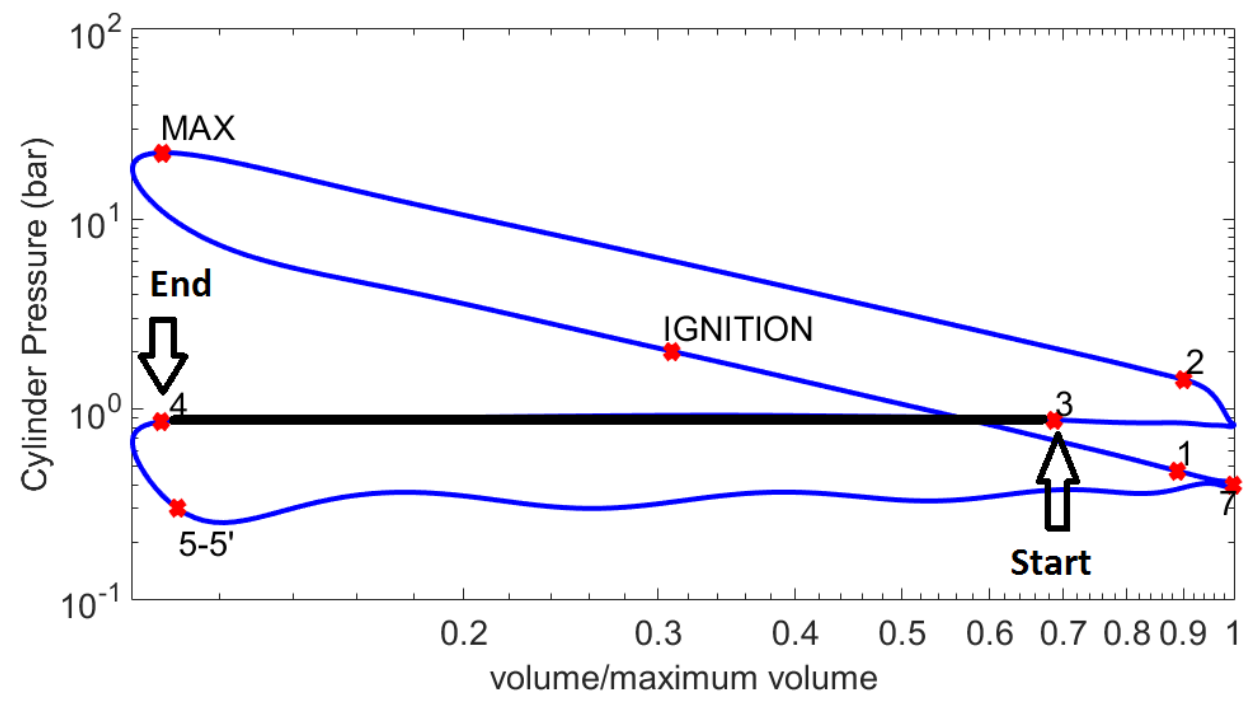

Figure 12- Exhaust stroke on P-V diagram

In this section, it is assumed that from point 3 to IVO (point 4), cylinder pressure is constant; since cylinder volume and mass are decreasing, it is assumed that temperature in this section is constant, so:

$$
T_{4}(k-1)=T_{3}(k-1)=T_{\text {exh }}(k-1)
$$

As discussed before, in residual mass estimation section using Method 2, which was a new approach to estimate residual mass with online applicability, one of the two residual components is trapped residual mass which is equal to cylinder mass at IVO as mentioned in Eq. (4-11). Mass at IVO is estimated by having pressure and temperature at this point using ideal gas law: 


$$
m_{I V O}(k-1)=\frac{P_{I V O}(k-1) \cdot \operatorname{Vol}_{I V O}(k-1)}{R_{\text {residual }} \cdot T_{I V O}(k-1)}
$$

The value for $R_{\text {residual }}$ is selected $273\left[\frac{\mathrm{J}}{\mathrm{Kg} \cdot \mathrm{K}}\right]$. This value is selected by trial and error where estimator outputs makes more sense in calibration process. (To be specific, this value guarantees mass conservation between IVC and EVO). In following sections there will be more discussions over estimator calibration.

The other term for the residual gas which is overlap backflow component will be estimated in next section.

\subsubsection{IVO to EVC (4 to 5) Equations}

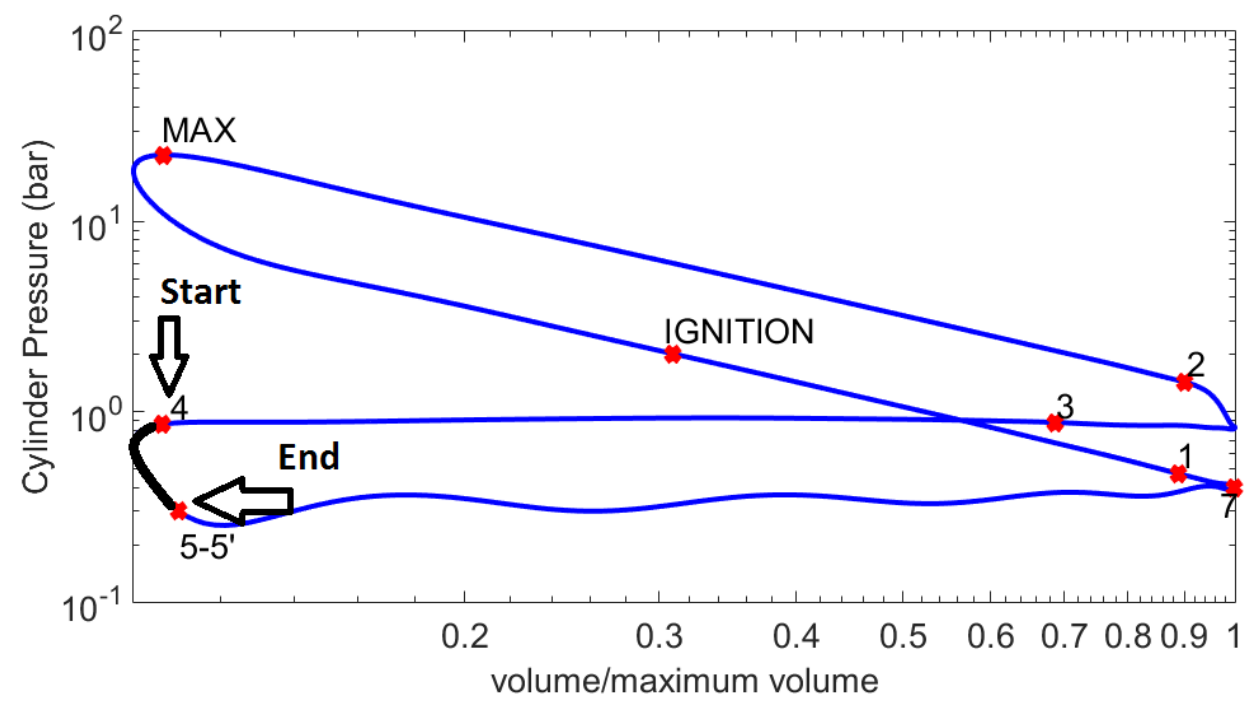

Figure 13- Section on P-V diagram regarding valve overlap 
In this section, from IVO to EVC an isentropic expansion equation is used to estimate the temperature at EVC.

$$
\frac{P_{E V C}(k-1)}{P_{I V O}(k-1)}=\left(\frac{T_{E V C}(k-1)}{T_{I V O}(k-1)}\right) \frac{\gamma_{I V O}}{\gamma_{I V O}-1}
$$

The value of $\gamma_{I V O}$ is assumed 1.344, which is air specific ratio at $900 \mathrm{~K}$ ( [52] figure 4-18). So at the end of this section $T_{E V C}$ is calculated.

There is also an assumption made here that no air is inducted into the cylinder from IVO to EVC. The period where both valves are open (valve overlap), exhaust gases from exhaust runner flow back to the cylinder and add up to the trapped mass which existed in the cylinder at IVO. Temperature at $\operatorname{EVC}\left(T_{E V C}\right.$, which is estimated in this section), is going to be used as residual gas temperature in following equations.

As mentioned before, as residual estimation using Method 2, the overlap term is estimated as (Eq. (4-11):

$$
m_{\text {overlap }}(k-1)=\alpha(k-1) \cdot\left(\frac{P_{i}(k-1)}{P_{e}(k-1)}\right)^{-0.87} \cdot \frac{\sqrt{\left|P_{e}(k-1)-P_{i}(k-1)\right|}}{N(k-1)}
$$

In this equation: 
$\alpha$ is the parameter, the value of which depends on engine run-time conditions including speed, load and cam phasing. By comparing the overlap term in Eq. (4-10) with the overlap term here, it is seen that Overlap Factor $(O F)$ and constant $C_{1}$ are lumped into $\alpha$ for the sake of less complexity in calculations. $\alpha$ is calibrated for different steady state tests and values are reported in Appendix C.

$P_{i}(k-1)$ and $P_{e}(k-1)$ are intake and exhaust pressures, respectively; Manifold Absolute Pressure (MAP) at the corresponding cycle $(M A P(k-1))$ is used as $P_{i}(k-1)$ and pressure at IVO is used for $P_{e}(k-1) . N(k-1)$ is engine speed with unit of $\left[\frac{r e v}{s e c}\right]$.

When using residual estimation Method 2, the residual mass is estimated from Eq. (4-11) and is going to be used as residual which exists at IVC in cycle ' $k$ ' $\left(m_{\text {res }}(k)=m_{\text {overlap }}(k-1)+m_{I V O}(k-1)\right.$. This value $\left(m_{\text {res }}(k)\right)$ is, at the same time, identical to the amount of residual mass existing at point 5' (in cycle ' $k-1$ ') as it is used in next step to calculate the internal energy at 5'. 


\subsubsection{EVC to BDC in Compression Stroke (5' to 7) Equations}

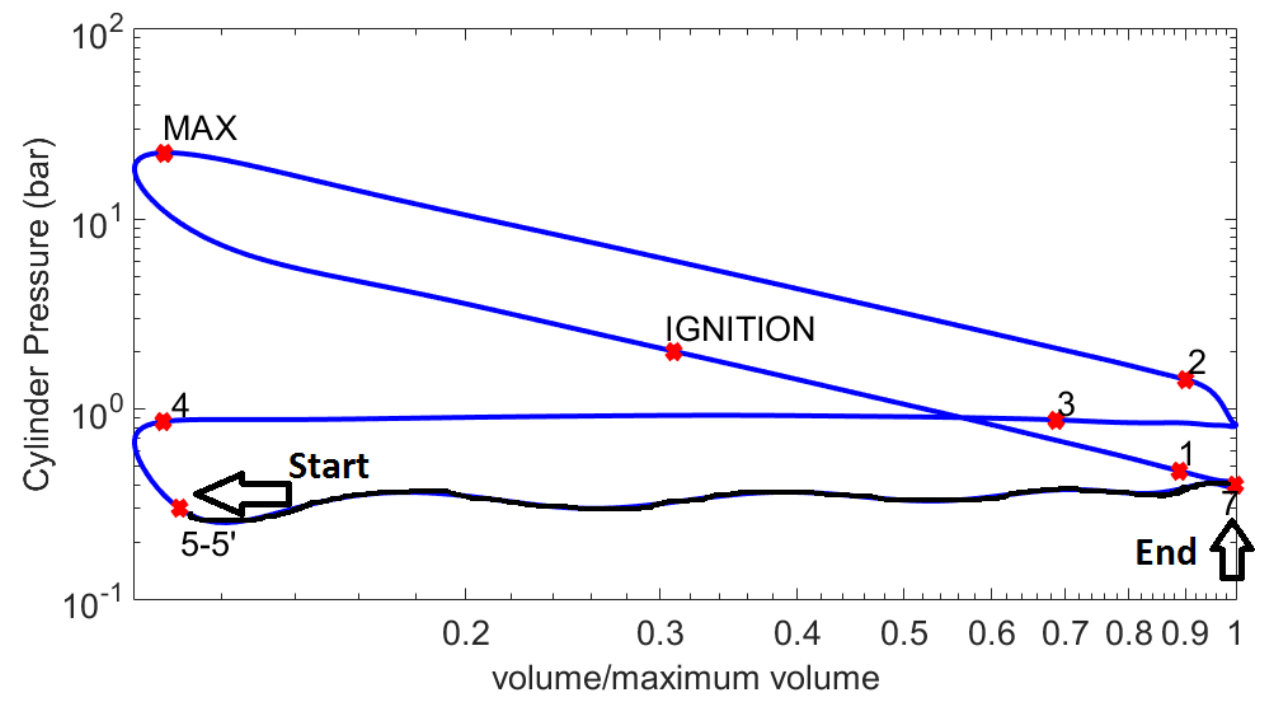

Figure 14- Intake stroke illustration

Calculations in this section deal with the air induction and fuel injection from point 5 ' to 7. $5^{\prime}$ is the point where fresh air is inducted into the cylinder (is not exactly equal to EVC (point 5)) and point 7 is where cylinder pressure rise due to compression is detectible; here it is assumed that point 7 is $\mathrm{BDC}$ in compression stroke.

The dominant equation in this section is first thermodynamics law for open system. At point $5^{\prime}$ cylinder content includes residual gas so internal energy at this point is equal to:

$$
U_{5^{\prime}}(k-1)=m_{\text {res }}(k) \cdot C_{v, r e s, 5} \cdot\left(T_{E V C}(k-1)-T_{r e f}\right)
$$


Here the value for $C_{v, r e s, 5}$ is assumed $787.6\left[\frac{\mathrm{J}}{\mathrm{kg} \cdot \mathrm{K}}\right]$ at $700 \mathrm{~K}$.

It is noted that, if online residual estimator (Method 2) is not used, the residual mass value must be applied as $m_{r e s}(k-1)$ (the one existing in the start of cycle ' $k-1$ '). In upcoming sections Method 1 estimation will be discussed.

Fuel injection happens in the middle of intake stroke (there is no injection in compression stroke) and its effect is studied in detail here. Different phases of injected fuel are depicted in Figure 15. Following scenario is described for fuel injection process:

It is assumed that fuel temperature is $50^{\circ} \mathrm{C}$. Fuel pressure before injection varies based on different run-time conditions (assumed a value between 15 and 30 bar (Table B-1)). At the exit of nozzle, fuel has a dramatic pressure drop through an approximately isenthalpic process (without change in its temperature). Therefore it reaches to the saturated liquid point $\left(\mathrm{T}=50^{\circ} \mathrm{C}\right.$ and quality $\left.=0\right)$. After injection, fuel undergoes an isobaric (constant pressure) process and reaches to the point as saturated vapor. It is assumed that fuel does not go into superheated vapor area and this is the end point for fuel phase changes. 


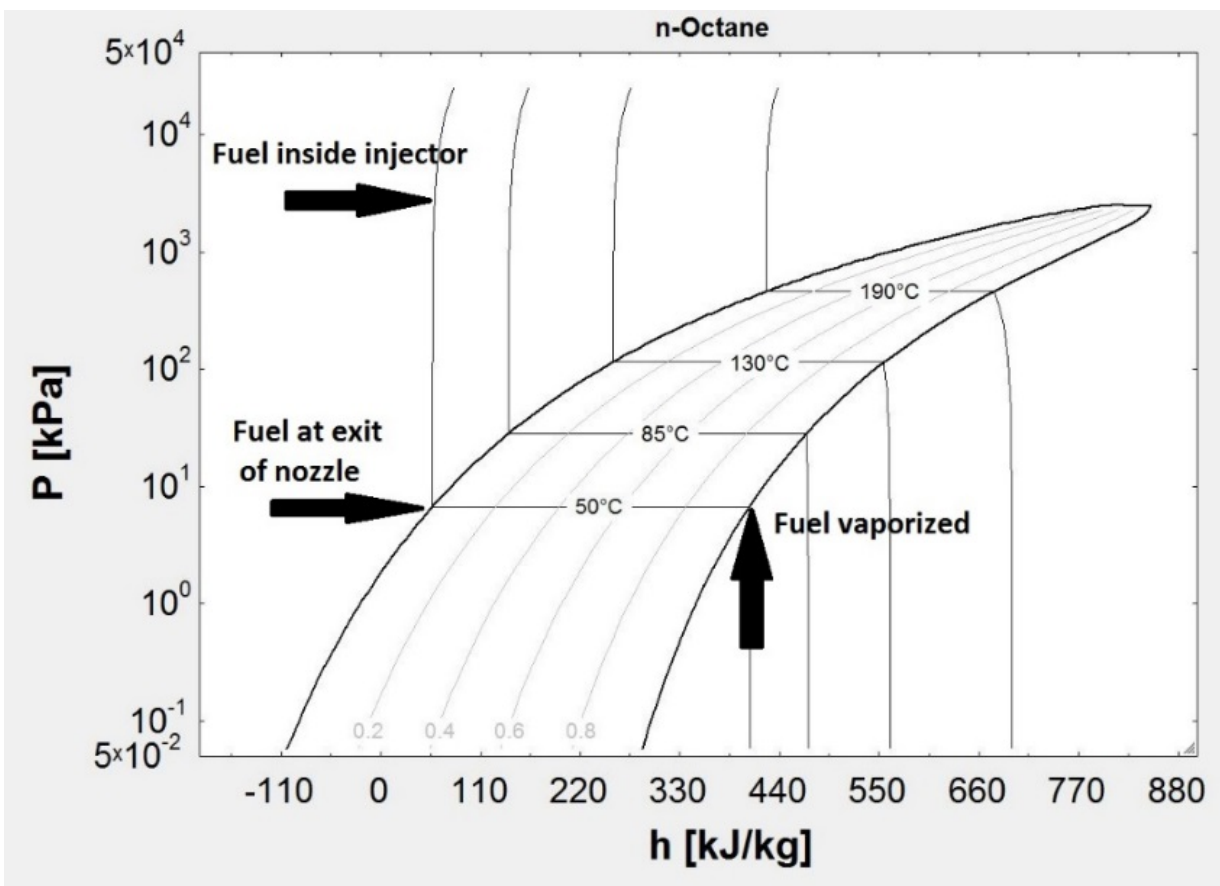

Figure 15- P-h diagram for fuel injected into the cylinder [51]

Almost all the enthalpy increase in fuel is related to vaporization from saturated liquid to saturated vapor, which consequently results in the cylinder charge to cool down.

$$
h_{f g, f u e l, \text { intake }}\left(T=50^{\circ} \mathrm{C}\right)=h\left(T=50^{\circ} \mathrm{C}, x=1\right)-h\left(T=50^{\circ} \mathrm{C}, x=0\right)
$$

$h_{f g, f u e l, \text { intake }}$ represents enthalpy of vaporization of fuel in intake stroke.

To quantify the amount of heat removed from charge (referred to as charge cooling), following assumption is made. After fuel is injected into the cylinder a fraction is impinged on the piston and other go into air. The fraction that goes into air is denoted by ' $z$ ', therefore 
' $1-z$ ' is the impingement fraction. In this work, the value of ' $z$ ' is assumed to be 0.9 (90\%). In addition, a fraction of fuel is vaporized before IVC, denoted by ' $y$ ', and ' $1-y$ ' is vaporized after IVC. Value of ' $y$ ' is also assumed to be 0.9 (in this work). Charge cooling is calculated by:

$$
Q_{\text {charge cooling,intake }}(k-1)=h_{f g, \text { fuel,intake }} \cdot z \cdot y \cdot m_{f u e l}(k)
$$

As discussed before, $m_{f u e l}(k)$ is the amount of fuel existing at IVC in cycle ' $k$ ', which is injected in cycle ' $k-1$ '. Therefore it is going to be used as the amount of fuel to evaluate charge cooling in cycle ' $k-1$ '. If there is no estimation on the amount of injected fuel mass in cycle ' $k-1$ ' by using injector pulse-width and fuel injection pressure, $m_{f u e l}(k)$ in the estimator, is calculated using $m_{\text {air }}(k-1)$ and $\lambda(k-1)$ in Eq.(4-9). Fuel mass calculation will be also discussed in following sections.

In section 4.2.5 (IVC to EVO), a portion of charge cooling takes place after IVC and its amount is:

$$
Q_{\text {charge cooling,IVC }}(k-1)=(1-y) \cdot z \cdot m_{f u e l}(k-1) \cdot h_{f g, f u e l, I V C}
$$

It is noted again that $Q_{\text {charge cooling,IVC }}(k-1)$ is evaluated regarding the fact that it happens in the beginning of cycle ' $k-1$ ' and corresponding fuel mass to that cycle is 
$m_{\text {fuel }}(k-1)$. This charge cooling is prior to $Q_{\text {charge cooling,intake }}(k-1)$ while in the same cycle; as mentioned before, to calculate the latter, $m_{f u e l}(k)$ is used.

The heat transfer to the impinged fraction of fuel on piston is estimated by following equation:

$$
Q_{\text {impinged }}(k-1)=(1-z) \cdot m_{f u e l}(k) \cdot h_{f g, f u e l, p i s t o n}
$$

Here an assumption is made that all the impinged fuel fraction is going to be vaporized (phase change to saturated vapor) by point 7.

The following values for fuel enthalpies of vaporization are obtained from EES software [51]:

$h_{f g, f u e l, \text { intake }}=349.8 \frac{\mathrm{kJ}}{\mathrm{kg}}$ at fuel temperature (assumed to be $323 \mathrm{~K}$ )

$h_{f g, f u e l, I V C}=301.5 \frac{\mathrm{kJ}}{\mathrm{kg}} \quad$ at IVC temperature (assumed to be $400 \mathrm{~K}$ )

$h_{f g, f u e l, p i s t o n}=306.2 \frac{\mathrm{kJ}}{\mathrm{kg}} \quad$ at piston temperature (assumed to be $\left.393 \mathrm{~K}\right)$

To estimate cylinder charge temperature at point 7 (target in this section), first thermodynamics law for open system is used. Figure 16 illustrates cylinder as the open system where fuel, fresh air charge and water vapor enter. 


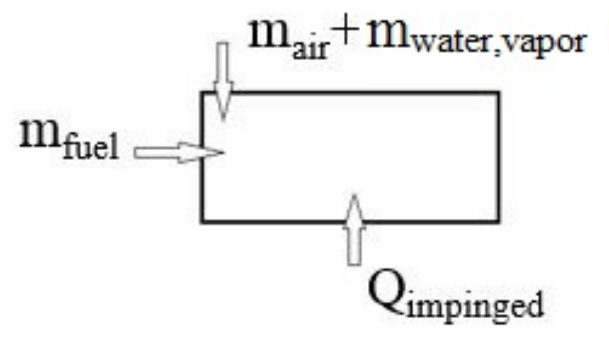

Figure 16- Open system control volume

First thermodynamics law is written as:

$$
\begin{gathered}
Q_{\text {impinged }}(k-1)-W_{\text {intake }}(k-1)+m_{\text {air }}(k-1) \cdot h_{\text {air }}+ \\
m_{\mathrm{H}_{2} \mathrm{O}, \text { vapor }}(k-1) \cdot h_{\mathrm{H}_{2} \mathrm{O}, \text { vapor }}+m_{f u e l}(k) \cdot h_{\text {fuel }}=U_{7}(k-1)-U_{5}(k-1)
\end{gathered}
$$

in which,

$$
W_{\text {intake }}(k-1)=P_{E V C}(k-1) \cdot\left(V o l_{7}-V o l_{E V C}\right)=P_{E V C}(k-1) \cdot \Delta V_{E V C-7}
$$

here $W_{\text {intake }}$ is work done on cylinder charge from EVC (5) to point 7 (intake stroke), and $\Delta V_{E V C-7}$ is cylinder volume change in this section. Also specific enthalpies of the input masses into the cylinder are calculated by:

$$
h_{\text {air }}=C_{p, \text { air }, \text { intake }} \cdot\left(T_{\text {intake }}-T_{\text {ref }}\right)
$$




$$
h_{\mathrm{H}_{2} \mathrm{O}, \text { vapor }}=C_{p, \mathrm{H}_{2} \mathrm{O}, \text { vapor,intake }} \cdot\left(T_{\text {intake }}-T_{\text {ref }}\right)
$$

$$
h_{\text {fuel }}=C_{p, \text { fuel }} \cdot\left(T_{\text {fuel }}-T_{\text {ref }}\right)
$$

As mentioned previously, $T_{r e f}$ is temperature at a reference point and is equal to $298 \mathrm{~K}$. $T_{\text {intake }}$ is assumed to be ambient temperature (to be measured during engine run-time) and $T_{\text {fuel }}$ is assumed to be $323 \mathrm{~K}\left(50^{\circ} \mathrm{C}\right)$. The values for $C_{p}$ 's are [51]:

$$
\begin{aligned}
& C_{p, \text { air, intake }}=1005 \frac{\mathrm{J}}{\mathrm{kg} \cdot \mathrm{K}} \\
& C_{p, \mathrm{H}_{2} \text { O,vapor,intake }}=4183 \frac{\mathrm{J}}{\mathrm{kg} \cdot \mathrm{K}} \\
& C_{p, \text { fuel }}=2320 \frac{\mathrm{J}}{\mathrm{kg} \cdot \mathrm{K}}
\end{aligned}
$$

All the terms in Eq. (4-64) are defined previously, except $U_{7}(k-1)$. This parameter is estimated based on the residual estimation method that is taken in two different ways:

$$
\begin{gathered}
U_{7}(k-1)= \\
C_{v, 7}(k-1) \cdot\left(m_{\text {air }}(k-1)+m_{\text {res }}(k-1)+m_{f u e l}(k)+m_{H_{2} O, v a p o r}(k-1)\right) \cdot\left(T_{7}(k-1)\right. \\
\left.-T_{\text {ref }}\right)
\end{gathered}
$$


This equation is used in Method 1. Since in this method, as will be explained, residual mass is not estimated until IVC, $m_{r e s}(k-1)$ is used. In addition, $m_{\text {air }}(k-1)$ and $m_{\mathrm{H}_{2} \mathrm{O} \text {,vapor }}(k-1)$, which are air and water vapor masses at IVC of cycle $k-1$, are inserted in this equation in both Method 1 and Method 2. Air charge and water vapor mass will be estimated at IVC of cycle ' $k$ '.

If Method 2 is utilized to estimate residual mass, $U_{7}(k-1)$ is obtained from:

$$
\begin{gathered}
U_{7}(k-1)= \\
C_{v, 7}(k-1) \cdot\left(m_{\text {air }}(k-1)+m_{\text {res }}(k)+m_{f u e l}(k)+m_{H_{2} O, \text { vapor }}(k-1)\right) \cdot\left(T_{7}(k-1)-T_{\text {ref }}\right)
\end{gathered}
$$

$C_{v, 7}(k-1)$ is $C_{v}$ of mixture at point 7 with all the components existing in cylinder charge:

$$
C_{v, 7}(k-1)=\sum y_{i, 7}(k-1) \cdot C_{v, i}
$$

The values for $C_{v, i}$ 's for different components are assumed to be the same as the ones selected to calculate $C_{v, I V C}$. Here $y_{i, I V C}(k-1)$ is mole fraction of different components at point 7 in cycle $k-1$.

Estimated $T_{7}(k-1)$ is used in next step, to estimate IVC temperature of cycle ' $k$ ' $\left(T_{I V C}(k)\right)$. 


\subsubsection{BDC in Compression Stroke to IVC (7 to 1) Equations}

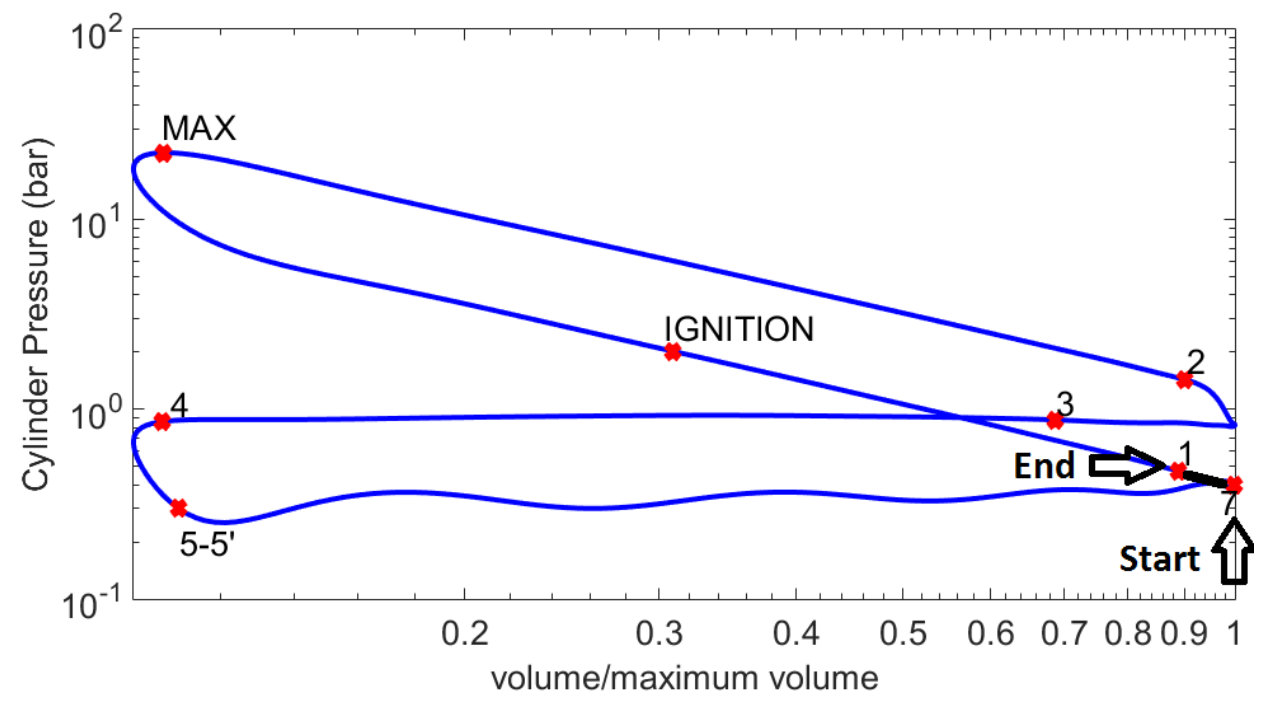

Figure 17- Section on P-V diagram from BDC to IVC

This is the last step to calculate the temperature at IVC and finally estimate total and fresh air mass of cycle ' $k$ '. Polytropic equation is used for this section:

$$
T_{I V C}(k)=T_{7}(k-1) \cdot\left(\frac{P_{I V C}(k)}{P_{7}(k-1)}\right)^{\frac{n_{p o l y}(k-1)-1}{n_{p o l y}(k-1)}}
$$

The value of polytropic index is used equal to the polytropic index in compression stroke obtained from calculations mentioned in 4.2.3. The value which is calculated in compression stroke of cycle ' $k-1$ ' $\left(n_{\text {poly }}(k-1)\right)$ is used in this equation. 
Ultimately, Temperature at IVC is estimated and all the parameters required to estimate fresh air charge using ideal gas law are available.

\subsubsection{Fresh Air Charge Estimation Equations}

The target of all this calculation is to estimate mass of air at IVC in cycle ' $k$ ' $\left(m_{\text {air }}(k)\right)$. By using ideal gas law, total number of moles at IVC is estimated having pressure, temperature and cylinder volume at IVC. Mole to mass conversion equation (Eq. (4-2)) is further used to have the value of $m_{\text {air }}(k)$. Total moles at cycle ' $k$ ' is estimated by:

$$
n_{t o t}(k)=\frac{P_{I V C}(k) \cdot V o l_{I V C}(k)}{R \cdot T_{I V C}(k)}
$$

$R$ is the universal gas constant of $8.3144598 \frac{\mathrm{kJ}}{\mathrm{kgmol} \cdot \mathrm{K}}$.

The total number of moles at IVC, is the summation of components' moles, therefore:

$$
n_{\text {tot }}(k)=n_{\text {air }}(k)+n_{\text {res }}(k)+n_{\text {fuel }}(k)+n_{\mathrm{H}_{2} \mathrm{O}, \text { vapor }}(k)
$$

$n_{\mathrm{H}_{2} \mathrm{O}, \text { vapor }}(k)$ is calculated from water vapor mass estimated from ideal gas law at IVC: 


$$
\begin{gathered}
m_{\mathrm{H}_{2} \mathrm{O}, \text { vapor }}(k)=\frac{P_{\mathrm{H}_{2} \mathrm{O}, \text { vapor }}\left(R H, T_{\text {ambient }}\right)(k) \cdot \operatorname{Vol}_{I V C}(k)}{0.4615 \cdot T_{I V C}(k)} \\
n_{\mathrm{H}_{2} \mathrm{O}, \text { vapor }}(k)=\frac{m_{\mathrm{H}_{2} \mathrm{O}, \text { vapor }}(k)}{M W_{\mathrm{H}_{2} \mathrm{O}, \text { vapor }}}
\end{gathered}
$$

$P_{\mathrm{H}_{2} \mathrm{O}, \text { vapor }}$ is function of RH (Relative Humidity) and ambient temperature (calculations described in 4.2.2). The value of $M W_{\mathrm{H}_{2} \text { O,vapor }}$ is $18.02\left[\frac{\mathrm{g}}{\mathrm{gmol}}\right]$.

As mentioned previously in the beginning of calculations at IVC in first cycle, an initial value for mass of fuel is assigned which is $14 \mathrm{mg}$. Also $T_{I V C}$ has been given an initial value of $370 \mathrm{~K}$. This is required for estimation of $m_{\text {air }}(1)$. Furthermore, to determine air and residual masses at the first cycle, an initial RGF value is assigned merely for calculations of first cycle regardless of the method which is used for residual estimation (Method 1 or Method 2). Initial value for RGF is 0.11 , which is relevant to test point $1500 \mathrm{RPM}, 2.62$ bar, intake advance $=0$ and $\lambda=1$. This value is provided by Ford in a lookup table for different engine run-time conditions; the value of 0.11 is used for the initial RGF in all test points.

Number of moles of fuel $\left(n_{\text {fuel }}\right)$ is obtained from: 


$$
n_{\text {fuel }}(k)=\frac{m_{\text {fuel }}(k)}{M W_{\text {fuel }}}
$$

Value of $M W_{\text {fuel }}$ is taken $100.1\left[\frac{\mathrm{g}}{\mathrm{gmol}}\right]$ as E10 is the fuel used for engine tests.

As previously mentioned, since in this estimator there is no measurement of the injected fuel in each cycle, the amount of fuel for each cycle has to be estimated using air charge from previous cycle. As fresh charge is estimated for cycle ' $k$ ' $\left(m_{\text {air }}(k)\right)$, the fuel mass for cycle ' $\mathrm{k}+1$ ' $\left(m_{\text {fuel }}(k+1)\right)$ is calculated using Eq. (4-9). The lambda value in this equation will be $\lambda(k)$, which is the lambda in cycle ' $k$ '. It is again noted that $m_{\text {fuel }}(k+1)$ is the fuel mass amount existing in IVC of cycle $k+1$, which is injected in intake stroke of cycle ' $k$ '.

Now depending on what method is taken to estimate residual gas, the calculations to estimate air charge differ:

If Method 1 is utilized ( $X_{\text {res }}$ estimated from high-fidelity correlations), using Eq.(4-7) in addition to Eq. (4-74), can solve for $n_{\text {air }}(k)$ and $n_{\text {res }}(k)$ (parameters $n_{\text {tot }}(k), n_{\text {fuel }}(k)$, and $n_{H_{2} O \text {,vapor }}(k)$ are already defined). Following equation will be obtained by some algebraic calculations:

$$
n_{\text {air }}(k)=\frac{n_{\text {tot }}(k) \cdot y_{\text {air }, \text { res }}(k) \cdot M W_{\text {res }} \cdot\left(1-X_{\text {res }}(k)\right)}{X_{\text {res }}(k) \cdot M W_{\text {air }}+M W_{\text {res }} \cdot\left(1-X_{\text {res }}(k)\right)}
$$


in which, $y_{\text {air,res }}(k)$ is mole fraction of air and residual gas altogether:

$$
y_{\text {air,res }}(k)=1-y_{\text {fuel }}(k)-y_{\text {vapor }}(k)
$$

$M W_{\text {res }}$ (residual gas molecular weight) is selected to be $30.45\left[\frac{g}{g m o l}\right]$. As discussed under Eq. (4-56) for $R_{\text {residual }}$, this value is selected by trial and error (Note that $R_{\text {residual }}=$ $\left.\frac{8.3144598}{\left(M W_{\text {res }} / 1000\right)}\right)$. Using this value for $M W_{\text {res }}$ guarantees mass conservation results during the time that both valves are closed (IVC to EVO), during estimator calibrations. More discussions can be found in following sections regarding estimator calibrations.

$M W_{\text {air }}$ (air molecular weight) is selected as $28.97\left[\frac{g}{g m o l}\right]$. By calculating $n_{\text {air }}(k)$, fresh air mass is obtained using air molecular weight. Also $n_{r e s}(k)$ is calculated.

If Method 2 is used, $n_{\text {tot }}(k), n_{H_{2} O, v a p o r}(k), n_{f u e l}(k)$ and $n_{r e s}(k)$ are already estimated. $n_{\text {res }}(k)$ is obtained from residual mass and molecular weight $\left(m_{\text {res }}(k)=m_{\text {overlap }}(k-1)+m_{I V O}(k-1)\right)$. Therefore using Eq.(4-74) leads to estimation of $n_{\text {air }}(k)$ and subsequently $m_{\text {air }}(k)$ is obtained.

A MATLAB ${ }^{\circledR}[53]$ script is generated including the equations mentioned in this section to estimate individual charge air for each cycle based on cylinder pressure during steady-state and transient tests. 
In following lines a schematic of the estimator is illustrated as an algorithm for both Method 1 and Method 2 used to estimate residual component.

\subsection{Schematic of Air Estimation Algorithm}

Thermodynamic and heat transfer relationships discussed in previous section can be arranged in an algorithm, based upon calculations in consequent iterations to estimate the

fresh charge mass in each engine cycle. Depending on residual mass estimation method (Method 1 or 2), two different algorithm schematics are illustrated:

Figure 18 demonstrates air charge estimation when using Method 1 in estimating residual fraction. 


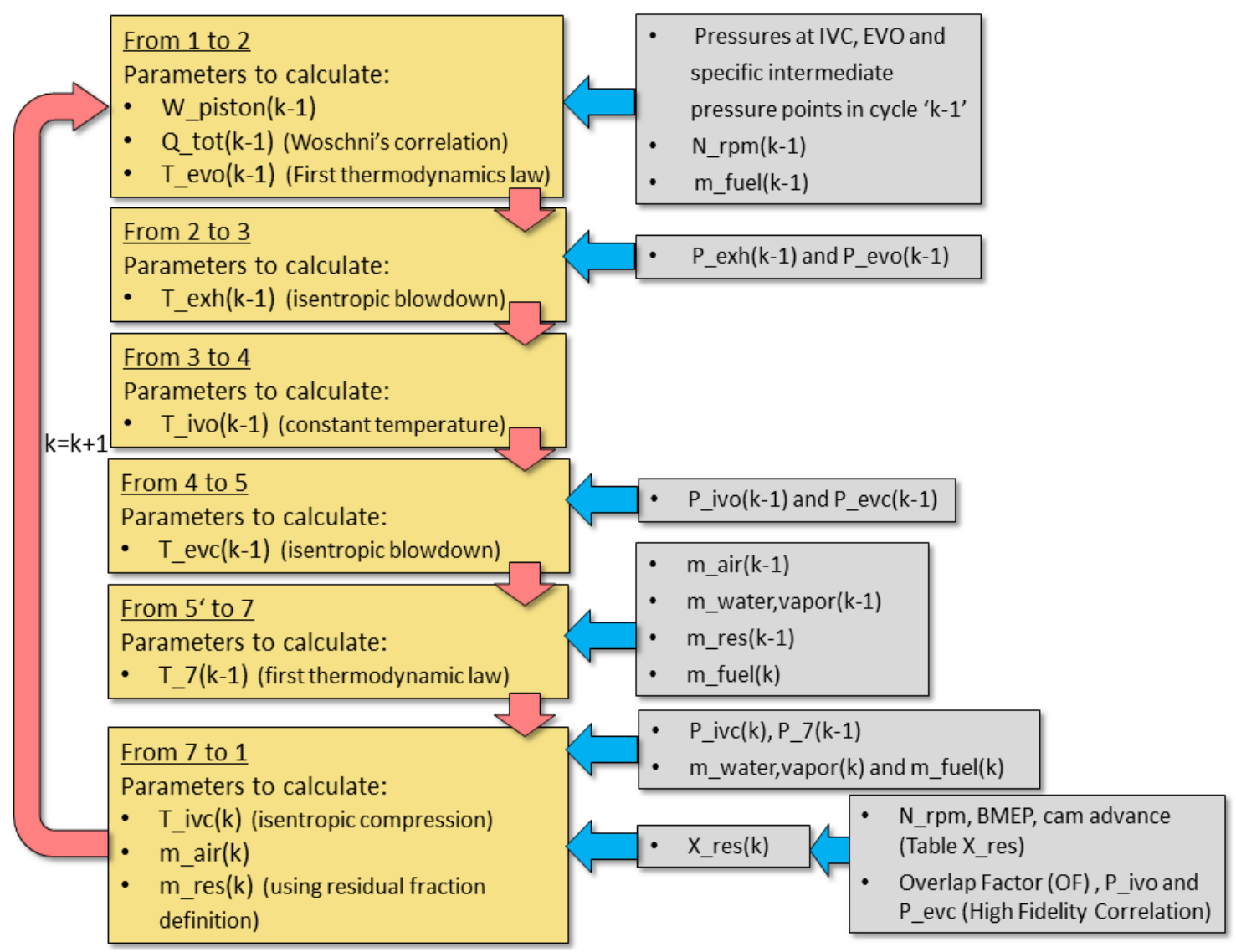

Figure 18- Air estimation algorithm using in-cylinder pressure (Method 1)

Here it is noted again that $m_{\text {air }}(k), m_{\text {res }}(k), m_{H_{2} \text { O,vapor }}(k)$, and $m_{f u e l}(k)$ are air, residual, water vapor and fuel mass which exist at IVC of cycle $k$, respectively. (for both Method 1 and Method 2)

Figure 19 shows the algorithm iteration steps when using Method 2. 


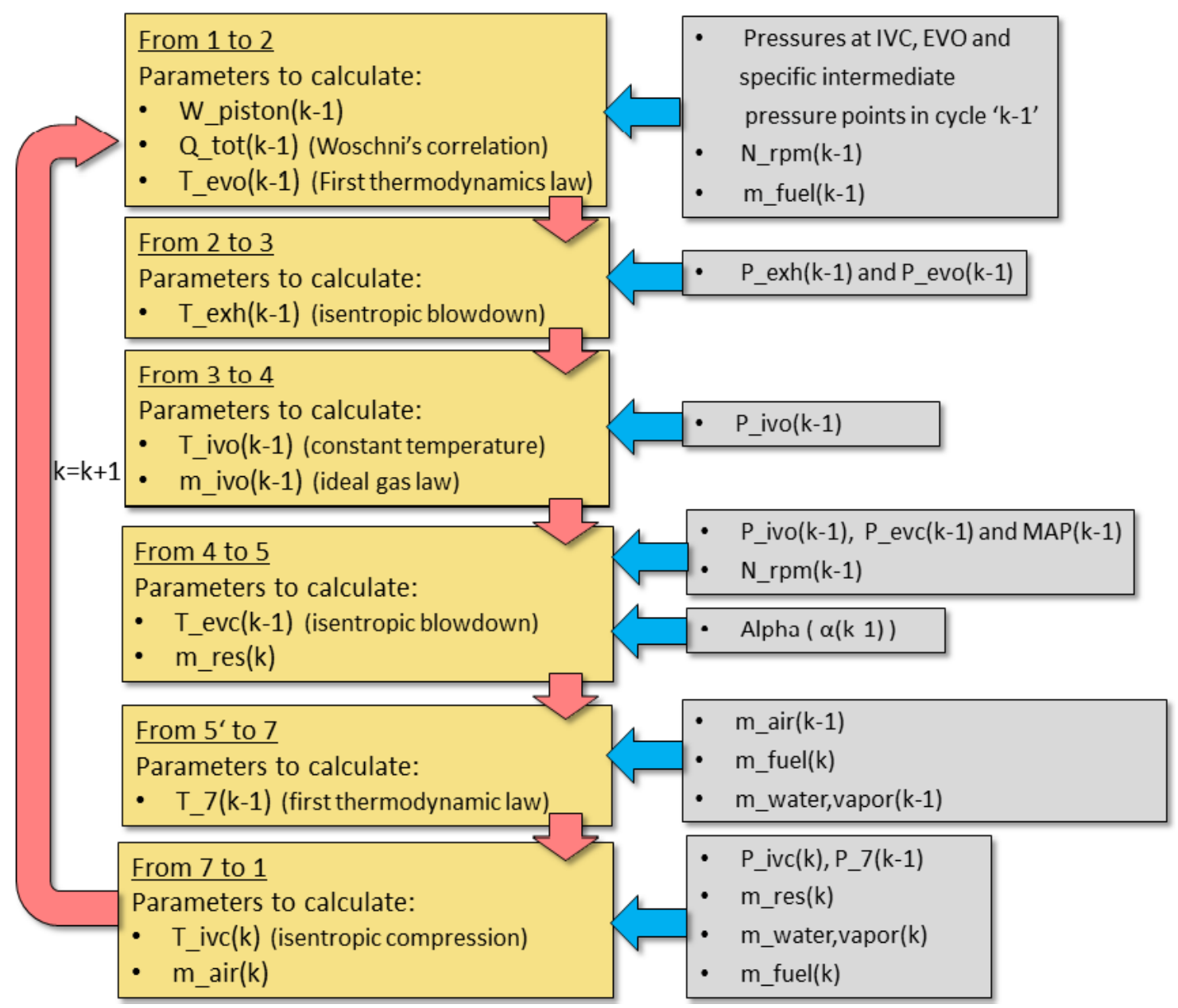

Figure 19- Air estimation algorithm using in-cylinder pressure (Method 2) 


\section{Chapter 5}

\section{Experimental Data from Engine Dynamometer Tests}

In the previous section, an algorithm was proposed to estimate fresh air mass using incylinder pressure transducer data. In this section, the individual air mass in each cylinder is calculated using fuel and lambda $(\lambda)$ data to validate the air charge estimator output.

Fuel flow into the 3.5L Ecoboost is measured by a Micro Motion ${ }^{\circledR}$ ELITE $^{\circledR}$ Coriolis flow and density meter which is mounted on the fuel delivery pipe from fuel cell. Fuel data is acquired and logged with $\mathrm{ACAP}^{\circledR}$ data acquisition tool. Furthermore lambda is measured by 6 individual wide-band sensors (More information can be found in Chapter 3 Experimental Setup) and data is logged with $\mathrm{ACAP}^{\circledR}$

To calculate the air charge Eq. (4-9) is used, in which fuel mass and lambda are required to obtain the value of air charge. Therefore to estimate air, fuel in each cycle must be known, which is equal to the injected fuel from the injector in each cycle. 


\subsection{Air Charge Estimation Using Fuel and Wide-Band Sensors}

The amount of fuel mass injected in cylinder ' $c$ ' at cycle ' $k$ ' is calculated by following equation (assuming fuel is incompressible) [54]:

$$
m_{f u e l, c, k}=\left(\Delta t_{c, k}-t_{0, k}\right) \cdot\left(C_{d} \cdot A\right)_{c} \cdot \sqrt{2 \cdot \rho_{f u e l} \cdot \Delta P_{c, k}}
$$

in which,

$m_{f u e l, c, k}$ is injected fuel mass in cylinder ' $\mathrm{c}$ ' and cycle ' $\mathrm{k}$ ', $\left(C_{d} \cdot A\right)_{c}$ is the effective flow area of injector in cylinder ' $c$ ' and it is assumed that this value is equal for all cylinder injectors, $\rho_{\text {fuel }}$ is fuel density (Table 3 ), and $\Delta P_{c, k}$ is the differential pressure across the injector as:

$$
\Delta P_{c, k}=F R P_{k}-M A P_{k}
$$

where,

$F R P_{k}$ and $M A P_{k}$ are injection fuel rail pressure and MAP (Manifold absolute pressure) at cycle ' $k$ '. Since injection occurs in the intake stroke, therefore cylinder pressure during injection is equal to MAP. 
In Eq. (5-1), $\Delta t_{c, k}$ is injector Pulse-Width (PW) and $t_{0, k}$ is injector delay timing (including opening and closing delays). As it is shown in Figure 20, injector opening delay (Start of Injection (SOI) delay) is the lag between start time of fuel flow from injector $\left(t_{2}\right)$ and the time that opening signal is commanded $\left(t_{1}\right)$. Therefore opening delay is equal to: $t_{2}-t_{1}$.

Closing delay (End of Injection (EOI) delay), which is the lag between the time that injection signal has been stopped $\left(t_{3}\right)$ and injection flow rate is terminated $\left(t_{4}\right)$ can also be shown as: $t_{4}-t_{3}$.

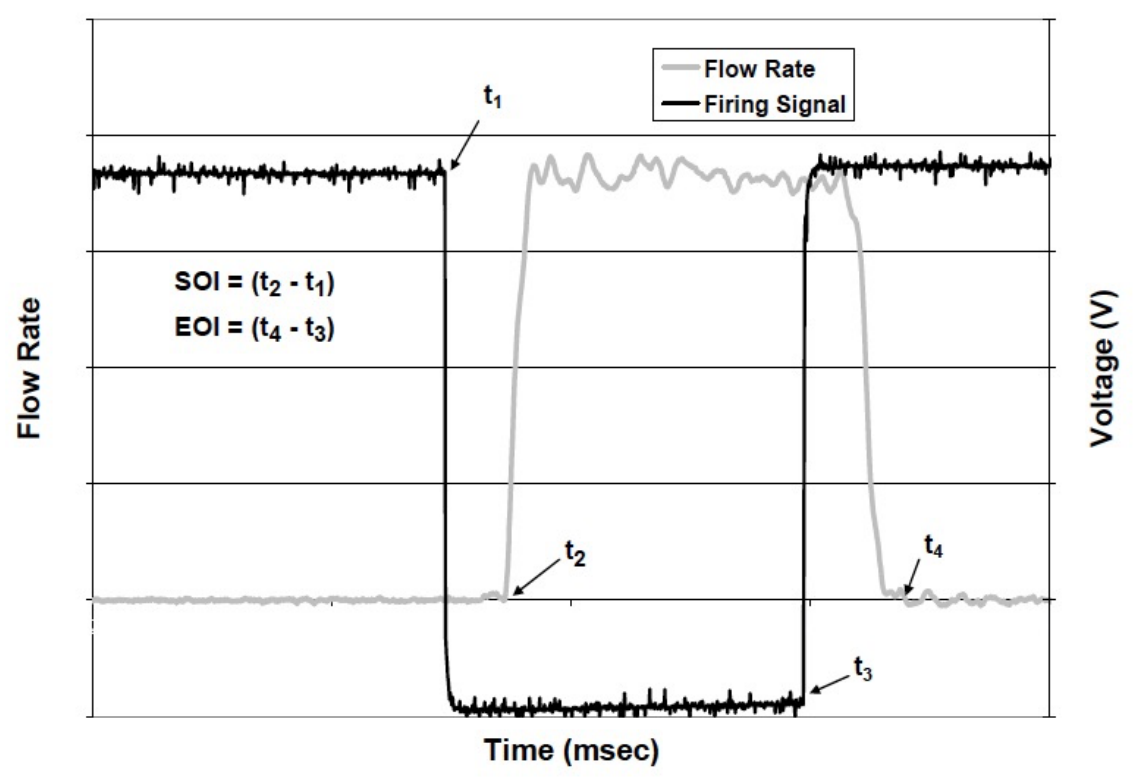

Figure 20- Injector PW, SOI and EOI delays (Courtesy of [55] )

Since fuel flow into the engine is measured by the fuel flow meter $\left(\dot{m}_{f u e l}\right.$ meter $)$, the amount of total injected fuel (in 6 cylinders and total cycles) can also be shown as: 


$$
m_{\text {fuel meter }}=\dot{m}_{\text {fuel meter }} \times \Delta T
$$

Here $m_{\text {fuel meter }}$ is amount of total fuel injected into the engine during $\Delta T$ time period (in $\underline{6 \text { cylinders over all cycles); }} \Delta T$ is the length of time elapsed during total cycles $\left(\right.$ Num $\left._{c y c}\right)$, which is calculated from engine speed $(N)$ :

$$
\Delta T[\mathrm{sec}]=\frac{2 \times 60}{N(R P M)} \times N u m_{c y c}
$$

Following procedure in experimental setup test is taken to fit total fuel data to injector pulse-width and injection pressure. Twenty-six steady-state tests with following conditions were performed:

- Engine speed at 1500 RPM and lambda sweep from 0.7 to 1.3 with 0.05 lambda increment

- Engine speed at 1000 RPM and lambda sweep from 0.7 to 1.3 with 0.05 lambda increment

Injector pulse-width and fuel rail pressure were logged from ATI Vision ${ }^{\circledR}$ (engine control unit interface). Logged parameters are 'DI_PW1_TPU[0]' to 'DI_PW1_TPU[5]' corresponding to injector pulse-widths of cylinders in firing order (1-4-2-5-3-6). Also fuel rail pressure and MAP are logged under ' $F R P \_A C T U A L$ ' and ' $M A P$ '. 
$\dot{m}_{\text {fuel meter }}$ was logged in $\mathrm{ACAP}^{\circledR}$ under parameter named as 'AVGFUEL.P01' which is test fuel flow rate in $\left[\frac{g r}{s}\right] .300$ cycles $\left(N u m_{c y c}=300\right)$ at each test point are selected and average value of logged $\dot{m}_{\text {fuel meter }}$ is obtained. Using Eq. (5-3) and Eq. (5-4) can lead us to $m_{\text {fuel meter }}$ (total amount of injected fuel into the engine for 300 cycles).

An average value obtained from total pulse-widths (in 300 cycles and for 6 cylinders) and an average value of differential injection pressure are calculated. All the calculated values are summarized in the table in Appendix B.

The amount of total injected fuel (in 300 cycles and 6 cylinders) against average injector pulse-width and injection differential pressure are depicted in Figure 21, Figure 22.

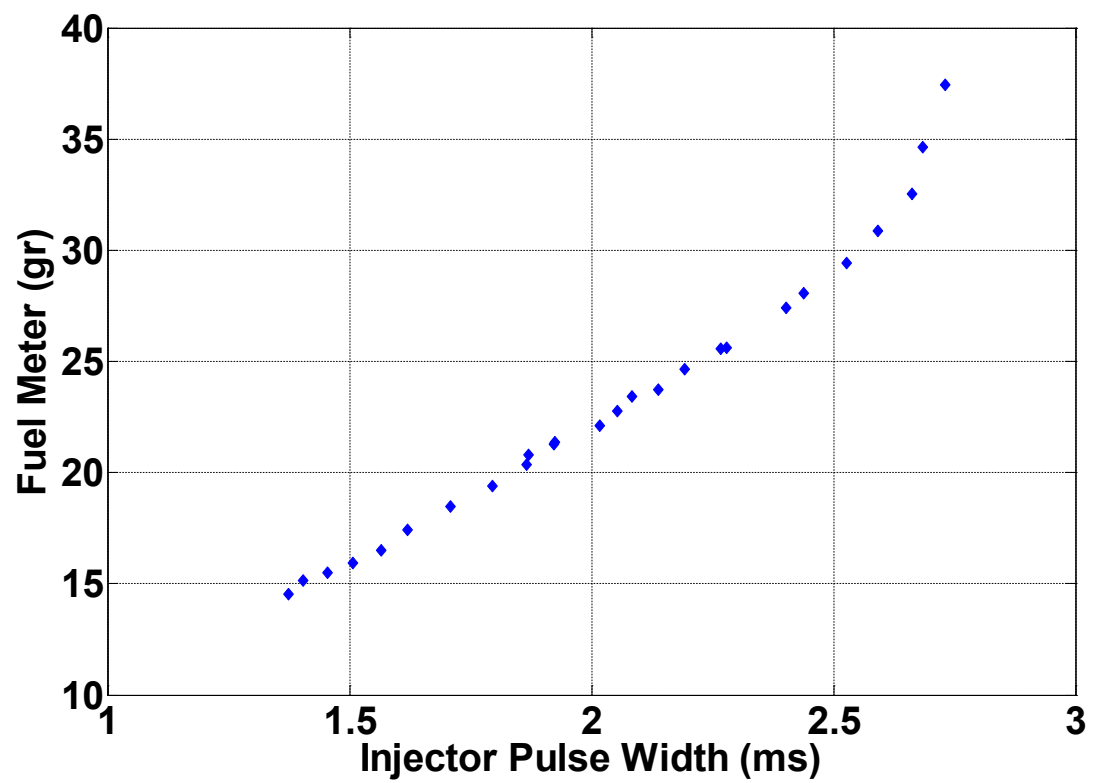

Figure 21- Total injected fuel vs. average injector pulse-width (all test conditions) 
An almost linear relation is noticed between fuel mass and Pulse-width in Figure 21.

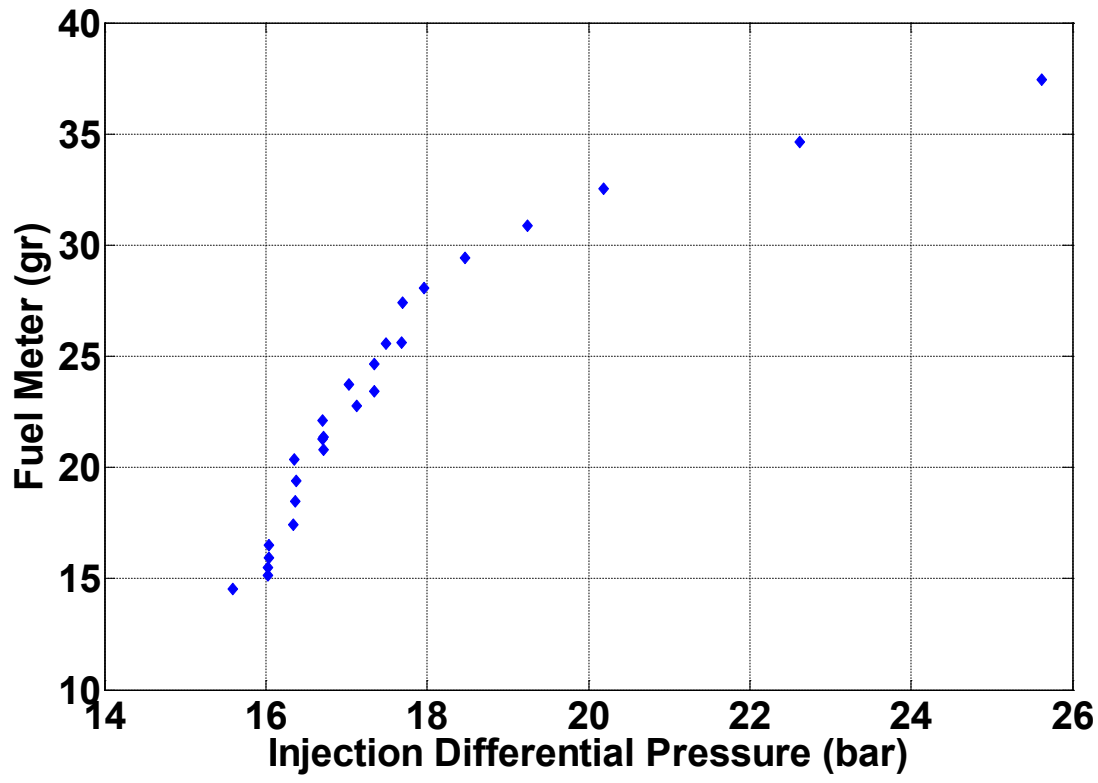

Figure 22-Total injected fuel vs. average injection differential pressure (all test conditions)

Also a square root relation between fuel mass and injection pressure is observed in Figure 22.

Curve Fitting Toolbox ${ }^{\mathrm{TM}}$ [56] in MATLAB is then used based on these observations and curve fitting is done to relate total injected fuel (300 cycles and 6 cylinders) data to average injector pulse-width and injection pressure, based on the general form of Eq. (5-1). The goodness of the fit is investigated with:

$\mathrm{SSE}=4.961 \mathrm{e}-1\left(g r^{2}\right)$

R-square $=0.9995$ 
RMSE $=0.1438(g r)$

Curve fitting error is calculated as:

$$
\text { curve fitting error }=\frac{\text { fitted injected mass }- \text { fuelflow meter data }}{\text { fuel flow meter data }} \times 100
$$

Fitted injected mass with $99.7 \%(3 \sigma)$ confidence is obtained by:

$$
\text { fitted injected mass }=\text { fuel meter data } \pm 3 \times R M S E
$$

And therefore an average error in fitting is quantified and expected as:

$$
\text { error in fitting }=\frac{3 \times R M S E}{\text { Average fuel flow meter data }}=0.0185
$$

Total calculated fuel (6 cylinders and 300 cycles) from the fit using average pulse-width and injection pressure is plotted against total measured fuel from flow meter in Figure 23: 


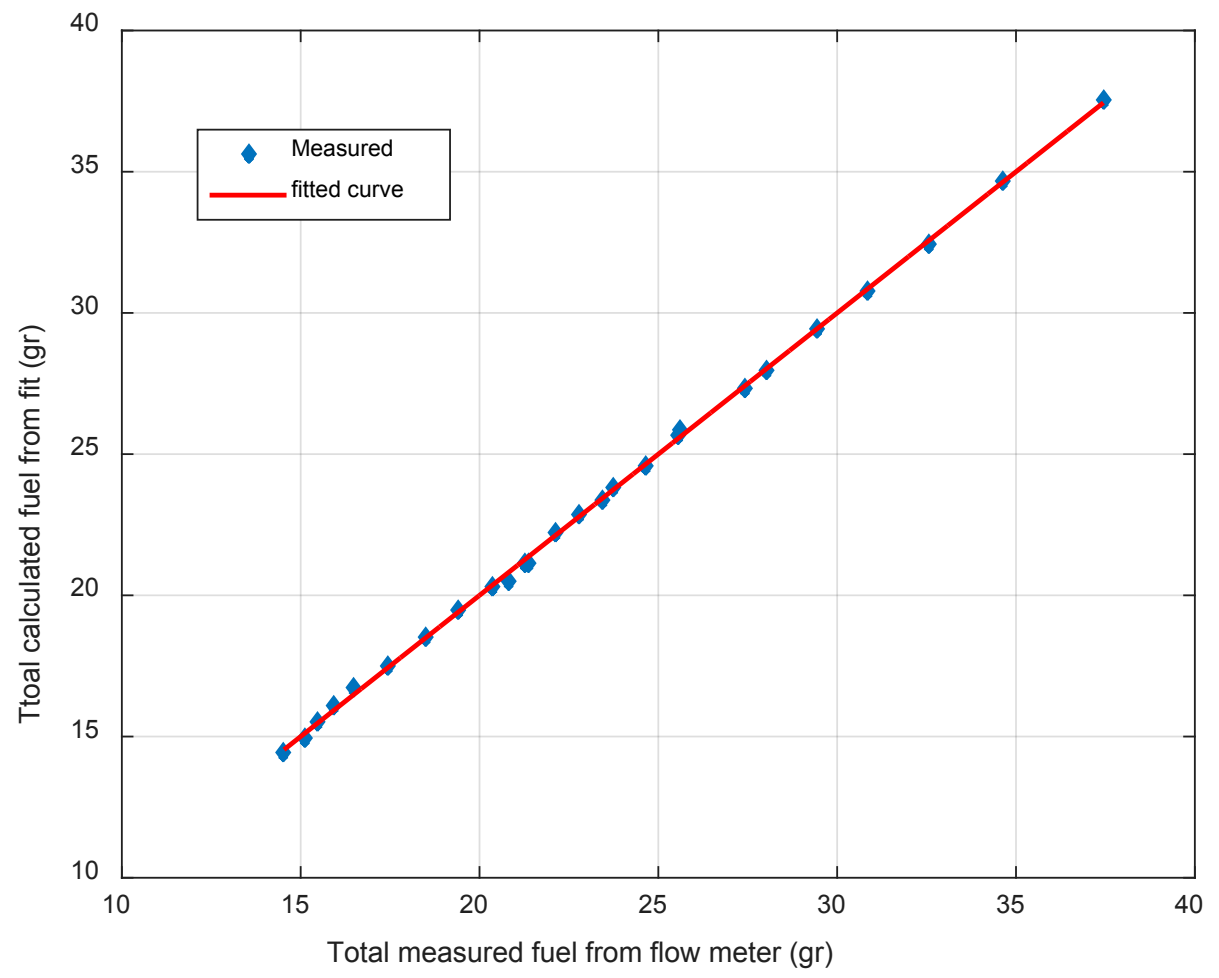

Figure 23- Total calculated fuel against total measured fuel (both fuel for 6 cylinders and 300 cycles)

It is concluded that, knowing average pulse-width and injection pressure and using the fit (obtained from curve fitting toolbox), leads us to calculation of total amount of injected fuel, with a good accuracy $(\mathrm{RMSE}=0.9995)$ in comparison to steady-state test data.

It is noted again that the total injected fuel is relating to 6 cylinders and $N u m_{c y c}=300$ cycles:

$$
m_{\text {fuel meter }}=\sum_{k=1}^{N_{\text {um }}{ }_{c y c}} \sum_{c=1}^{6} m_{f u e l, c, k}
$$


The objective here, is to estimate the amount of injected fuel in each cylinder and each cycle using the fit data to the fuel meter using injector pulse-width and injector differential pressure at different test points. The advantages of this approach are:

1. The model of fuel meter used in the experimental setup has an accuracy of $\pm 0.10 \%$ of mass and volume flow rate [44]. Therefore, using fuel meter data leads to an accurate calculation of injected fuel.

2. By using the curve fit, $m_{f u e l, c, k}$ is estimated from injector PW and FRP at each test point (steady-state and transient) without the need to know fuel flow.

3. There would be no requirement to have the values for $t_{0, k},\left(C_{d} \cdot A\right)_{c}$, and $\rho_{\text {fuel }}$ (in Eq. (5-1)).

Therefore to calculate the amount of fuel in each cylinder and each cycle the fit output is divided by number of cylinders (6) and number of cycles (300). So by logging individual injector pulse-width and corresponding injection pressure at each cycle, at each test (steady-state or transient), individual injected fuel for that cycle is calculated. Next step is to estimate the amount of air charge which is obtained by Eq. (4-9) into the following form: 


$$
\begin{aligned}
& m_{\text {air }, c, k}=m_{f u e l, c, k} \cdot A F R_{\text {stoich }} \cdot \lambda_{c, k} \\
& c: \text { cylinder index } \quad k \text { : cycle index }
\end{aligned}
$$

Outputs of air charge estimation with cylinder pressure will be compared and validated with the air charge from fuel meter and fit data (which will be referred to as experimental air charge from now on) in following section.

\subsection{Estimator Validation and Calibration}

In this section, estimator air charge output will be validated with experimental air charge obtained from fuel meter and fit data using injector PW and injection pressure.

Also Method 2 in residual mass estimation is used alongside air estimation; hence, there will be two parameters that need to be calibrated for different test conditions:

1. Heat transfer constant $\left(h_{\text {constant }}\right)$ which is the multiplier in Woschni's correlation (Eq. (4-37)) regarding heat transfer from cylinder charge to the cylinder wall as discussed in Section 4.2.5.

2. Alpha $(\alpha)$ which is the parameter in residual mass estimator (regarding to overlap term in Eq. (4-58)) in Method 2. 
A set of 61 steady-state tests at different loads, engine speeds, intake cam advance timing and lambdas were performed and $h_{\text {constant }}$ and $\alpha$ parameters are calibrated based on two criteria that must meet:

1. Mass conservation from IVC to EVO must hold,

2. Estimated air charge must match experimental air charge (calculated from fuel).

There are some issues that were considered for estimator calibration:

- Cylinders 1, 5, and 6 are selected for calibration. There are errors in pressure measurement in other cylinders.

- The value for $h_{\text {constant }}$ and $\alpha$ for each test point is selected as the average between values for 3 cylinders.

The final calibration table for all steady-state tests is shown in Appendix C. In this section, the calibrated values for one of the tests is reported. Same procedure was taken for other tests. The test condition is, Engine speed $=1500 \mathrm{RPM}, \mathrm{IMEP}=310 \mathrm{kPa}$, intake cam advance $=0^{\circ} \mathrm{CA}$, and lambda $=1$. 
Table 7-Calibration parameters for different cylinders

\begin{tabular}{|c|c|c|c|c|}
\hline Cylinder \# & alpha $\left({ }^{\circ} \mathbf{C A} / \mathbf{m}\right)$ & $\mathbf{h}\left(\mathbf{W} / \mathbf{m}^{2} \cdot \mathbf{K}\right)$ & Air charge $\mathbf{( m g )}$ & LFE air $(\mathbf{m g})$ \\
\hline 1 & 0.360 & 2.5 & 199 & \multirow{2}{*}{204} \\
\cline { 1 - 4 } 5 & 0.345 & 2.2 & 196 & \multirow{2}{*}{} \\
\hline 6 & 0.310 & 2.4 & 199 & \multicolumn{1}{|c|}{} \\
\hline
\end{tabular}

The average value over three cylinders is calculated for two calibration parameters; therefore,

$$
h_{\text {constant }}=2.34\left[\frac{\mathrm{W}}{\mathrm{m}^{2} \cdot \mathrm{K}}\right] \quad, \quad \alpha=0.338\left({ }^{\circ} \mathrm{CA} / \mathrm{m}\right)
$$

LFE (Laminar Flow Element) air measurement is also used as another approach to measure air charge. LFE air calculations can be found in Appendix A. The accuracy of the LFE module which is used in the test cell is $0.86 \%$ reading for full scale flow of 1000 SCFM or higher [45].

Since LFE is mounted in the upstream of air intake pathway, any transience in throttle position is sensed by LFE pressure sensors with a considerable delay; in other words LFE measurement on upstream of the air pathway does not include throttle and intake manifold dynamics which affect the measurement of cylinder air charge. Therefore LFE air charge is not reliable in transient tests.

The logged LFE value is in $\left[\frac{\mathrm{kg}}{\mathrm{hr}}\right]$, which is converted into air charge per cylinder per cycle by: 
individual air in cycle $(\mathrm{mg})=$ air flow $\left(\frac{\mathrm{kg}}{\mathrm{hr}}\right) \times \frac{10^{6}}{N(\mathrm{rpm}) \times 30 \times \text { cylinder }_{\text {number }}}$

This individual air in cycle is denoted as LFE air in Table 7. It should be noted that LFE measurement is divided by number of cylinders (cylinder number $=6$, in this thesis) to get individual air charge.

\subsection{Uncertainty Analysis on Estimated Air Charge}

The amount of uncertainty in the estimated parameters, which is propagated from the uncertainty in the measured or run-time parameters used in the model, is evaluated by uncertainty propagation analysis.

In this work, uncertainty in the estimated parameter (fresh air mass) is calculated by knowing the uncertainties in: 1) measured variables such as cylinder pressure and 2) model run-time parameters such as combustion efficiency. The contribution of each of these parameters to the final air charge uncertainty, is attained by uncertainty analysis propagation study. 
Engineering Equation Solver (EES) [51] software is used as the tool for performing uncertainty analysis on estimated air charge using the estimator algorithm. Uncertainty in the estimated variable $\left(U_{Y}\right)$ is calculated by [51]:

$$
U_{Y}=\sqrt{\sum_{i}\left(\frac{\partial Y}{\partial X_{i}}\right)^{2} U_{X_{i}}^{2}}
$$

In which $X_{i}$ are variables (measured or model parameters) with uncertainty of $U_{X_{i}}$.

The uncertainty analysis propagation in this section is done in three different sub-sections; 1) Uncertainty analysis in air charge mass and estimated exhaust temperature; 2) Uncertainty analysis in air charge with uncertainty sweep in pumping loop pressures for different test points; and 3) comparison between uncertainties in air charge estimator in this work and two other estimators in the literature ( [34] and [35]).

\subsubsection{Air Charge Mass and Exhaust Temperature Uncertainties}

An uncertainty analysis on cylinder air charge mass $\left(m_{\text {air }}\right)$ and exhaust temperature $\left(T_{\text {exh }}\right)$ is done on data from cylinder 5 for test point 1500 RPM, 2.62 bar BMEP (3.1 bar IMEP), $0^{\circ}$ intake cam advance, and $\lambda=1$. The most important parameters with their corresponding uncertainties are shown in Table 8. Absolute uncertainty in crank angle degree is assumed to be $2 \mathrm{CA}$ degree (suggested by Ford). Pressure is also assumed to have $5 \mathrm{kPa}$ absolute 
uncertainty; except the maximum pressure which is assumed to include $15 \mathrm{kPa}$. It should be noted that, in this work, no uncertainty is assumed for parameters $h_{\text {constant }}$ and $\alpha$ (Method 2 used in the estimator).

Relative uncertainty is calculated by:

$$
\text { relative uncertainty }(\%)=\frac{\text { Absolute uncertainty }}{\text { Parameter value }} \times 100
$$


Table 8- Uncertainty in measured and model parameters data for cylinder 5 for test point 1500 RPM, 2.62 bar BMEP (3.1 bar IMEP), lambda=1, intake cam advance $=0$

\begin{tabular}{|c|c|c|c|c|}
\hline Parameter & Definition & Value [unit] & $\begin{array}{c}\text { Absolute } \\
\text { uncertainty } \\
\text { [unit] }\end{array}$ & $\begin{array}{c}\text { Relative } \\
\text { uncertainty } \\
{[\%]}\end{array}$ \\
\hline thet $a_{I V C}$ & IVC crank angle & -124 [CA deg] & 2 [CA deg] & 1.6 \\
\hline theta $a_{I V O}$ & IVO crank angle & 360 [CA deg] & 2 [CA deg] & 0.6 \\
\hline theta $_{E V O}$ & EVO crank angle & 134 [CA deg] & $2[\mathrm{CA}$ deg] & 1.5 \\
\hline thet $a_{E V C}$ & EVC crank angle & 370 [CA deg] & 2 [CA deg] & 0.5 \\
\hline$N$ & Engine speed & $1500[\mathrm{RPM}]$ & $10[\mathrm{RPM}]$ & 0.7 \\
\hline$P_{I V C}$ & IVC pressure & $49.9[\mathrm{kPa}]$ & $5.0[\mathrm{kPa}]$ & 10.0 \\
\hline$P_{I V O}$ & IVO pressure & $83.7[\mathrm{kPa}]$ & $5.0[\mathrm{kPa}]$ & 6.0 \\
\hline$P_{E V C}$ & EVC pressure & $56.5[\mathrm{kPa}]$ & $5.0[\mathrm{kPa}]$ & 8.8 \\
\hline$P_{E V O}$ & EVO pressure & $141.5[\mathrm{kPa}]$ & $5.0[\mathrm{kPa}]$ & 3.5 \\
\hline$P_{\max }$ & Maximum pressure & $2169.0[\mathrm{kPa}]$ & $15.0[\mathrm{kPa}]$ & 0.7 \\
\hline$P_{7}$ & Pressure at point 7 & $44.2[\mathrm{kPa}]$ & $5.0[\mathrm{kPa}]$ & 11.3 \\
\hline$P_{\text {exh }}$ & Exhaust pressure & $93.6[\mathrm{kPa}]$ & $5.0[\mathrm{kPa}]$ & 5.3 \\
\hline$P_{\text {ignition }}$ & Ignition pressure & $220.5[\mathrm{kPa}]$ & $5.0[\mathrm{kPa}]$ & 2.3 \\
\hline$M A P$ & $\begin{array}{l}\text { Manifold Absolute } \\
\text { Pressure }\end{array}$ & $40[\mathrm{kPa}]$ & $5.0[\mathrm{kPa}]$ & 12.5 \\
\hline$\eta_{c}$ & Combustion efficiency & $0.97[-]$ & $0.02[-]$ & 2.1 \\
\hline$y$ & $\begin{array}{c}\text { Fuel fraction vaporized } \\
\text { before IVC }\end{array}$ & $0.9[-]$ & $0.09[-]$ & 10.0 \\
\hline$z$ & $\begin{array}{l}\text { Fuel fraction going into } \\
\text { air after injection }\end{array}$ & $0.9[-]$ & $0.09[-]$ & 10.0 \\
\hline$h_{\text {constant }}$ & Heat transfer parameter & $2.34\left[\frac{W}{m^{2} \cdot K}\right]$ & $0\left[\frac{W}{m^{2} \cdot K}\right]$ & 0.0 \\
\hline$\alpha$ & $\begin{array}{l}\text { Residual estimator } \\
\text { parameter }\end{array}$ & $\begin{array}{c}0.338 \\
{\left[{ }^{\circ} \mathrm{CA} / \mathrm{m}\right]}\end{array}$ & $0\left[{ }^{\circ} \mathrm{CA} / \mathrm{m}\right]$ & 0.0 \\
\hline
\end{tabular}


The results of the uncertainty analysis on cylinder air charge and estimated temperature based on the data in Table 8, are reported in Table 9.

Uncertainty propagation analysis in EES also calculates the amount of contribution of each measured or model parameter on the estimated parameter; so in Table 9 it is seen that cylinder pressure has the highest contribution (83.2\%) to the uncertainty in the air charge (19 $\mathrm{mg}$ absolute value). In other words, almost $16 \mathrm{mg}$ of uncertainty in air charge comes from cylinder pressure $(19 \times 83.2 \%=15.8 \mathrm{mg})$.

Table 9- Calculated uncertainty in estimated air charge and exhaust temperature for cylinder 5

\begin{tabular}{|c|c|c|c|c|c|}
\hline Parameter & $\begin{array}{l}\text { Estimated } \\
\text { value }\end{array}$ & $\begin{array}{c}\text { Absolute } \\
\text { uncertainty }\end{array}$ & $\begin{array}{c}\text { Relative } \\
\text { uncertainty }\end{array}$ & \multicolumn{2}{|c|}{ Contributing parameters } \\
\hline$m_{\text {air }}$ & $197[\mathrm{mg}]$ & $19[\mathrm{mg}]$ & 9.6 & $\begin{array}{l}\text { - } \text { Cylinder pressure } \\
\text { - MAP } \\
\text { - theta } \\
\text { - } z \\
\text { - } \eta_{c} \\
\text { - } y \\
\text { - Other parameters }\end{array}$ & $\begin{array}{l}83.2 \% \\
12.6 \% \\
2.0 \% \\
0.9 \% \\
0.6 \% \\
0.2 \% \\
0.5 \%\end{array}$ \\
\hline$T_{\text {exh }}$ & $1122[\mathrm{~K}]$ & $186[\mathrm{~K}]$ & 16.6 & $\begin{array}{l}\text { - Cylinder pressure } \\
\text { - MAP } \\
\text { - } \eta_{c} \\
\text { - theta } \\
\text { - } z \\
\text { - y } \\
\text { - Other parameters }\end{array}$ & $\begin{array}{l}85.6 \% \\
8.8 \% \\
2.2 \% \\
2.1 \% \\
0.5 \% \\
0.2 \% \\
0.6 \%\end{array}$ \\
\hline
\end{tabular}


It is concluded from Table 9 that cylinder pressure has majority of contribution to both air charge and exhaust temperature estimation. The contribution of maximum pressure $\left(P_{\max }\right)$ on both air charge and exhaust temperature is less than $1 \%$, although $15 \mathrm{kPa}$ uncertainty is included. IVC pressure $\left(P_{I V C}\right)$ has highest contribution on air charge $(60 \%)$ and exhaust temperature $(70 \%)$.

It is seen that MAP is the second significant parameter in uncertainty of estimated parameters. Uncertainty in encoder measurement (theta) has almost equal effect on both parameters, and combustion efficiency has $2 \%$ effect on exhaust temperature, while less than $1 \%$ on air charge.

\subsubsection{Uncertainty Sweep in Pumping Loop Pressures}

The uncertainty in cylinder pressure was assumed to be $5 \mathrm{kPa}$ in previous sub-section. In another effort, to calculate the uncertainty in air charge, an uncertainty sweep in pumping loop pressures is studied at different test points for cylinder 5. Uncertainties in MAP, and pressures at IVC, IVO, EVC, EVO, exhaust and point 7 are simultaneously changed to 1, $1.25,2.5$ and $5 \mathrm{kPa}$. This uncertainty analysis is performed for 9 different steady-state tests. It should be noted here that uncertainties in ignition and maximum pressure points are kept at 5 and $15 \mathrm{kPa}$, respectively. Theta represents crank angle, and other parameters are the same as Table 8 . 
Table 10- Pumping pressure uncertainty sweep

\begin{tabular}{|c|c|}
\hline Parameter & Absolute uncertainty [Unit] \\
\hline theta & 2 [CA deg] \\
\hline$N$ & 10 [RPM] \\
\hline$\eta_{c}$ & $0.02[-]$ \\
\hline$y$ & $0.09[-]$ \\
\hline$Z$ & $0.09[-]$ \\
\hline$M A P$ & $\{1,1.25,2.5,5.0\}[\mathrm{kPa}]$ \\
\hline$P_{I V C}$ & $\{1,1.25,2.5,5.0\} \quad[\mathrm{kPa}]$ \\
\hline$P_{I V O}$ & $\{1,1.25,2.5,5.0\}[\mathrm{kPa}]$ \\
\hline$P_{E V C}$ & $\{1,1.25,2.5,5.0\} \quad[\mathrm{kPa}]$ \\
\hline$P_{E V O}$ & $\{1,1.25,2.5,5.0\}[\mathrm{kPa}]$ \\
\hline$P_{7}$ & $\{1,1.25,2.5,5.0\}[\mathrm{kPa}]$ \\
\hline$P_{\text {exh }}$ & $\{1,1.25,2.5,5.0\}[\mathrm{kPa}]$ \\
\hline$P_{\max }$ & $15.0[\mathrm{kPa}]$ \\
\hline$P_{\text {ignition }}$ & $5.0[\mathrm{kPa}]$ \\
\hline
\end{tabular}

Table 11 summarizes uncertainty propagation analysis, considering different pumping loop pressure uncertainty at different test points. Test number (\#) is regarding test numbers in finalized steady state test conditions and calibrated parameters table (Table C- 1) in Appendix C. 
Table 11- Relative uncertainty in air charge (\%) with pumping loop pressure sweep for different tests

\begin{tabular}{|c|c|c|c|c|c|c|}
\hline \multirow{2}{*}{ Test condition } & \multirow{2}{*}{ Test \# } & \multirow{2}{*}{$\mathrm{m}_{\text {air }}(\mathrm{mg})$} & \multicolumn{4}{|c|}{$\begin{array}{c}\text { Pumping loop pressure } \\
\text { uncertainty (kPa) }\end{array}$} \\
\hline & & & 1 & 1.25 & 2.5 & 5 \\
\hline $\begin{array}{c}1000 \text { RPM, } 209 \text { IMEP, } \\
\text { lambda } 1.1 \text {, cam=10 }\end{array}$ & 36 & 154 & 2.9 & 3.4 & 6.0 & 11.5 \\
\hline $\begin{array}{c}1000 \mathrm{RPM}, 208 \mathrm{IMEP}, \\
\text { lambda }=1.0, \text { cam }=0\end{array}$ & 31 & 148 & 2.9 & 3.4 & 5.9 & 11.4 \\
\hline $\begin{array}{c}1500 \mathrm{RPM}, 213 \text { IMEP, } \\
\text { lambda=1.0, cam=0 }\end{array}$ & 45 & 138 & 3.4 & 3.9 & 6.9 & 13.4 \\
\hline $\begin{array}{c}1500 \mathrm{RPM}, 310 \mathrm{IMEP}, \\
\text { lambda }=1.0, \mathrm{cam}=0\end{array}$ & 1 & 197 & 2.7 & 3.0 & 5.1 & 9.6 \\
\hline $\begin{array}{c}2500 \mathrm{RPM}, 328 \mathrm{IMEP}, \\
\text { lambda=1.2, cam=30 }\end{array}$ & 61 & 215 & 3.7 & 4.1 & 6.6 & 12.2 \\
\hline $\begin{array}{c}2500 \mathrm{RPM}, 333 \text { IMEP, } \\
\text { lambda=1.0, cam=20 }\end{array}$ & 56 & 199 & 3.2 & 3.6 & 6.1 & 11.7 \\
\hline $\begin{array}{c}1500 \text { RPM, } 510 \text { IMEP, } \\
\text { lambda }=1.1 \text {, cam }=10\end{array}$ & 20 & 324 & 2.4 & 2.7 & 4.2 & 7.7 \\
\hline $\begin{array}{c}1500 \mathrm{RPM}, 604 \mathrm{IMEP}, \\
\text { lambda=1.0, cam=0 }\end{array}$ & 49 & 360 & 2.5 & 2.8 & 4.4 & 8.1 \\
\hline $\begin{array}{l}1500 \text { RPM, } 603 \text { IMEP, } \\
\text { Lambda }=1.2, \text { cam }=30\end{array}$ & 53 & 400 & 2.8 & 3.1 & 4.8 & 9.0 \\
\hline
\end{tabular}

The uncertainty in maximum pressure $\left(P_{\max }\right)$ was assumed to be $15 \mathrm{kPa}$ for all pumping loop pressure sweep. This was done to investigate the effects of potentially larger uncertainties existing in pressure measurement at high pressures, in comparison to pumping loop pressures. The percentage of contribution of the uncertainty in $P_{\max }$ to air 
charge uncertainty in two test numbers 31 (low IMEP) and 49 (high IMEP) was studied. In low IMEP test, maximum pressure contribution changes from $0.8 \%$ to $0.1 \%$, when pumping pressure uncertainties are changed from 1 to $5 \mathrm{kPa}$, respectively. In high IMEP test, $P_{\max }$ has no contribution $(0.0 \%)$ to air charge uncertainty. Therefore, in all tests, uncertainty in air charge caused by maximum pressure can be neglected.

It is observed in Table 10 that, uncertainty in cylinder air charge increases when higher uncertainty is assumed in cylinder pressure. Uncertainty in air charge varies from $2.4 \%$ (in test \#20) to $3.7 \%$ (test \#61) when uncertainty in pumping loop pressures is $1 \mathrm{kPa}$. If the uncertainty in pressure is increased to $5 \mathrm{kPa}$, air charge uncertainty changes between $7.7 \%$ (test \# 20) to $13.4 \%$ (test \#45).

Figure 24 illustrates the values in Table 11. Relative uncertainty in air charge is plotted against pumping loop uncertainty at different tests. 


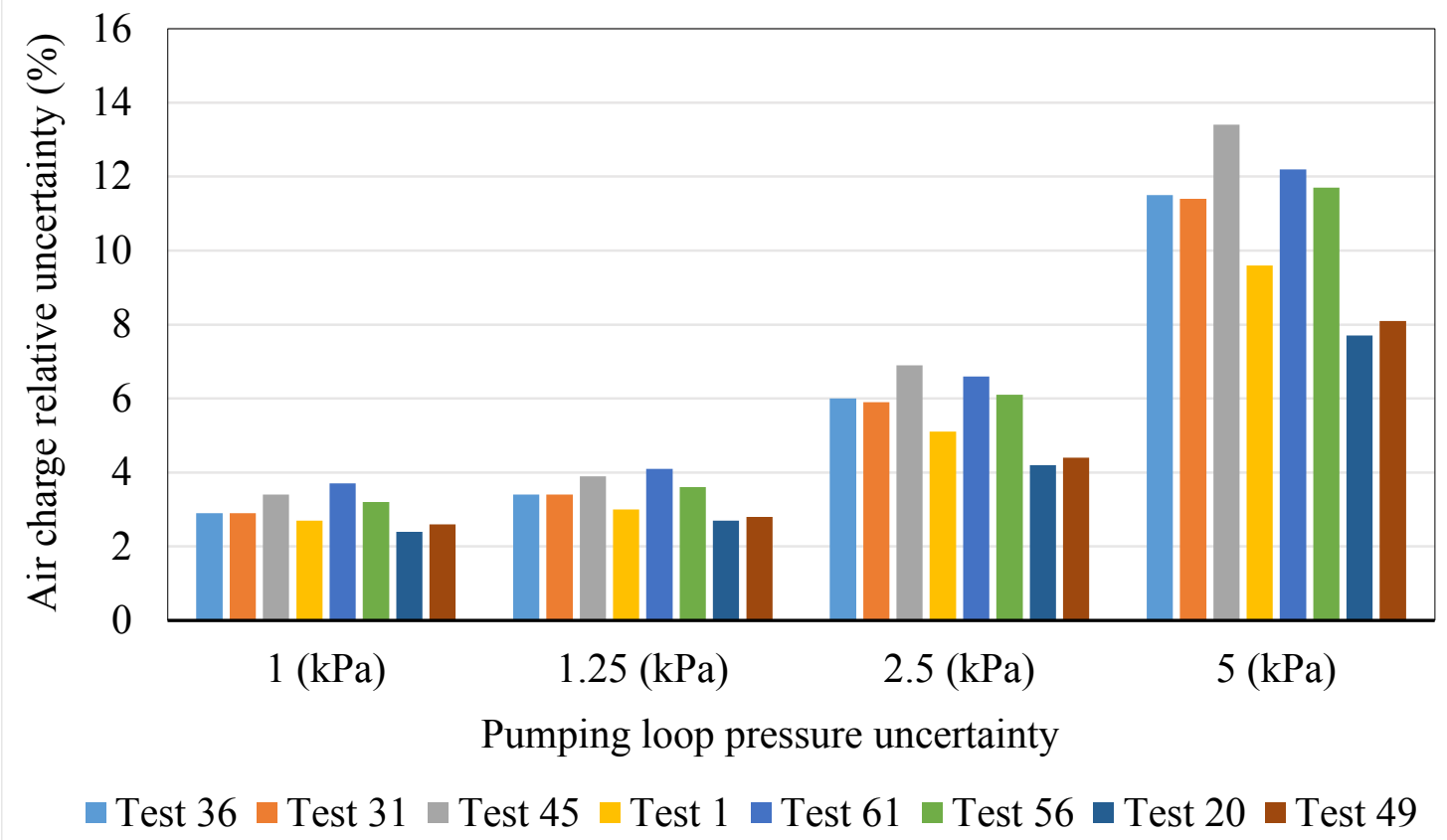

Figure 24- Estimator relative uncertainties for different tests (pumping loop pressure uncertainty sweep)

It is seen in Figure 24 that, test numbers 20 and 49 have lowest relative uncertainties in air charge for different uncertainties in cylinder pressures. Also test numbers 61 and 45 have highest amount of relative uncertainty corresponding to different uncertainties in pumping loop pressures.

Variations in absolute and relative air charge uncertainty against pumping loop pressure uncertainty are illustrated in Figure 25, based on results summarized in Table 11. Test numbers 31 and 49 are selected as low and high IMEP. 

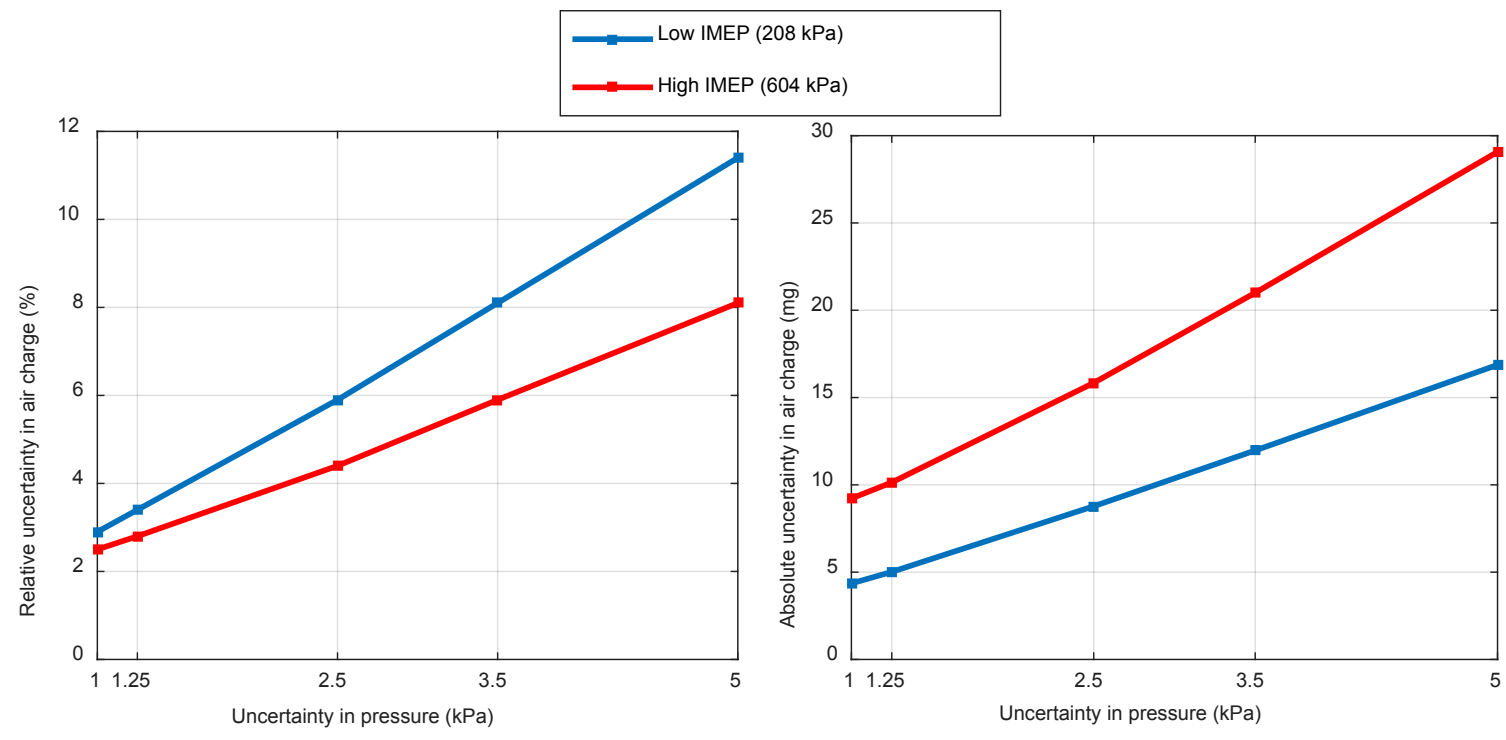

Figure 25- Relative and absolute air charge uncertainty against uncertainty sweep in pumping loop pressures

It is observed that, there is a linear relationship between cylinder air charge uncertainty (both relative and absolute) and cylinder pressure uncertainty for both tests. The rate of air charge relative uncertainty increase in low IMEP test, is larger the one in high IMEP test. The relative uncertainty varies from $2.9 \%$ to $11.4 \%$ for low IMEP test (increase rate $\left.=\frac{11.4-2.9}{5-1}=2.13\left[\frac{\%}{k P a}\right]\right)$; whereas, it increases from $2.5 \%$ to $8.1 \%$ in high IMEP test (increase rate $\left.=\frac{8.1-2.5}{5-1}=1.4\left[\frac{\%}{k P a}\right]\right)$ 


\subsubsection{Air Charge Uncertainty Comparison between Different Estimators}

In another attempt, the uncertainty in estimated air charge from estimator (this research) is compared to two other air estimation methods in [34] (G.Colin et al.) and [35] (J. Worm,). Data from cylinder 5 in test point 1500 RPM, 2.62 bar BMEP (3.1 bar IMEP), $0^{\circ}$ intake cam advance, and $\lambda=1$ (Test 1 in Table 11) is selected for all three estimators.

In the estimator in G.Colin et al., it is proposed that a number of pressure points after IVC and before ignition, to be selected and used in a least square method to estimate polytropic exponent ' $k$ ' and variable ' $C$ ' (same definition in the paper). Here, for the sake of simplicity, two pressure points are selected; one at -120 CA degree $\left(P_{1}\right)$ and the other at $60 \mathrm{CA}$ degree $\left(P_{2}\right)$; these points are in compression stroke after IVC and prior to ignition point. Absolute uncertainty of $5 \mathrm{kPa}$ is considered for these pressures.

Table 12- Data for estimator in G.Colin et al., 2007-24-0049 ( [34])

\begin{tabular}{|c|c|c|c|}
\hline Variable & Definition & $\begin{array}{c}\text { Value } \\
\text { [Unit] }\end{array}$ & $\begin{array}{c}\text { Absolute } \\
\text { uncertainty } \\
\text { [Unit] }\end{array}$ \\
\hline$P_{1}$ & Pressure at point 1 & $51.4[\mathrm{kPa}]$ & $5.0[\mathrm{kPa}]$ \\
\hline$P_{2}$ & Pressure at point 2 & $153.5[\mathrm{kPa}]$ & $5.0[\mathrm{kPa}]$ \\
\hline$T_{\text {exh }}$ & Exhaust gas temperature & $700[\mathrm{~K}]$ & $56[\mathrm{~K}]$ \\
\hline$T_{\text {man }}$ & Manifold temperature & $303[\mathrm{~K}]$ & $2[\mathrm{~K}]$ \\
\hline$\Delta T_{h t}$ & Increase in fresh air due to warming up from runners & $10[\mathrm{~K}]$ & $0[\mathrm{~K}]$ \\
\hline$X_{\text {res }}$ & Residual gas mass fraction & $0.11[-]$ & $0.056[-]$ \\
\hline
\end{tabular}


The uncertainty in exhaust temperature measurement is suggested by Ford to be equal to $100^{\circ} \mathrm{F}(56 \mathrm{~K})$. The value of $700 \mathrm{~K}$ is also assumed for the temperature of gas in exhaust manifold (not to be confused with exhaust temperature definition in air charge estimator in this work). Uncertainty in intake manifold temperature is $2 \mathrm{~K}$ (suggested by Ford) and it is assumed that a $10 \mathrm{~K}$ degree temperature increase happens to intake air on the pathway in the manifold and runners into the cylinder (no uncertainty is assumed in this temperature increase).

As mentioned previously, the RGF for the test point under study is 0.11 (based on the RGF table provided by Ford for different engine test points). The uncertainty in the RGF is taken from [49], which is the RMSE (with 95\% confidence $(2 \sigma)$ ) for an improved Fox model ( [48]) for a single cylinder engine in a range of 150-6000 RPM. This value is equal to 0.056 (5.6\% absolute uncertainty in RGF).

'Delta P' method to estimate fresh air charge is explained in [35] (J. Worm). Two pressure points in compression stroke between IVC and ignition are selected and air charge is estimated using a linear correlation for different engine speeds at steady-state condition. Here two pressures equal to $153 \mathrm{kPa}$ and $200 \mathrm{kPa}$ are used; these two pressures, between IVC and ignition, are selected by trial and error to match the estimated air charge with the air charge from estimator in this work. Absolute uncertainty of $5 \mathrm{kPa}$ is also assumed for these two pressures. 
The uncertainties for air charge estimator in this work (with Method 2 in residual estimation), are already defined in Table 8 . It is noted again that uncertainty in all pressures is assumed $5 \mathrm{kPa}$ (except maximum pressure). In an additional study, a $50 \%$ relative uncertainty is assumed in $h_{\text {constant }}$ parameter (estimator calibration parameter) in addition to the previous analysis (without uncertainty in $h_{\text {constant }}$ ). Table 13 includes uncertainty propagation analysis summary for three different estimators.

Table 13- Uncertainty in estimated air charge for three different estimators; data for cylinder5 at test point 1500 RPM, 2.62 bar BMEP (3.1 bar IMEP), lambda=1, intake cam advance $=0$

\begin{tabular}{|c|c|c|c|c|c|}
\hline \multirow{2}{*}{ Method } & \multirow{2}{*}{$\begin{array}{c}\text { Air mass } \\
{[\mathrm{mg}]}\end{array}$} & \multicolumn{2}{|c|}{ Uncertainty } & \multirow{2}{*}{\multicolumn{2}{|c|}{ Contributing parameters }} \\
\hline & & {$[\mathrm{mg}]$} & {$[\%]$} & & \\
\hline $\begin{array}{c}\text { Estimator } \\
\text { (honstant } \text { uncertainty } \\
\text { excluded) }\end{array}$ & 197 & 19 & 9.6 & $\begin{array}{l}\text { - Cylinder pressure } \\
\text { - MAP } \\
\text { - theta } \\
\text { - Other parameters }\end{array}$ & $\begin{array}{l}\mathbf{8 3 . 2 \%} \\
12.6 \% \\
2.0 \% \\
2.2 \%\end{array}$ \\
\hline $\begin{array}{c}\text { Estimator } \\
\left(\boldsymbol{h}_{\text {constant }} \text { uncertainty }\right. \\
\text { included })\end{array}$ & 197 & 21 & 10.8 & $\begin{array}{l}\text { - Cylinder pressure } \\
\text { - } h_{\text {constant }} \\
\text { - MAP } \\
\text { - theta } \\
\text { - Other parameters }\end{array}$ & $\begin{array}{l}\mathbf{6 8 . 3} \% \\
17.9 \% \\
10.4 \% \\
1.7 \% \\
1.7 \%\end{array}$ \\
\hline G.Colin et al. & 235 & 38 & 16.2 & $\begin{array}{l}\text { - Cylinder pressure } \\
\text { - } X_{\text {res }} \\
\text { - } T_{\text {exh }} \\
\text { - Other parameters }\end{array}$ & $\begin{array}{l}\mathbf{3 7 . 5 \%} \\
59.9 \% \\
1.1 \% \\
1.5 \%\end{array}$ \\
\hline $\begin{array}{c}\text { Delta P } \\
\text { (J. Worm) }\end{array}$ & 196 & 38 & 19.4 & - Cylinder pressure & $100 \%$ \\
\hline
\end{tabular}


It is seen in Table 13 that estimated air with air charge estimation algorithm in this work (with $h_{\text {constant }}$ uncertainty included and excluded) has less than $11 \%$ uncertainty, while estimated air from G.Colin et al. has almost 16\% uncertainty. Uncertainty in 'Delta P' method (19.4\%) is almost twice the uncertainty in air estimated in this work.

\subsection{Sensor Sensitivity Analysis}

Transducer sensitivity analysis on estimated air charge is done in this section. Effect of change in transducer gain, offset and noise is separately studied on IMEP and estimated air charge. This analysis is performed to recognize the impact of existing errors in transducer data on estimator output.

Transducer gain and offset change, in addition to including White-Noise (WN), are applied to the logged cylinder pressure data from $\mathrm{ACAP}^{\circledR}$. Based on this modified data, gross IMEP $\left(I M E P_{g}\right)$ is calculated from Eq. (4-17) (discrete integrated approximated of cylinder pressure over corresponding cylinder volume on interval of -180 to 180 degree). Air charge is also estimated based on new pressure data.

The effect of each of these changes on IMEP is explained as:

- IMEP changes proportionally with gain change in the pressures (as seen in Table 14.) 
- IMEP is not affected by adding offset do the pressure. IMEP is the area under P-V diagram in compression and expansion strokes. Since adding offset to the pressure shifts the entire curve upward or downward, the area under the curve remains constant; hence IMEP remains unchanged.

- Noise also tends to cancel out during the integration which calculates IMEP; therefore white noise added to the pressure will not change the IMEP.

Table 14 includes 9 steady-state tests (same as those ones used for estimator uncertainty analysis) with base values for IMEP and estimated air charge (base values are the ones obtained before applying transducer gain change). As shown above, since adding offset and white noise to pressure data does not change IMEP, they are not included in the table. It can also be shown that estimated air charge using post-processed pressure form adding offset and white noise, is equal to the one estimated from base pressure. Therefore, Table 14 only includes the change of IMEP and air charge when applying gain change. IMEP in cylinder 5 is denoted by $I M E P_{5}$.

The numbers in the parentheses next to each value, represent the percentage of change to base value. 
Table 14- Effect of changing transducer gain on IMEP and estimated air charge mass

\begin{tabular}{|c|c|c|c|c|c|}
\hline \multirow{2}{*}{ Test Condition } & \multirow{2}{*}{$\begin{array}{c}\text { Test } \\
\#\end{array}$} & \multirow{2}{*}{ Parameter } & \multirow{2}{*}{$\begin{array}{l}\text { Base } \\
\text { Value }\end{array}$} & \multicolumn{2}{|c|}{ Transducer gain } \\
\hline & & & & $(x \quad 0.95)$ & $(x$ 1.05) \\
\hline \multirow{2}{*}{$\begin{array}{c}1000 \text { RPM, } 209 \text { IMEP, } \\
\text { lambda=1.1, cam=10 }\end{array}$} & \multirow{2}{*}{36} & $I M E P_{5}(\mathrm{kPa})$ & 210 & $200(-4.8 \%)$ & $221(5.2 \%)$ \\
\hline & & Air Charge (mg) & 155 & $154(-0.6 \%)$ & $157(1.3 \%)$ \\
\hline \multirow{2}{*}{$\begin{array}{c}1000 \text { RPM, } 208 \text { IMEP, } \\
\text { lambda }=1.0, \text { cam }=0\end{array}$} & \multirow{2}{*}{31} & $I M E P_{5}(\mathrm{kPa})$ & 211 & $201(-4.7 \%)$ & $222(5.2 \%)$ \\
\hline & & Air Charge (mg) & 149 & $147(-1.3 \%)$ & $150(0.7 \%)$ \\
\hline \multirow{2}{*}{$\begin{array}{c}1500 \text { RPM, } 213 \text { IMEP } \\
\text { lambda=1.0, cam=0 }\end{array}$} & \multirow{2}{*}{45} & $I M E P_{5}(\mathrm{kPa})$ & 213 & $203(-4.7 \%)$ & $224(5.2 \%)$ \\
\hline & & Air Charge (mg) & 138 & $138(0.0 \%)$ & $139(0.7 \%)$ \\
\hline \multirow{2}{*}{$\begin{array}{c}1500 \text { RPM, } 310 \text { IMEP, } \\
\text { lambda }=1.0, \text { cam }=0\end{array}$} & \multirow{2}{*}{1} & $I M E P_{5}(\mathrm{kPa})$ & 307 & $292(-4.9 \%)$ & $323(5.3 \%)$ \\
\hline & & Air Charge (mg) & 198 & $196(-1.0 \%)$ & $200(1.0 \%)$ \\
\hline \multirow{2}{*}{$\begin{array}{c}2500 \mathrm{RPM}, 328 \mathrm{IMEP} \\
\text { lambda=1.2, cam=30 }\end{array}$} & \multirow{2}{*}{61} & $I M E P_{5}(\mathrm{kPa})$ & 324 & $309(-4.6 \%)$ & $341(5.2 \%)$ \\
\hline & & Air Charge (mg) & 216 & $215(-0.5 \%)$ & $217(0.5 \%)$ \\
\hline \multirow{2}{*}{$\begin{array}{c}2500 \text { RPM, } 333 \text { IMEP, } \\
\text { lambda=1.0, cam=20 }\end{array}$} & \multirow{2}{*}{56} & $I M E P_{5}(\mathrm{kPa})$ & 328 & $312(-4.7 \%)$ & $345(5.2 \%)$ \\
\hline & & Air Charge (mg) & 199 & $198(-0.5 \%)$ & $201(1.0 \%)$ \\
\hline \multirow{2}{*}{$\begin{array}{c}1500 \text { RPM, } 510 \text { IMEP, } \\
\text { lambda=1.1, cam=10 }\end{array}$} & \multirow{2}{*}{20} & $\operatorname{IMEP} P_{5}(\mathrm{kPa})$ & 506 & $482(-4.7 \%)$ & $533(5.3 \%)$ \\
\hline & & Air Charge (mg) & 324 & $320(-1.2 \%)$ & $327(0.9 \%)$ \\
\hline \multirow{2}{*}{$\begin{array}{c}1500 \text { RPM, } 604 \text { IMEP, } \\
\text { lambda }=1.0, \text { cam }=0\end{array}$} & \multirow{2}{*}{49} & $I M E P_{5}(\mathrm{kPa})$ & 608 & $578(-4.9 \%)$ & $639(5.1 \%)$ \\
\hline & & Air Charge (mg) & 360 & $355(-1.4 \%)$ & $365(1.4 \%)$ \\
\hline \multirow{2}{*}{$\begin{array}{c}1500 \text { RPM, } 603 \text { IMEP, } \\
\text { lambda=1.2, cam=30 }\end{array}$} & \multirow{2}{*}{53} & $I M E P_{5}(\mathrm{kPa})$ & 603 & $573(-5.0 \%)$ & $634(5.1 \%)$ \\
\hline & & Air Charge (mg) & 402 & $400(-0.5 \%)$ & $404(0.5 \%)$ \\
\hline
\end{tabular}

It is noticed from Table 14 that, applying a 5\% absolute gain change in pressure, results in approximately 5\% relative error in IMEP (absolute values considered, rather than positive or negative). The change in corresponding value for estimated air charge after applying $5 \%$ absolute gain, varies for different test conditions and is not greater than $1.5 \%$. 


\subsection{Generated Lookup Tables based on Calibration Data}

In this section, lookup tables for parameters $h_{\text {constant }}$ (multiplier in Woschni's correlation) and $\alpha$ (used in the residual estimator) are generated to be implemented in the estimator algorithm. The corresponding values used are reported in final calibration table (Table C- 1) in Appendix C.

As mentioned earlier, neural networks are used here as the lookup tables for $h_{\text {constant }}$ and $\alpha$, the values of which, will be calculated based on four variables: engine speed, IMEP, lambda and cam advance (inputs to the neural network).

Neural networks show satisfactory performance within the range of the inputs that are used in learning process; whereas the extrapolation for values outside the learning range might not be good. Since net performance is crucial in transient tests, the range of the inputs used in learning process, as it is seen in the final steady-state table, is wide enough to include transient conditions and to guarantee that the extrapolation is not required in transient tests. Current test condition range includes engine speed from 1000 to 2500 RPM, IMEP from 210 to $610 \mathrm{kPa}$, lambda from 1.0 to 1.3 , and intake cam advance from $0^{\circ}$ to $30^{\circ} \mathrm{CA}$ (Table C-1). It is obvious that more steady-state calibrations are needed to be done and corresponding parameters to be fed into neural network, in order to run the transient test estimation for conditions outside the current range. 
The Fitting Tool of Neural Network Toolbox ${ }^{\text {TM }}$ [57] in MATLAB is used to generate two neural networks; one for ' $h h_{\text {constant }}$ ', and one network for ' $\alpha$ '. Initial attempt was made to have a four-input-two-output network; but considering two separate four-input-one-output neural networks resulted in better output for each of the networks. The specifications of the networks used in the training process are as follows.

For both the networks $85 \%$ of data is used for training, $10 \%$ for validation, and $5 \%$ for testing. Number of hidden neurons is selected to be five for neural network with ' $\alpha$ ' output; and 10 for network with ' $h$ constant' output. Among the four inputs, lambda is multiplied by 1000 and cam advances are multiplied by 100; hence, the orders of magnitude will be 2 for IMEP input and 3 for other inputs. This conversion is performed to obtain equal orders of magnitude for lambda and cam.

The output of trained networks are compared to the table data and reported in Table 15:

Table 15-Goodness of trained neural network output

\begin{tabular}{|c|c|c|c|}
\hline $\begin{array}{c}\text { Neural } \\
\text { Network }\end{array}$ & RMSE & $\begin{array}{c}\text { SSE } \\
\text { (Root Mean Squared Error) }\end{array}$ & R-Squared \\
\hline $\boldsymbol{\alpha}$ & $0.022\left[{ }^{\circ} \mathrm{CA} / \mathrm{m}\right]$ & 0.030 & 0.997 \\
\hline $\boldsymbol{h}_{\text {constant }}$ & $0.086\left[\frac{\mathrm{W}}{\mathrm{m}^{2} \cdot \mathrm{K}}\right]$ & 0.446 & 0.966 \\
\hline
\end{tabular}

These parameters are calculated from following equations: 


$$
R M S E=\sqrt{\frac{\sum_{l=1}^{n}\left(y_{l}-\hat{y}_{l}\right)^{2}}{n}}
$$

where , ' $n$ ' is number of data. R-squared is calculated by:

$$
R^{2}=1-\frac{S S E}{S S T O}
$$

Here, SSTO is total sum of squares obtained from [58]:

$$
\text { SSTO }=\sum_{l=1}^{n}\left(y_{l}-\bar{y}\right)^{2}
$$

and sum of squares of the error is:

$$
S S E=\sum_{l=1}^{n}\left(y_{l}-\hat{y}\right)^{2}
$$

The values of R-squared for fit neural networks for ' $\alpha$ ' and ' $h_{\text {constant }}$ ' in Table 15, are greater than 0.96 , which indicates the goodness of the fitted data. 
Figure 26 to Figure 29 also show table data and neural network outputs. Figure 26 and Figure 27 show a comparison for ' $\alpha$ ' and $h_{\text {constant }}$ from corresponding neural network output and tabulated data, against different lambdas and cam advances, for 1000 RPM and 212 IMEP.

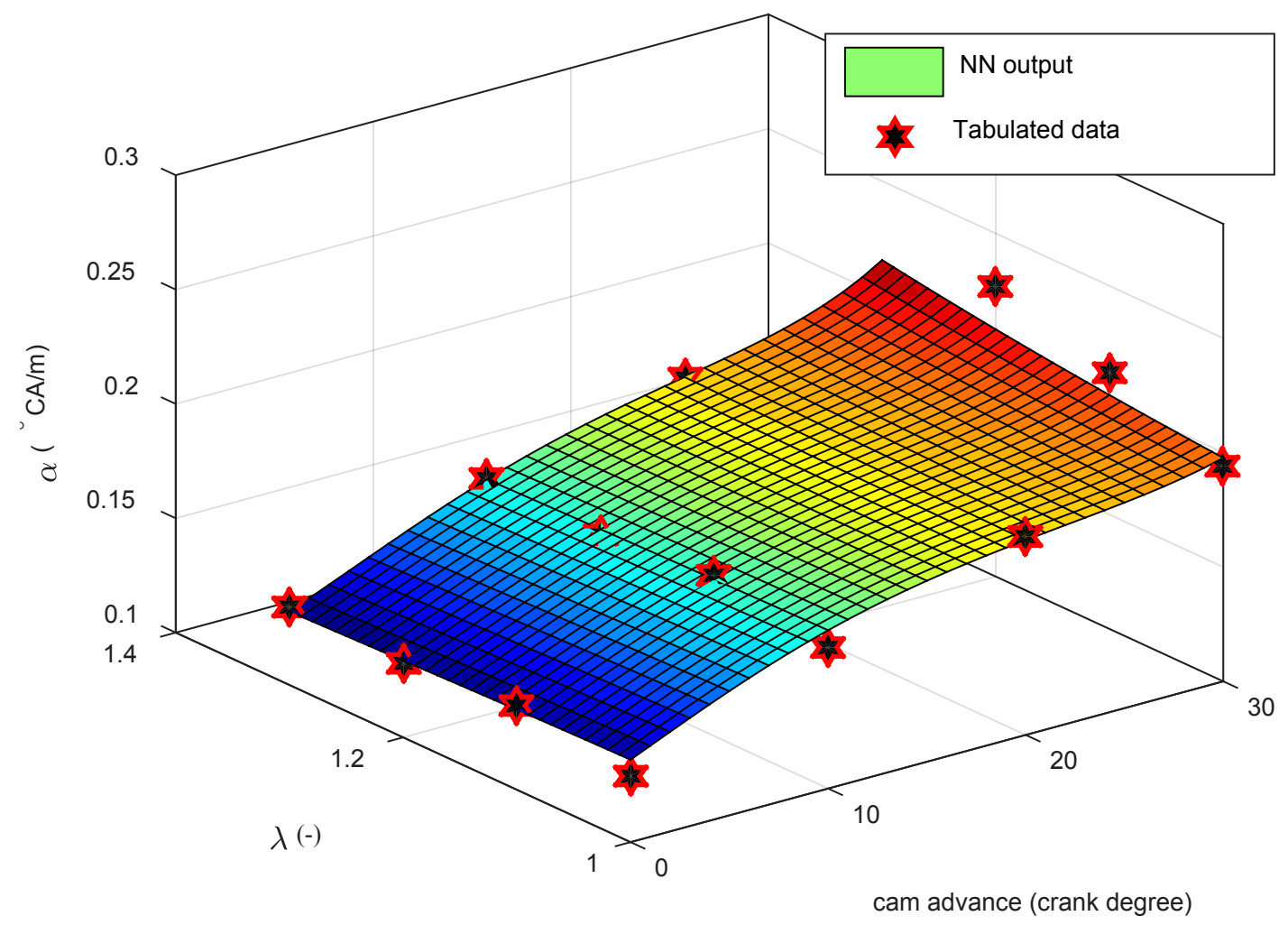

Figure 26- Comparison between ' $\alpha$ ' values from neural network output and tabulated data for 1000 RPM and 212 IMEP 


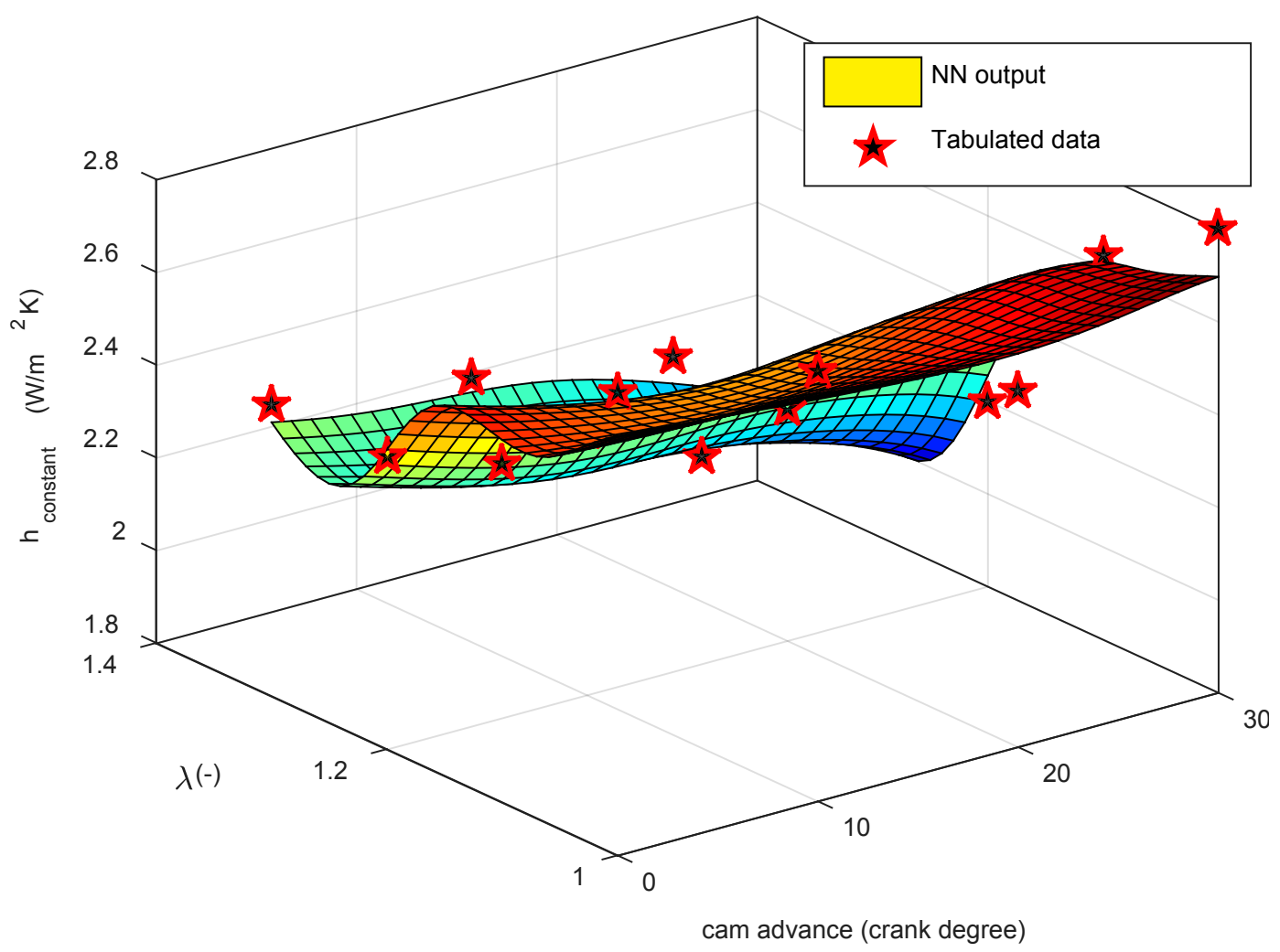

Figure 27- Comparison between $\mathrm{h}_{\text {constant }}$ values from network output and tabulated data for 1000 RPM and 212 IMEP

The goodness of neural network fit to the tabulated data for 1000 RPM and 212 IMEP (shown in Figure 26 and Figure 27) is evaluated with corresponding RMSE, which is 0.007 $\left[{ }^{\circ} \mathrm{CA} / \mathrm{m}\right]$ for ' $\alpha$ ', and $0.06\left[\frac{W}{m^{2} \cdot K}\right]$ for ' $h$ constant'.

' $\alpha$ ' and ' $h_{\text {constant }}$ ' from corresponding neural network output and tabulated data are plotted against different IMEP's and engine speeds (RPM) at lambda=1 and cam advance $=0$ in Figure 28 and Figure 29. 


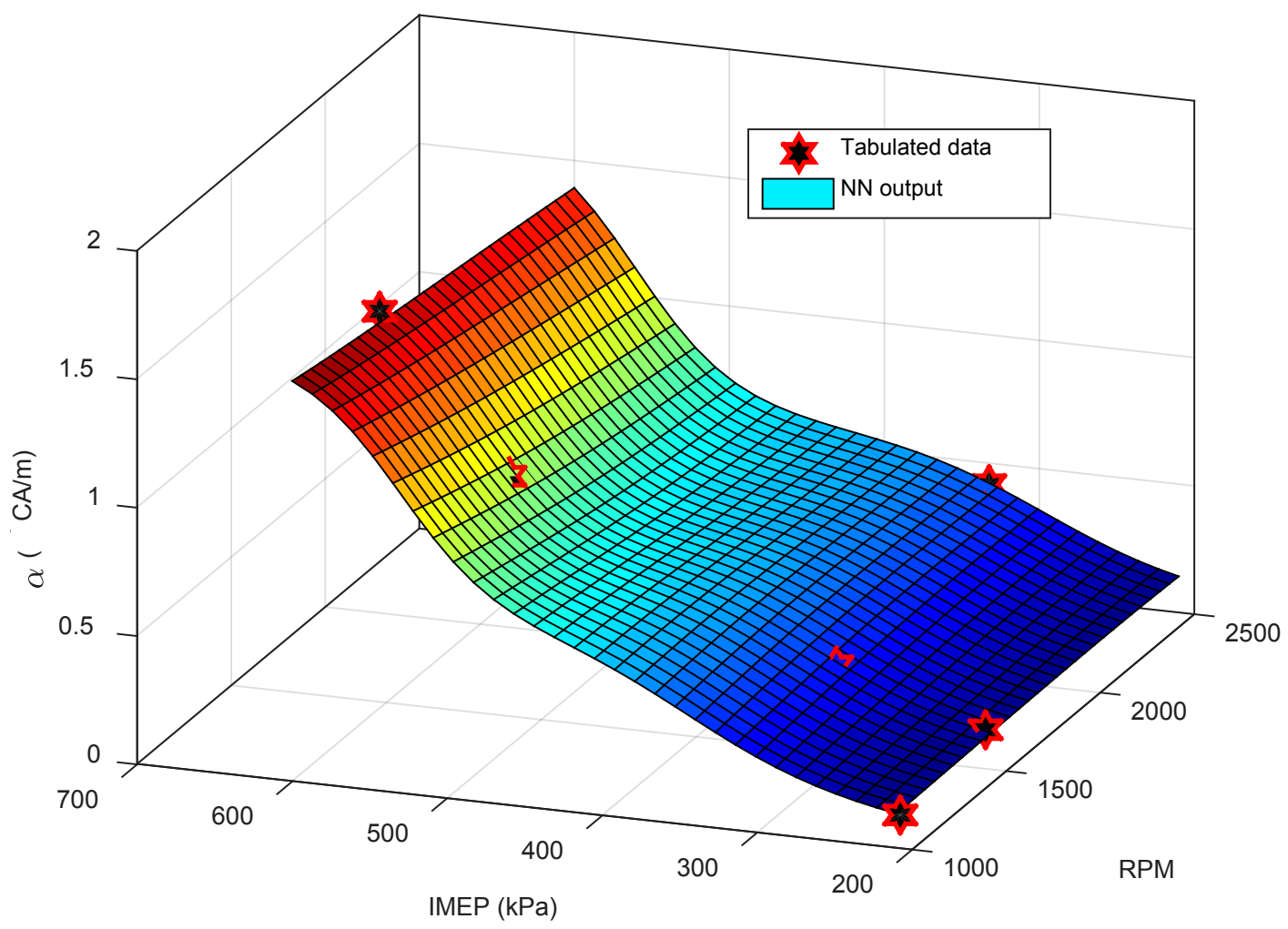

Figure 28-Comparison between ' $\alpha$ ' values from neural network output and tabulated data for $\lambda=1$, and intake cam advance $=0$ 


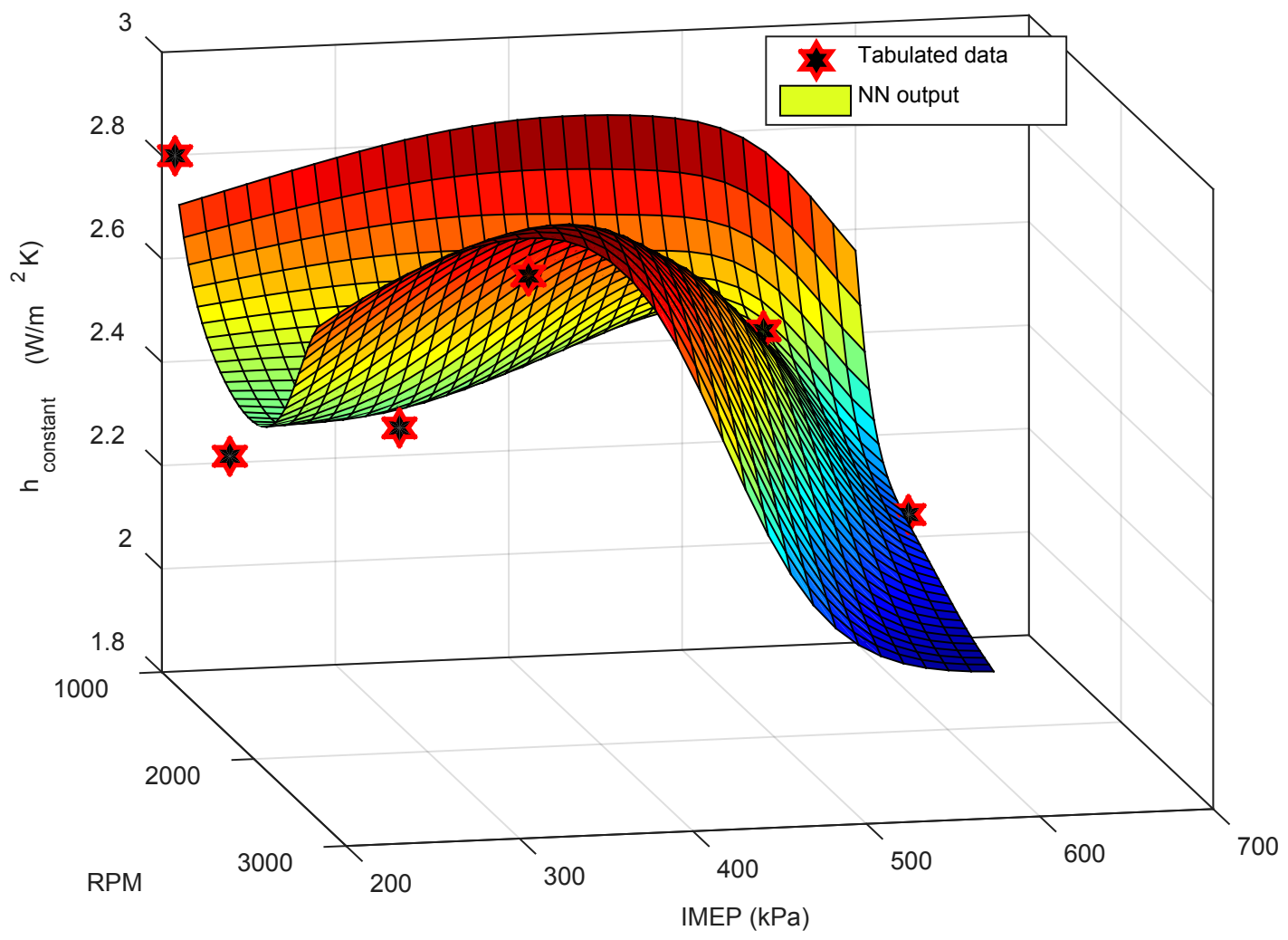

Figure 29- Comparison between $h_{\text {constant }}$ values from neural network output and tabulated data for $\lambda=1$, and intake cam advance $=0$

For the data shown in Figure 28 and Figure 29, the RMSE between neural network and tabulated data is $0.0155\left[{ }^{\circ} \mathrm{CA} / \mathrm{m}\right]$ for ' $\alpha$ ', and $0.0864\left[\frac{W}{m^{2} \cdot K}\right]$ for ' $h h_{\text {constant }}$ '.

The neural networks generated for $h_{\text {constant }}$ and ' $\alpha$ ' in this section, are further utilized as lookup tables for these parameters and their output based on the four input parameters, will be used in the air charge estimation algorithm in transient tests. As mentioned before, to avoid neural network extrapolation issues, transient tests are performed in the range of the calibration table (Table C- 1). 


\subsection{Transient Tests}

In this section, three transient tests, at different operating points are performed. Table 16 summarizes different conditions for engine operation.

Table 16- Transient tests operating conditions

\begin{tabular}{|c|c|}
\hline Test \# & \multicolumn{1}{|c|}{ Test Condition } \\
\hline $\mathbf{1}$ & $\begin{array}{l}\text { - dyno is set to 1500 RPM (speed control) } \\
\text { - APP changed intermittently }\end{array}$ \\
\hline $\mathbf{2}$ & $\begin{array}{l}\text { - dyno is set to 2500 RPM (speed control) } \\
\text { - APP changed intermittently }\end{array}$ \\
\hline $\mathbf{3}$ & $\begin{array}{l}\text { - Dyno is set to 1500 RPM (speed control) } \\
\text { - APP and lambda changed intermittently }\end{array}$ \\
\hline
\end{tabular}

Accelerator Pedal Position (APP) parameter is manually changed in ATI interface to change the engine load. In these tests, intake cam timings are automatically changed (according to the ECU strategy).

\subsubsection{Transient Test \#1}

The speed in dyno control software is set to 1500 RPM and APP is changed at different time steps and its effects are seen in MAP and 'ETC_TP_ARB' parameters in ATI; the 
latter denotes actual throttle angle in degrees [41] which is shown by ETC (deg) in Figure 30.
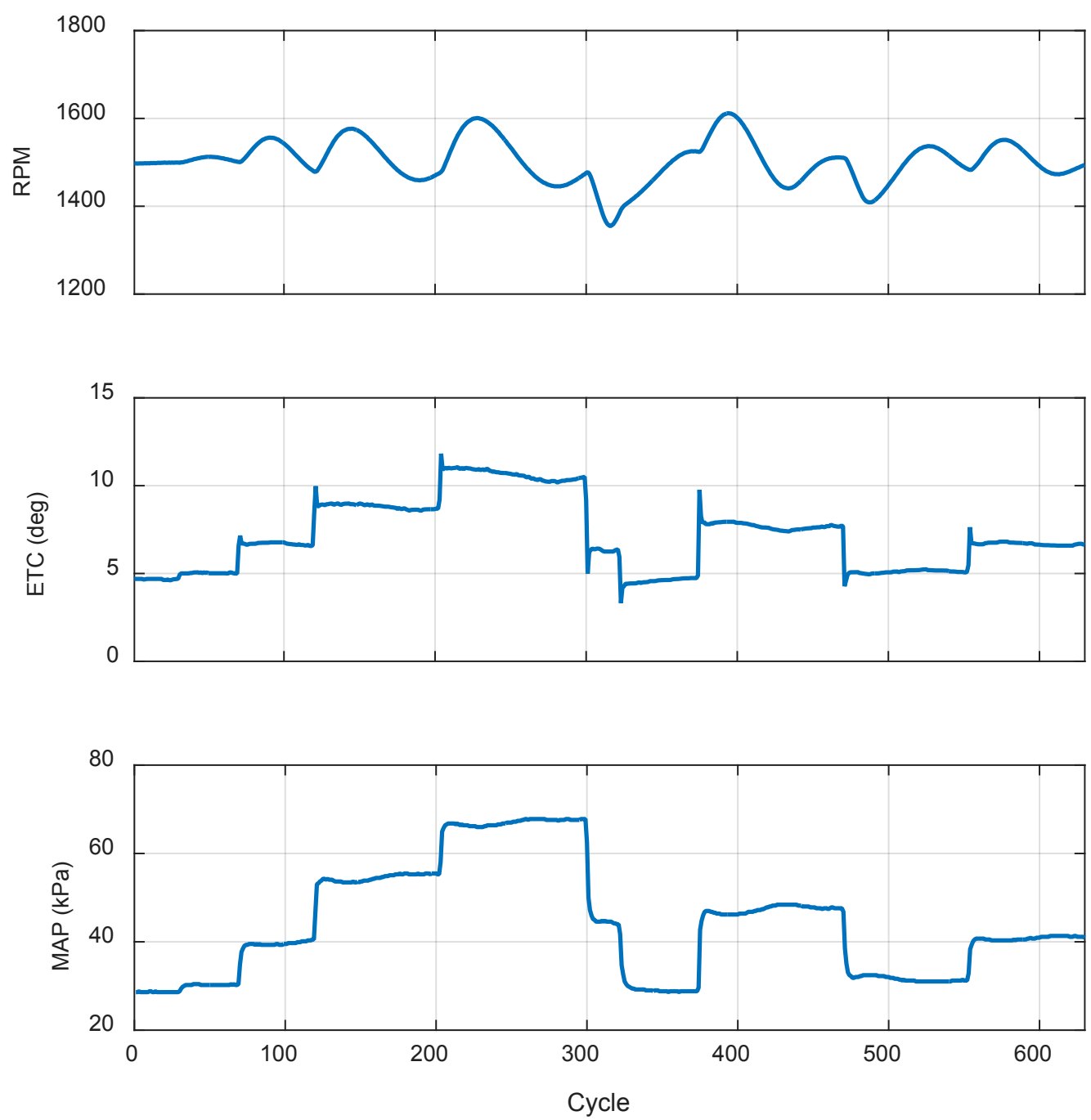

Figure 30- Engine speed, throttle angle and MAP in test \#1

Variation in MAP and engine speed due to the change in throttle angle (ETC) are seen in Figure 30; the engine speed tends to vary in the range of 1400 to 1600 RPM since ETC is 
changed intermittently, although it is controlled at 1500 RPM. MAP has its maximum value between cycles 200 to 300 , when throttle angle, for this duration, is greater than 10 degree.

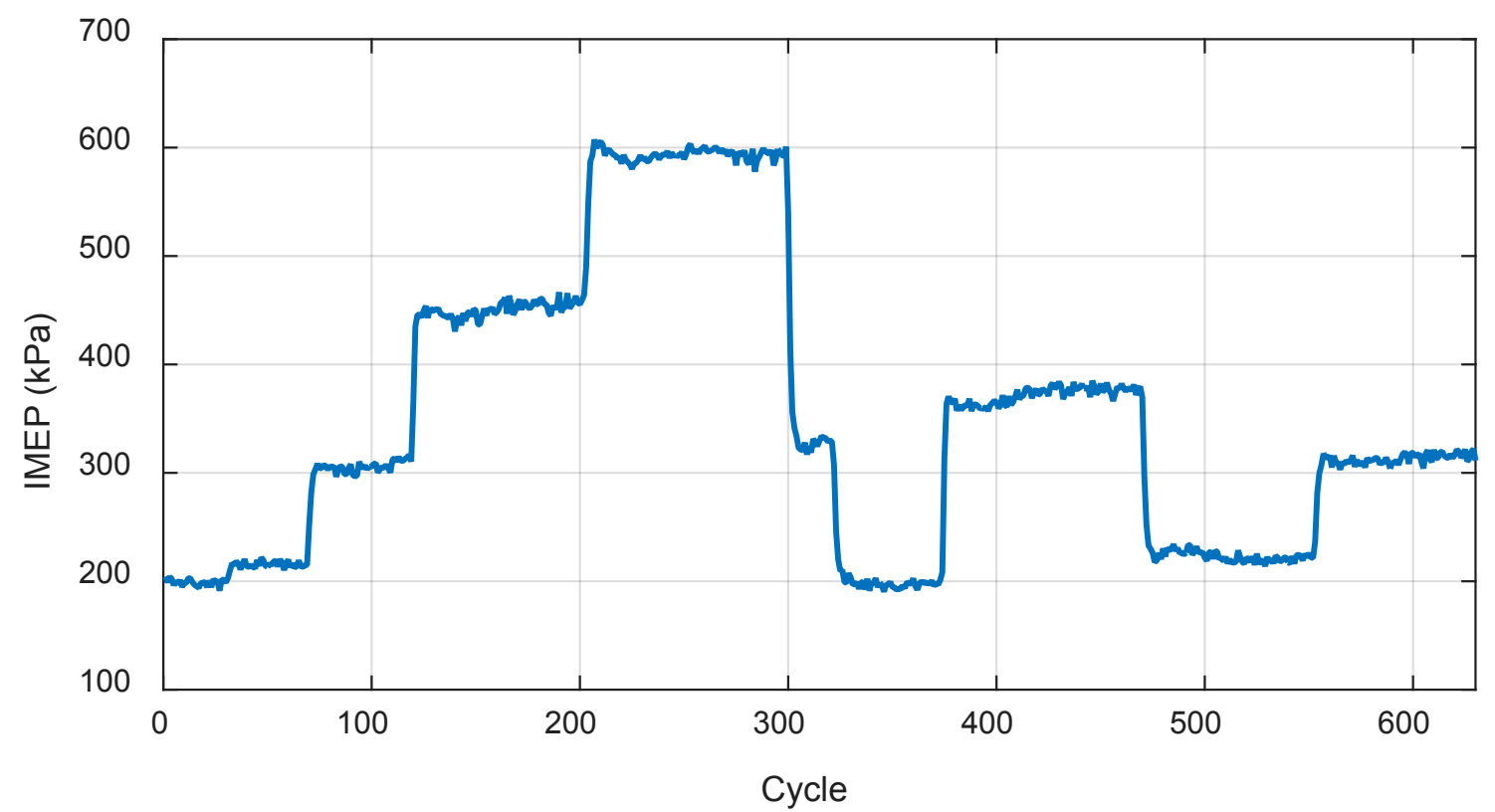

Figure 31 - IMEP variation in test \#1

Figure 31 shows variation of the IMEP; the value for the IMEP is the average over cylinders 1, 5, and 6. It is seen that IMEP varies between 200 and $600 \mathrm{kPa}$ based on the differert throttle angles. 

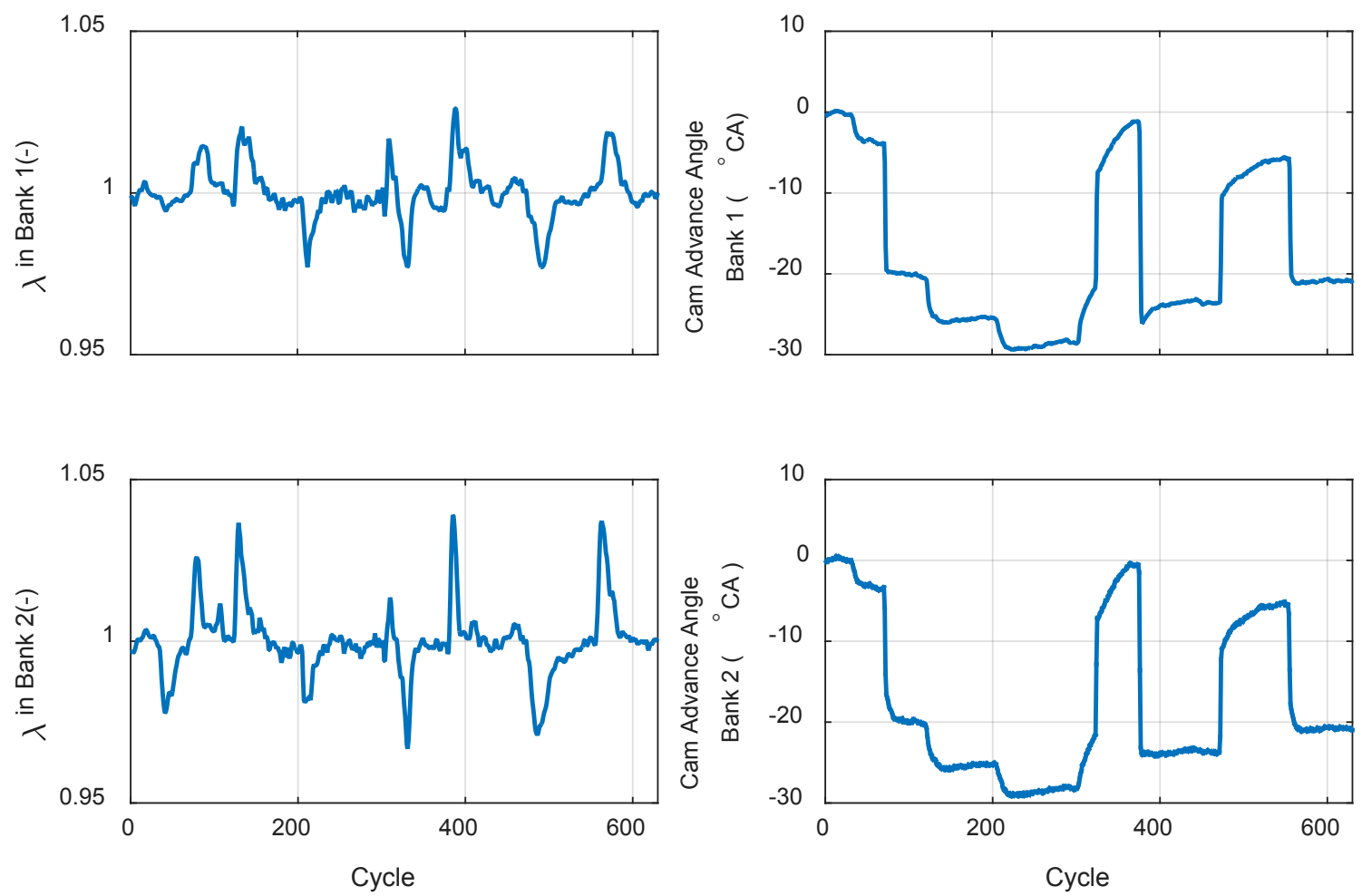

Figure 32- Lambda and cam advance angles in different banks in test \#1

In Figure 32, lambda for two banks are shown; bank 1 corresponds to cylinders 1, 2, and 3 , and bank 2 is related to cylinders 4,5 , and 6 . These lambda values are logged in ATI interface from production lambda sensors on engine banks (not to confuse with individual cylinder lambda sensors). Target value for lambda is set to 1.0 in this test and the lambda for different banks is controlled through ECU strategy. The values for intake cam advance angles, which is controlled automatically based on ECU strategy, are also shown in Figure 32; negative value indicates advance in comparison to cam base timing). 
Figure 33 shows estimator output compared to the experimental air for cylinder 1, 5, and 6. As discussed in section 5.1, experimental air is calculated from injected fuel and individual wide-band sensor data.
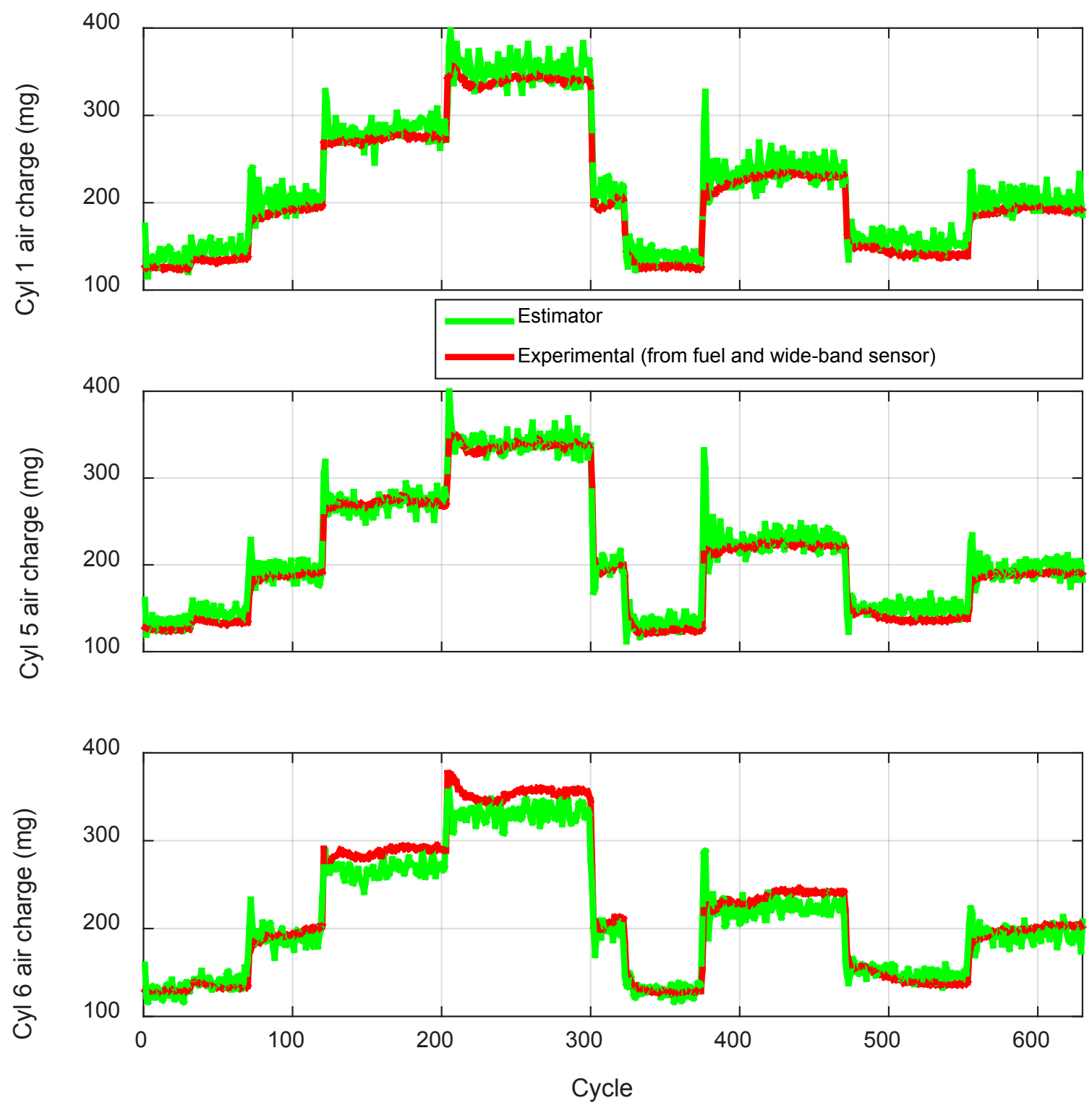

Figure 33- Estimator and experimental air charge for cylinders 1, 5, and 6 in test \#1 
The transient response of the estimator output is seen in Figure 33. The performance of estimator output is investigated by calculating the Root Mean Squared Error (RMSE) between estimated and experimental air charge. The RMSE values are $17 \mathrm{mg}, 11 \mathrm{mg}$, and $16 \mathrm{mg}$ for cylinders 1,5 and 6 , respectively. Based on these values, it is concluded that air charge estimator shows better performance for cylinder 5, in terms of error between estimated air and experimental air calculated from injected fuel and wide-band sensor data. 


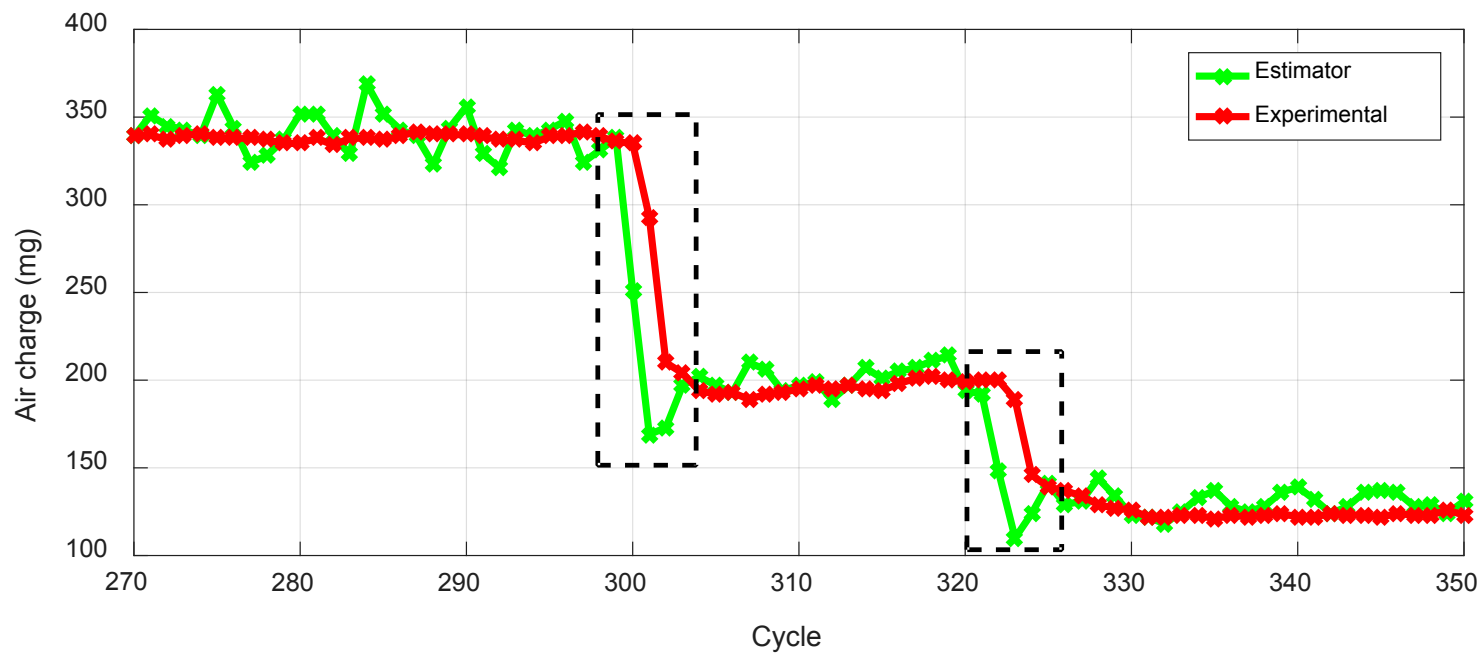

(a)

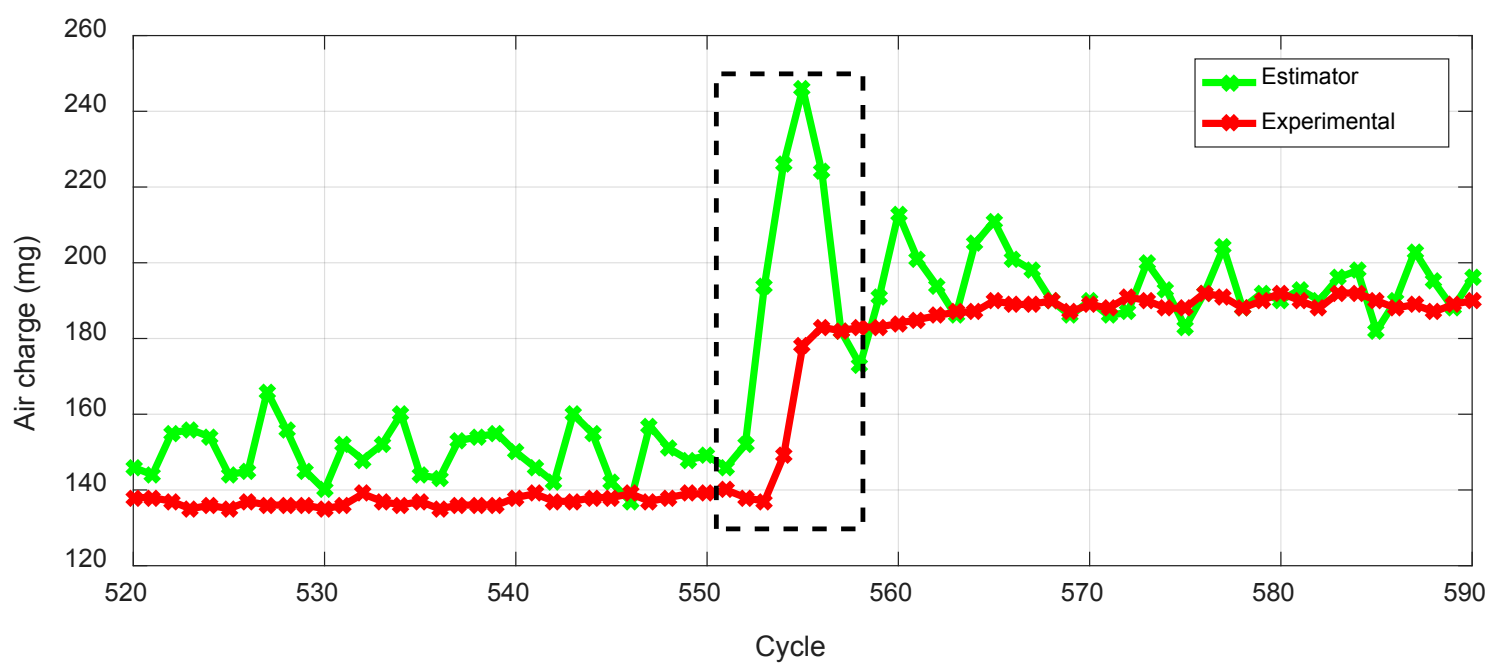

(b)

Figure 34 (a) and (b)- Estimator air charge compared to experimental air charge (estimated from fuel and lambda sensor) for cylinder 5 in test \#1

Figure 34 shows two different sections in test \#1 with dashed rectangles indicating the transience intervals. It is noticed that estimator air charge leads the experimental air charge 
which is calculated from fuel and wide-band sensor data. This is justified by the transport delay existing in lambda sensor response.

\subsubsection{Transient Test \#2}

In this test, dyno speed is set to 2500 RPM and APP parameter is manually changed to change engine load. Lambda target value is again set to 1.0, and lambda and cam advance are automatically controlled via ECU. Figure 35 and Figure 36 illustrate the engine conditions in this test. 

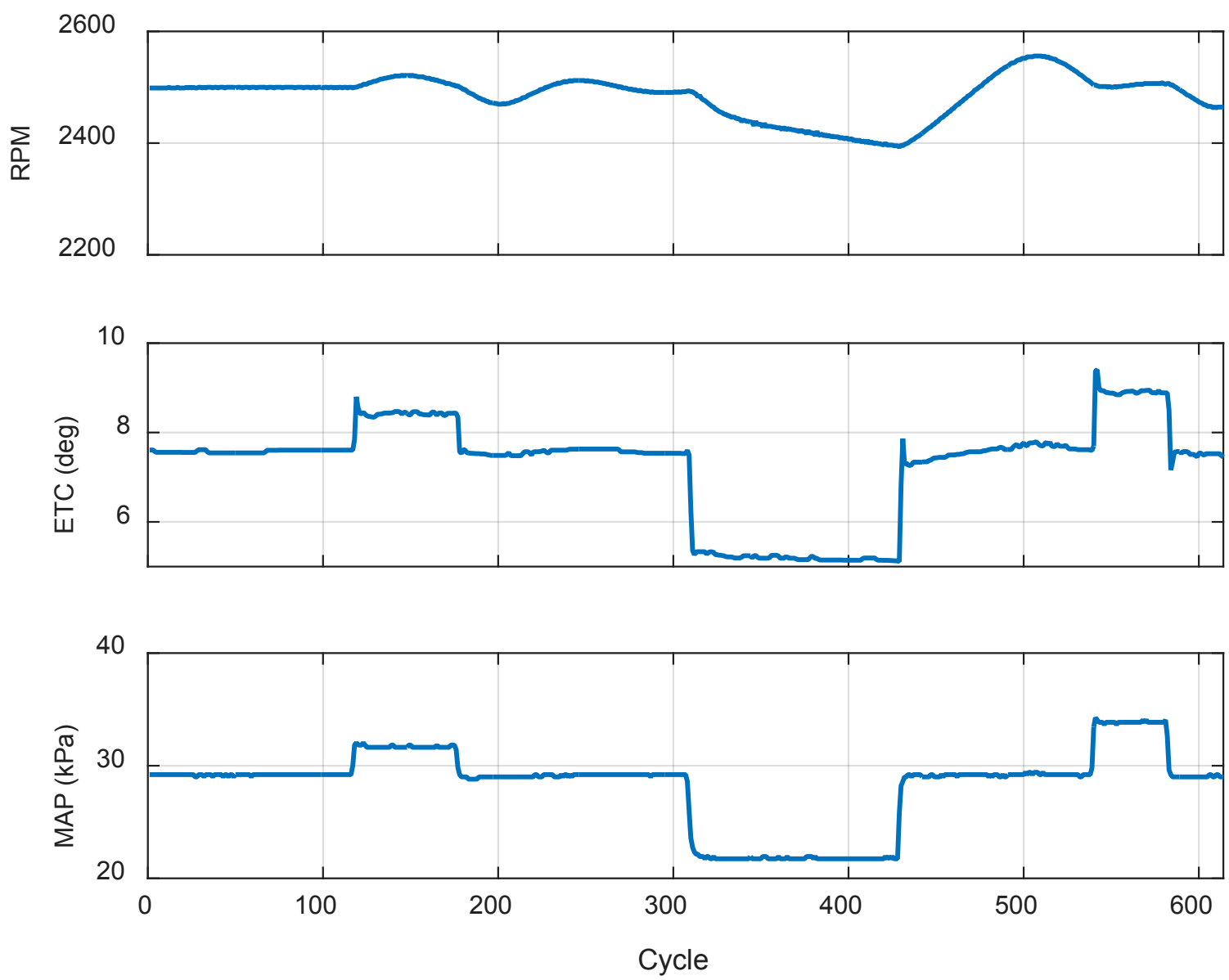

Figure 35- Engine speed, throttle angle and MAP in test \#2

It is seen in Figure 35 that engine speed varies between 2400 and 2600 RPM (set to be controlled at $2500 \mathrm{RPM}$ ). MAP changes between $22 \mathrm{kPa}$ (when throttle angle is almost 5 degree) and $35 \mathrm{kPa}$ (throttle angle is almost 9 degree). 

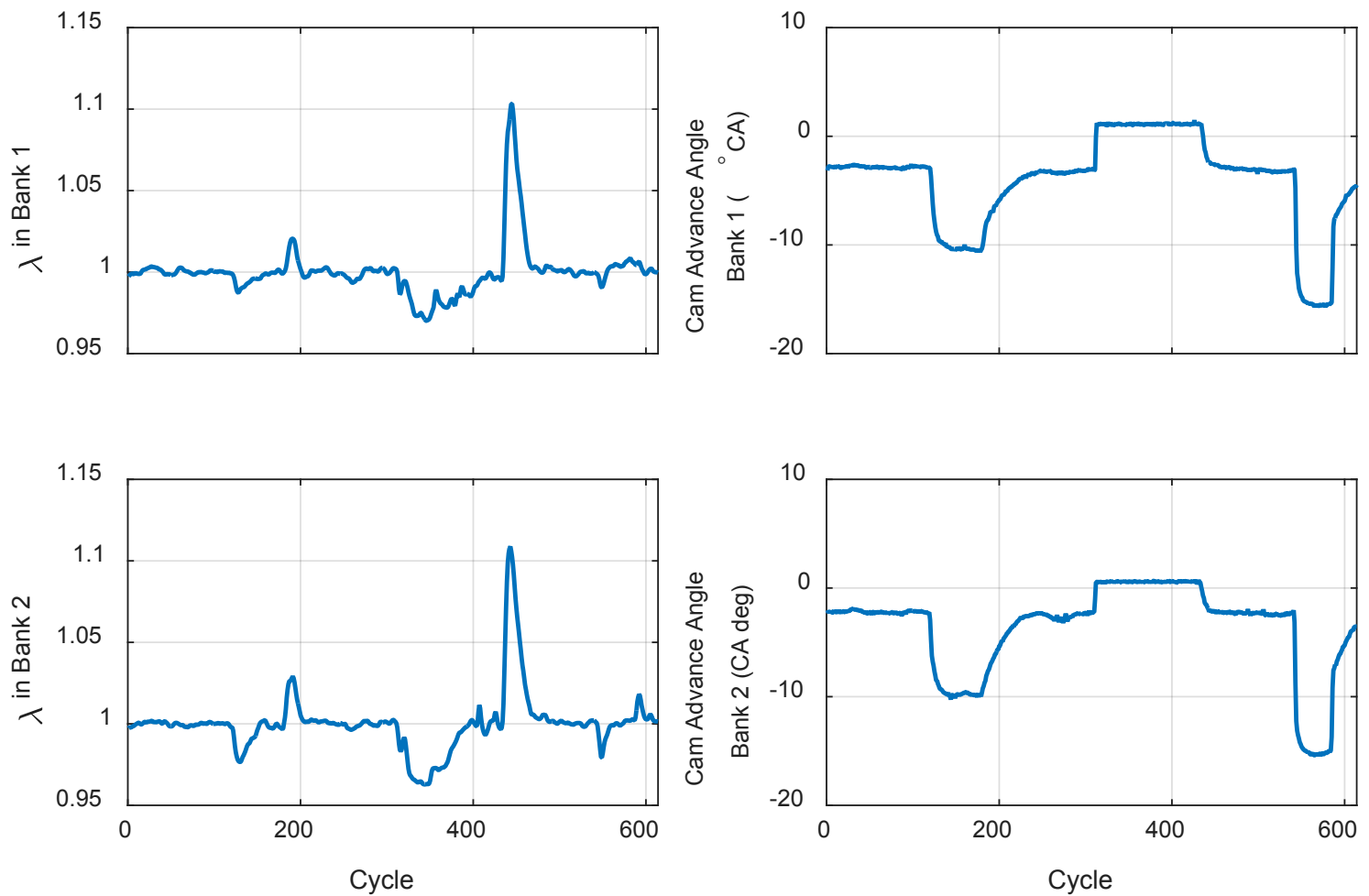

Figure 36- Lambda and cam advance angles in different banks in test \#2

In Figure 36, lambda for banks one and two are shown; Target value for lambda is set to 1.0 in this test and the lambda for different banks is controlled through ECU strategy. It is seen that lambdas peak around cycle 450 reaching to almost 1.1; this is because of the APP command causing throttle angle to suddenly increase from approximately 5 degree to almost 7.5 degree. The values for intake cam advance angles, which is controlled automatically based on ECU strategy, are also shown in Figure 36.

Figure 37 shows transient response of estimated air charge for cylinders 1, 5, and 6 compared to experimental air charge calculated from fuel and wide-band sensors. 

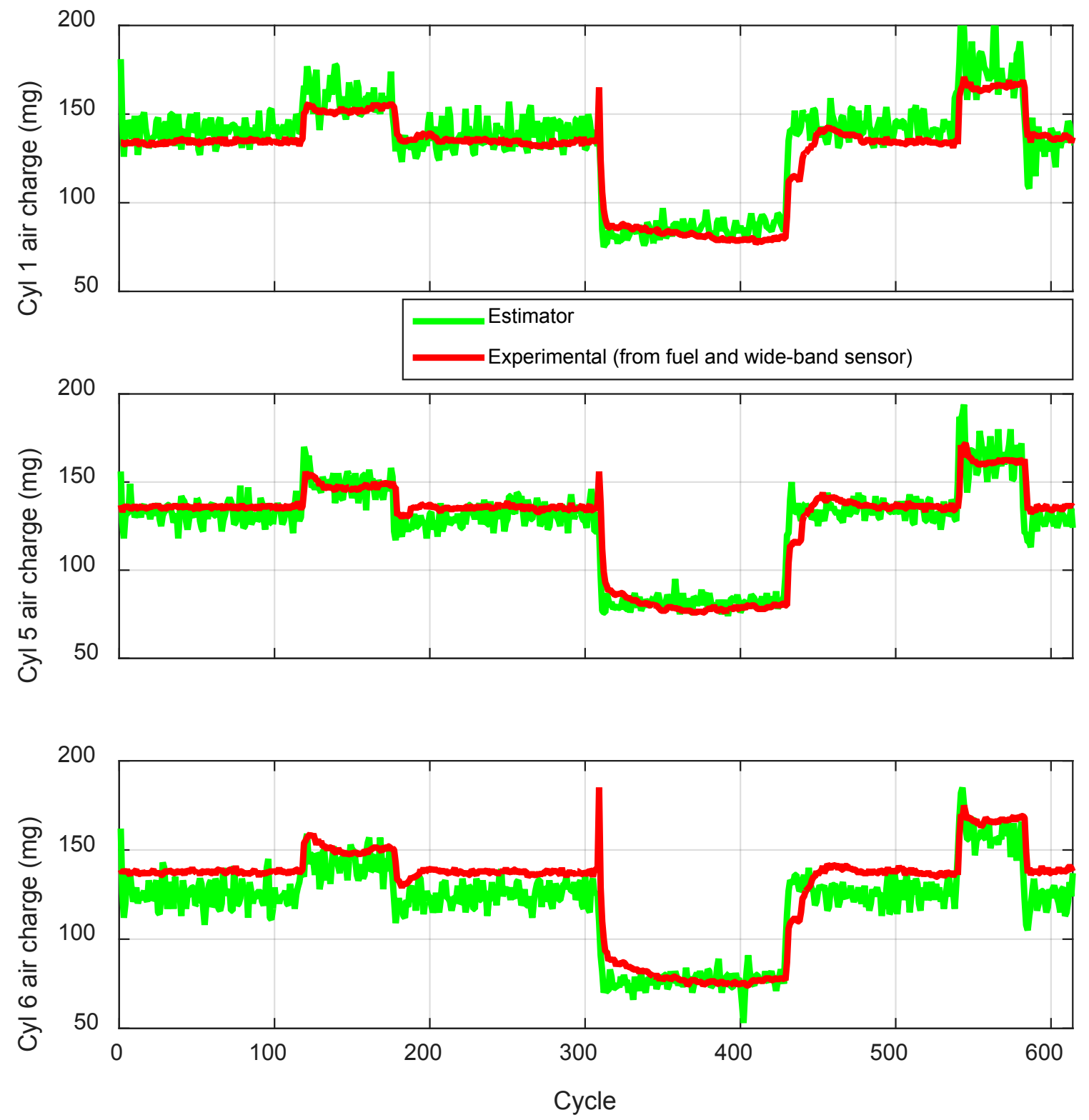

Figure 37- Estimator and experimental air charge for cylinders 1, 5, and 6 in test \#2

The RMSE values between estimated and experimental air charge in Figure 37, are $9 \mathrm{mg}$, $8 \mathrm{mg}$, and $13 \mathrm{mg}$ for cylinders 1,5 and 6 , respectively. 


\subsubsection{Transient Test \#3}

In this test dyno speed is set to $1500 \mathrm{RPM}$, and APP parameter and target lambda are changed intermittently. The ETC parameter shows actual throttle angle in Figure 38 and lambda change is shown in Figure 40 for different banks. The cam advance value (seen in Figure 40) is changed automatically through ECU strategy.
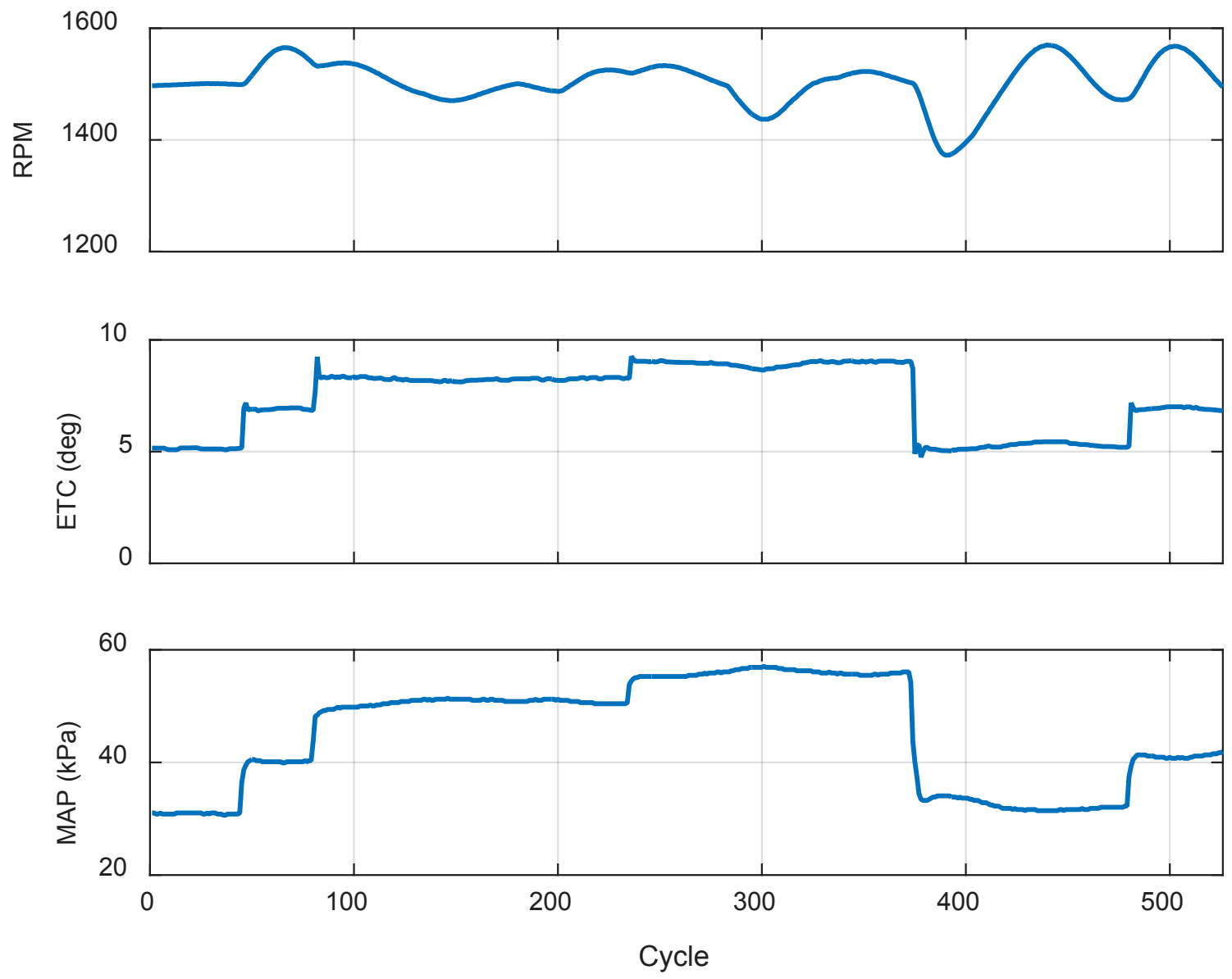

Figure 38- Engine speed, throttle angle and MAP in test \#3

As seen in Figure 38, throttle angle changes between five and nine degree according to the change in APP command. The MAP also changes intermittently between 30 and $55 \mathrm{kPa}$. 


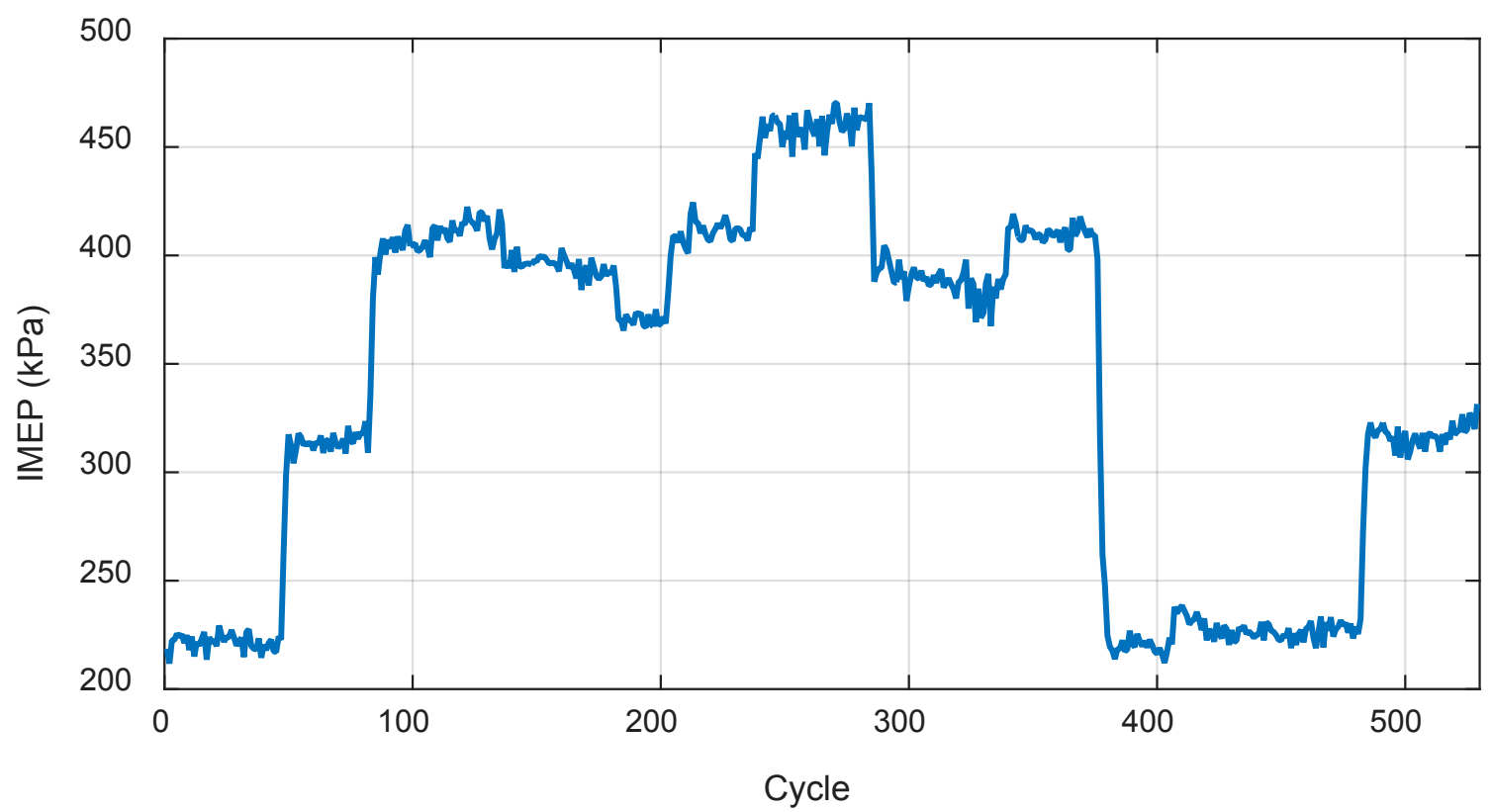

Figure 39- IMEP variation in test \#3

In Figure 39, the value for the IMEP is the average over cylinders 1, 5, and 6. The IMEP varies intermittently between 220 and $460 \mathrm{kPa}$. 

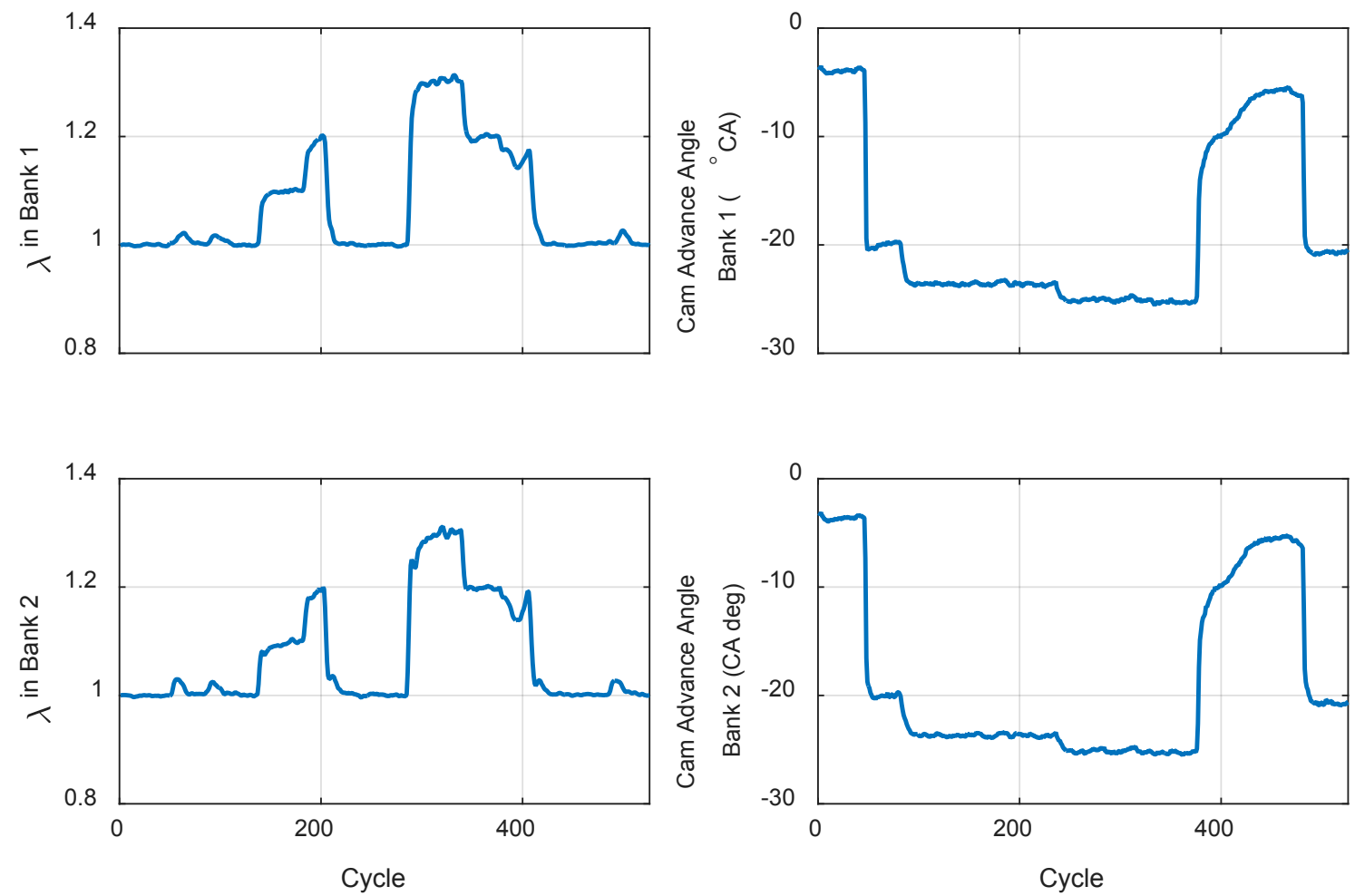

Figure 40- Lambda and cam advance angles in different banks in test \#3

Figure 40 shows variation in lambda from two banks. Lambda is changed manually to see the estimator performance in comparison to calculated air from fuel and individual lambda sensors. It is noted again that, the values of lambdas in two banks are corresponding to lambda sensors used in production engine and the data is logged and monitored in ATI interface. The calculation of experimental air charge is done by calculation of fuel in each cylinder and individual lambda sensors' data for each cylinder; the individual cylinder lambda sensors' data is monitored and logged in ACAP. It is seen in Figure 40 that, lambda values for two banks change between 1.0 and 1.3, intermittently. Also, in this figure, the values for intake cam advance angles (controlled automatically via ECU strategy) are 
shown. Intake cam for both banks is advanced approximately between four and 25 crank degree. 

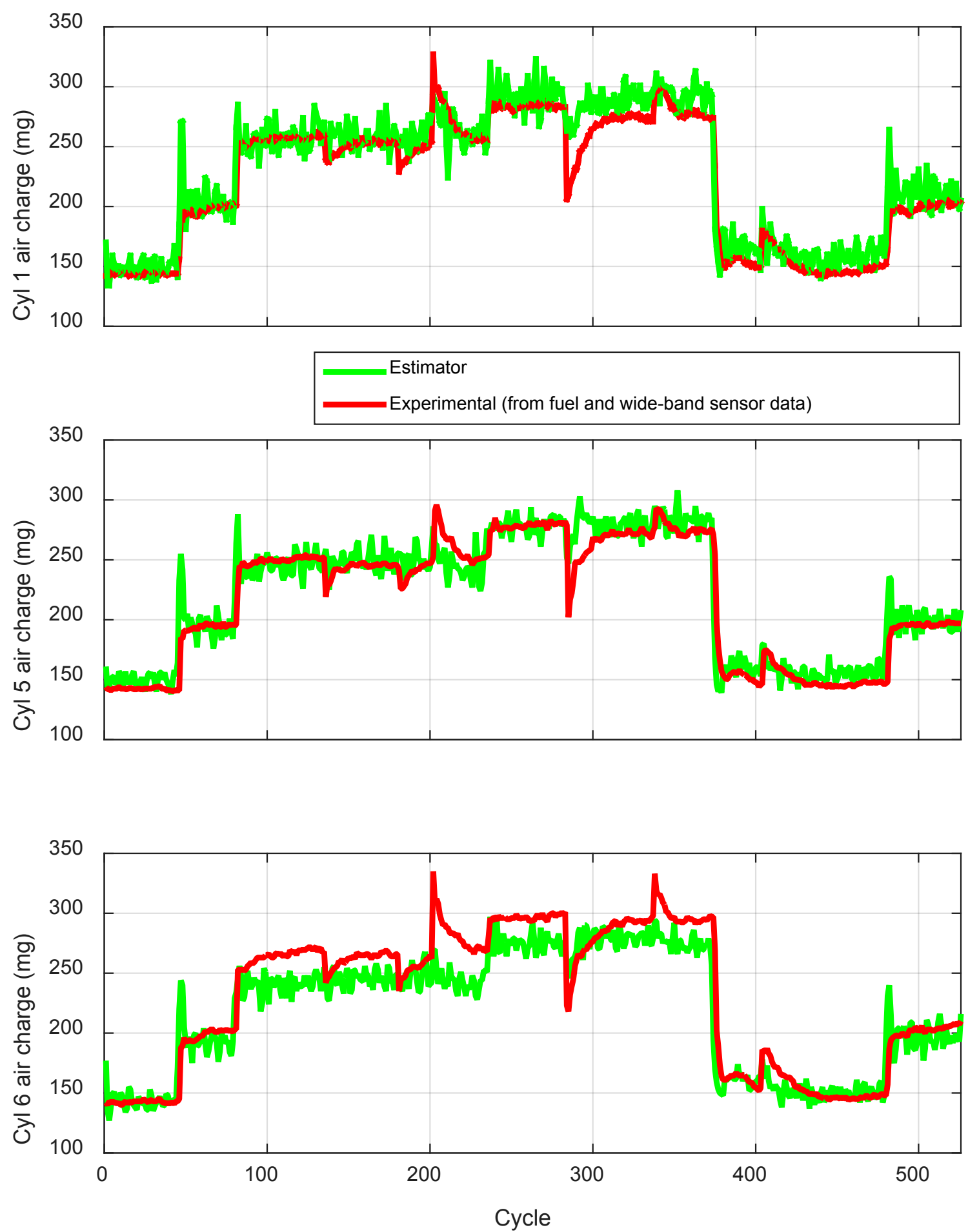

Figure 41- Estimator and experimental air charge for cylinders 1, 5, and 6 in test \#3 
Figure 41 illustrates transient performance of air charge estimator for different cylinders compared to experimental air charge, calculated from fuel and individual wide-band sensors. The RMSE values between estimated and experimental air charge are $15 \mathrm{mg}, 13$ $\mathrm{mg}$, and $19 \mathrm{mg}$ for cylinders 1,5 and 6 , respectively.

Table 17 summarizes the performance of estimator outputs by showing the RMSE between estimated and experimental air. To interpret the relative performance of estimator in these tests, the Coefficient of Variation of the RMSE (CV(RMSE)) is calculated, which is defined by [59]:

$$
C V(R M S E)=\frac{R M S E}{\bar{y}} \times 100
$$

The average experimental air charge for each cylinder in different tests is used as $\bar{y}$.

Table 17-RMSE (mg) and CV(RMSE) (\%) in transient tests for different cylinders

\begin{tabular}{|c|c|c|c|}
\cline { 2 - 4 } & Cylinder 1 & Cylinder 5 & Cylinder 6 \\
\hline \multirow{2}{*}{ Test \#1 } & $17 \mathrm{mg}$ & $11 \mathrm{mg}$ & $16 \mathrm{mg}$ \\
& $(8.0 \%)$ & $(5.2 \%)$ & $(7.3 \%)$ \\
\hline \multirow{2}{*}{ Test \#2 } & $9 \mathrm{mg}$ & $8 \mathrm{mg}$ & $13 \mathrm{mg}$ \\
& $(7.0 \%)$ & $(8.6 \%)$ & $(10.1 \%)$ \\
\hline \multirow{2}{*}{ Test \#3 } & $15 \mathrm{mg}$ & $13 \mathrm{mg}$ & $19 \mathrm{mg}$ \\
& $(6.8 \%)$ & $(6.0 \%)$ & $(8.3 \%)$ \\
\hline
\end{tabular}


As it is seen in Table 17, cylinder 5 shows the smallest values for RMSE and CV(RMSE) in comparison to other cylinders in transient tests . 


\section{Chapter 6}

\section{Summary and Conclusions}

\subsection{Summary}

In this thesis, a developed air charge estimation method using in-cylinder pressure transducer data is proposed for a SI engine equipped with intake variable valve timing. Cylinder pressure data at specific cycle events is used in thermodynamics and heat transfer relationships, in an algorithm to estimate fresh air and residual gas mass in each cylinder and each cycle. Two different methods are studied for air estimation algorithm based on the approach to estimate residual fraction mass. Method 1 uses the Residual Gas Fraction (RGF), which can be estimated from a high fidelity correlation or engine simulation software. The second method (Method 2), is an online residual estimator that is incorporated into the algorithm. Considering the two main terms for residual gas mass (trapped and overlap backflow), a correlation is proposed which estimates residual mass at each cycle (rather than RGF in Method 1). Using Method 2 has this advantage that can be applied in online estimation and improves estimator performance in transient conditions. The schematics of the algorithm are provided for better understanding of the estimator operation. 
Air charge measurements with Laminar Air Flow Element (LFE) and air calculation based on injected fuel and wide-band sensor data are also discussed in this work. The method to calculate individual fresh charge for each cycle, using individual injected fuel and wideband sensor data is explained and the calculated air, mentioned as experimental air, is further used as a validation and calibration reference for algorithm under different test conditions. There are two parameters in air charge estimator that are calibrated such that estimated air charge matches the experimental air charge; 1) heat transfer parameter $\left(h_{\text {constant }}\right)$, and 2) residual gas estimation parameter $(\alpha)$. These calibrations are done for a range of steady-state tests (61 total). In order to calculate the uncertainty in estimated air charge, uncertainty propagation analysis is performed.

\subsection{Conclusions}

The results of uncertainty analysis for nine different steady state tests show that in different tests,

- when pressure has $5 \mathrm{kPa}$ uncertainty, the relative uncertainty in air charge is between 7 to $13 \%$.

- having a $1.25 \mathrm{kPa}$ uncertainty in measured pressure, causes maximum 4\% uncertainty in estimated air mass.

- to have maximum $5 \%$ uncertainty in estimated air charge, uncertainty in measured pressure must be maximum $2 \mathrm{kPa}$ 
The uncertainty in estimated air from air charge estimator in this work was compared to two other air charge estimation methods in the literature. It was shown that, when there is $5 \mathrm{kPa}$ uncertainty in cylinder pressure measurement,

- estimated air with air charge estimation algorithm in this work has less than $11 \%$ uncertainty, while estimated air from other methods had 16\% and 19\% uncertainty.

Sensitivity analysis is performed on sensor measurement to investigate the error in pressure measurement effect on estimated air and IMEP calculation. It was shown that,

- transducer offset change and white-noise included in pressure do not have effect on estimated air charge and IMEP.

- It was also shown that maximum change in IMEP and air charge, due to a $5 \%$ change in transducer gain, will be approximately 5\% and $1.4 \%$, respectively.

Two neural networks are developed and used as lookup table for two calibrated parameters in the estimator $\left(h_{\text {constant }}\right.$ and $\alpha$ ) for different test points within the range of steady-state test conditions (total 61 tests). To show neural network output goodness of fit,

- the calculated R-squared values, were greater than 0.96 for both estimator calibrated parameters. 
- The RMSE for neural network fit on $h_{\text {constant }}$ parameter was obtained 0.086 $\left[\frac{W}{m^{2} \cdot K}\right]$, and for parameter $\alpha$, the RMSE was $0.022\left[{ }^{\circ} \mathrm{CA} / \mathrm{m}\right]$, indicating that the trained network shows good performance within the range of trained data.

To avoid potential extrapolation issues of the neural network, transient tests are done in the range of the training data, obtained from steady-state tests. Three transient tests under different engine conditions (speed, load and lambda) are done and estimator performance is investigated in comparison to the experimental air charge which is calculated from injected fuel and lambda.

- The RMSE between estimated and experimental air charge varies between $8 \mathrm{mg}$ to $19 \mathrm{mg}$ for different cylinders;

- the Coefficient of Variation of the RMSE (CV(RMSE)) varies from $5.2 \%$ to maximum $10.1 \%$ for different cylinders.

\subsection{Suggestions for Future Work}

Following investigations can be done in to order to improve the performance and applicability of the air charge estimator: 
- Investigating the performance of the air charge estimator by including the effects of additional engine control actuators such as external EGR and exhaust valve timings, for the engines with higher degrees of freedom

- Determining correlations for the calibrated parameters in the estimator (heat transfer and residual gas), which give the capability to be utilized beyond the range of steady-state tests and avoid extrapolation issues around using neural network

- Investigating the feasibility of real-time application of air charge estimator, with online estimation of residual gas mass, using the residual estimator incorporated into the estimation algorithm.

- Integration of the online air estimation algorithm into the 2.0L Ford Ecoboost engine CPDC in Delphi controller

- Utilizing the exhaust manifold temperature measurement in the estimator with the aim of reducing the uncertainty in air charge and residual mass estimation 


\section{References}

[1] "United States Environmental Protection Agency," [Online]. Available: https://www3.epa.gov/.

[2] D. Kodjak, "Consumer Acceptance of Electric Vehicles in the US," December 2012. [Online]. Available: https://www.epa.gov/sites/production/files/201409/documents/kodjak121312.pdf.

[3] "U.S. Department of Energy, Quadrennial Technology Review 2015," [Online]. Available: http://energy.gov/sites/prod/files/2015/11/f27/QTR2015-8C-InternalCombustion-Engines.pdf.

[4] Z. Wang, Q. Zhu and R. Prucka, "A Review of Spark-Ignition Engine Air Charge," SAE 2016-01-0620, 2016.

[5] W. Brandstetter and M. Carr, "Measurement of Air Distribution in a Multicylinder Engine by Means of a Mass Flow Probe," SAE Technical Paper 730494, 1973.

[6] P. Berggren and A. Perkovic, "Cylinder Individual Lambda Feedback Control in an SI Engine," 1996.

[7] F. Taglialatela, N. Cesario and M. Lavorgna, "Soft Computing Mass Air Flow Estimator for a Single-Cylinder SI Engine," SAE 2006-01-0010, 2006.

[8] M. Jankovic, "Cylinder Air-Charge Estimation for Advanced Intake Valve Operation in Variable Cam Timing Engines," JSAE Rev. 22(4):445-452, 2001.

[9] A. Stotsky and I. Kolmanovsky, "Application of input estimation techniques to charge estimation and control in automotive engines," Control Eng. Pract. 10(12):1371-1383, 2002.

[10] T. Leroy and J. Chauvin, "Air Path Estimation for a Turbocharged SI Engine with Variable Valve Timing," Proceedings of the 2007 American Control Conference, 2007.

[11] M. Subramaniam, "A Multi-Cylinder Airflow \& Residual Gas Estimation Tool Applied to a Vehicle Demonstrator," SAE 2010-01-0169, 2010.

[12] Kolmanovsky et al., "Method and system for engine air charge estimation," United States Patent, 2003.

[13] C.-S. Liu, "Simultaneous Unknown State and Input Estimation With Application to Virtual Air Charge and EGR Sensors for Automotive Engines," ASME 2010 Dynamic Systems and Control Conference, 2010. 
[14] T. Leroy, J. Chauvin, N. Petit and G. Corde, "Motion Planning Control of the Airpath of an SI Engine with Valve Timing Actuators," Fifth IFAC Symposium on Advances in Automotive Control, AAC, 2007.

[15] A. Dutka, H. Javaherian and M. J. Grimble, "State-Dependent Kalman Filters for Robust Engine Control," Proceedings of the 2006 American Control Conference, 2006.

[16] E. Hendricks, "Isothermal vs. Adiabatic Mean Value SI Engine Models," Advances in Automotive Control 2001. Proceedings of the 3rd IFAC Workshop, 2001.

[17] . F. Castillo, E. Witrant, V. Talon and L. Dugard, "Simultaneous air fraction and lowpressure EGR mass flow rate estimation for diesel engines," IFAC Proc. Vol. 731736, 2013.

[18] P. Andersson and L. Eriksson, "Cylinder Air Charge Estimator in Turbocharged SIEngines," SAE 2004-01-1366, 2004.

[19] E. Hendricks, T. Vesterholm and S. Sorenson, "Nonlinear, Closed Loop, SI Engine Control Observers," SAE 920237, 1992.

[20] T. Polóni , B. Rohal'-Ilkiv and T. Arne Johansen, "Mass flow estimation with model bias correction for a turbocharged Diesel engine," Control Eng. Pract. 23(1):22-31, 2014.

[21] O. Barbarisi, A. Gaeta and L. Glielmo, "An Extended Kalman Observer for the InCylinder Air Mass Flow Estimation," Proc. MECA02 Int. Work. Diagnostics Automot. Engines Veh. 1-14, 2002.

[22] P. Andersson and L. Eriksson, "Observer based feedforward air-fuel control of turbocharged SI-engines," IFAC World Congress, 2005.

[23] P. Andersson and L. Eriksson, "Air-to-Cylinder Observer on a Turbocharged SIEngine with Wastegate," SAE 2001-01-0262, 2001.

[24] Q. Ahmed, and I. Bhatti, "Second order sliding mode observer for estimation of SI engine Volumetric Efficiency amp; Throttle Discharge Coefficient," Var. Struct. Syst. (VSS), 2010 11th Int. Work. 307-312, 2010.

[25] M. Hassani, V. Salehi, R. Salarieh, H. Alasty and G. Vossoughi, "Real-time estimation of the volumetric efficiency in spark ignition engines using an adaptive sliding-mode observer," Proc. Inst. Mech. Eng. Part D J. Automob. Eng., 2015.

[26] O. Storset, A. Stefanopoulou and R. Smith, "Adaptive Air Charge Estimation for Turbocharged Diesel Engines Without Exhaust Gas Recirculation," J. Dyn. Syst. Meas. Control 126(3), 2004. 
[27] A. Stefanopoulou, O. Storset and R. Smith, "Pressure and temperature-based adaptive observer of air charge for turbocharged diesel engines," Int. J. Robust Nonlinear Control 14(6), 2004.

[28] T. Tseng and W. Cheng, "An Adaptive Air/Fuel Ratio Controller for SI Engine Throttle Transients," SAE 1999-01-0552, 1999.

[29] A. Stotsky and I. Kolmanovsky, "Simple unknown input estimation techniques for automotive applications," Proceedings of the 2001 American Control Conference, IEEE, 2001.

[30] B. Wu, Z. Filipi and D. M. Kramer, "Using Artificial Neural Networks for Representing the Air Flow Rate through a 2.4 Liter VVT Engine," SAE 2004-013054, 2004.

[31] G. Malaczynski, M. Mueller, J. Pfeiffer and Cabush D. et al., "Replacing Volumetric Efficiency Calibration Look-up Tables with Artificial Neural Network-based Algorithm for Variable Valve Actuation," SAE 2010-01-0158, 2010.

[32] J. El Hadef, G. Colin, V. Talon and Y. Chamaillard, "Neural Model for Real-Time Engine Volumetric Efficiency Estimation," SAE 2013-24-0132, 2013.

[33] M. Mladek and C. H. Onder, "A Model for the Estimation of Inducted Air Mass and the Residual Gas Fraction using Cylinder Pressure Measurements," SAE 2000-010958, 2000.

[34] G. Colin, P. Giansetti, Y. Chamaillard and P. Higelin, "In-Cylinder Mass Estimation using Cylinder Pressure," SAE 2007-24-0049, 2007.

[35] J. Worm, "An Evaluation of Several Methods for Calculating Transient Trapped Air Mass with Emphasis on the "Delta P" Approach," SAE 2005-01-0990, 2005.

[36] N. Müller and R. Isermann, "Control of Mixture Composition Using Cylinder Pressure Sensors," SAE 2001-01-3382, 2001.

[37] J. Desantes, J. Galindo, C. Guardiola and V. Dolz, "Air mass flow estimation in turbocharged diesel engines from in-cylinder pressure measurement," Exp. Therm. Fluid Sci. 34(1):37-47, 2010.

[38] P. Giansetti, G. Colin, P. Higelin and Y. Chamaillard, "Residual gas fraction measurement and computation," International Journal of Engine Research, Vol. 8, 2007.

[39] Jianwen Yi et al, "Development and Optimization of the Ford 3.5L V6 EcoBoost Combustion System," SAE 2009-01-1494, 2009.

[40] "LabVIEW 2009 Service Pack 1, version 9.0.1 (32-bit), NATIONAL INSTRUMENTS". 
[41] "ATI Vision version 3.7.4, Accurate Technologies," 47199 Cartier Drive, Wixom, Michigan 48393, USA, Copyright 1997-2013.

[42] Kistler, [Online]. Available: https://www.kistler.com/us/en/.

[43] "ACAP 6.00B, Advanced Combustion Analysis Program," Copyright 1988-2000 MTS-DSP Technology Inc, Special GM Version.

[44] "Micro Motion ${ }^{\circledR}$ ELITE ${ }^{\circledR}$ Coriolis Flow and Density Meters" Product Data Sheet, September 2011.

[45] Meriam Laminar Flow Elements User Manual.

[46] Y. A. Cengel and M. A. Boles, Thermodyanmics, An Engineering Approach.

[47] M. Tazerout, O. Le Corre and S. Rousseau, "TDC Determination in IC Engines Based on the Thermodynamic Analysis of the Temperature-Entropy Diagram," SAE 199901-1489, 1999.

[48] J.W. Fox et al,, "A Model for Predicting Residual Gas Fraction in Spark-Ignition Engines," SAE 931025, 1993.

[49] V. Kale, Y. Yeliana, J. Worm and J. D. Naber, "Development of an Improved Residuals Estimation Model for Dual Independent Cam Phasing Spark-Ignition Engines".

[50] A. Singh, "Estimating Residual Gas Fraction for SI Engines with Dual Independent Cam Systems," Master's Report, Michigan Technological University, 2008.

[51] "Engineering Equation Solver (EES), F-Chart Software, Academic Preofessional V9.902," 1992-2015.

[52] J. B. Heywood, Internal Combustion Engine Fundamentals, 1988.

[53] "MathWorks, MATLAB R2013a (8.1.0.604)," Copyright 1984-2013.

[54] C. R. Ferguson and A. T. Kirkpatrick, Internal Combustion Engines: Applied Thermosciences, John Wiley \& Sons .

[55] A. H. Gandhi and M. Meinhart, "Fuel Injector Flow Rate Analysis for the Duratec 35 Ecoboost Engine," SAE 2009-01-1505, 2009.

[56] L. U. N. Guan-de, "MATLAB Curve Fitting Toolbox in Disposing of Experiment Data," Tractor \& Farm Transporter 4, 2006.

[57] M. H. Beale, M. T. Hagan and B. Howard, Neural Network Toolbox ${ }^{\text {TM }}$ User's Guide R2014a ed 2014, 1992.

[58] M. H. Kutner, C. J. Nachtsheim and J. Neter, Applied Linear Regression Models, McGraw-Hill/Irwin.

[59] "https://en.wikipedia.org/wiki/Root-mean-square_deviation," [Online]. 
[60] C. R. Hutton, "An Experimental Investigation Into The Passive Oxidation Of Particulate Matter In A Catalyzed Particulate Filter," Master's Thesis, Michigan Technological University, 2010. 


\section{Appendix A}

\section{Laminar Flow Element (LFE) Calculations}

Four variables are to be measured and considered for air flow measurement:

Ambient temperature in $\left[{ }^{\circ} \mathrm{F}\right]$, relative humidity in [\%], differential pressure along the LFE matrix element in $\left[\mathrm{inH}_{2} \mathrm{O} @ 4^{\circ} \mathrm{C}\right]$, and absolute pressure in [inHg].

Dry air flow is calculated with the following approximately linear equation:

$$
\text { flow }_{\text {dry }}=B \times \Delta P+C \times \Delta P^{2}
$$

Where $\Delta P$ is differential pressure across LFE element; $B$ and $C$ are LFE calibration coefficients with values [45]:

$$
B=51.2193 \quad \text { and } \quad C=-0.15892
$$

Actual air mass flow rate is calculated using correction factors for viscosity, density and considering standard condition temperature and pressure. 
actual air flow rate $\left(\frac{k g}{h r}\right)=2.0467 \times$ flow $_{\text {dry }} \times\left(\right.$ factor $\left._{\mu}\right) \times\left(\right.$ factor $\left._{T P}\right) \times\left(\frac{\rho_{\text {wet }}}{\rho_{\text {dry }}}\right)$

(A. 3)

in which,

factor $_{\mu}$ is correction factor for viscosity,

factor $_{T P}$ is standard temperature and pressure correction factor, and

$\frac{\rho_{w e t}}{\rho_{d r y}}$ is density correction factor.

Correction factor for viscosity $\left(\right.$ factor $\left._{\mu}\right)$ is calculated using following equation (T denotes ambient temperature):

$$
\text { factor }_{\mu}=\left(\frac{14.58 \cdot\left(\frac{459.67+T}{1.8}\right)^{1.5}}{110.4+\frac{459.67+T}{1.8}}\right) \cdot\left(\frac{\frac{\mu_{\text {wet }}}{\mu_{d r y}}}{\frac{14.58 \cdot\left(\frac{459.67+70}{1.8}\right)^{1.5}}{110.4+\frac{459.67+70}{1.8}}}\right)
$$

in which, relative humidity viscosity correction factor $\left(\frac{\mu_{w e t}}{\mu_{d r y}}\right)$ is obtained from Figure A- 1 . 


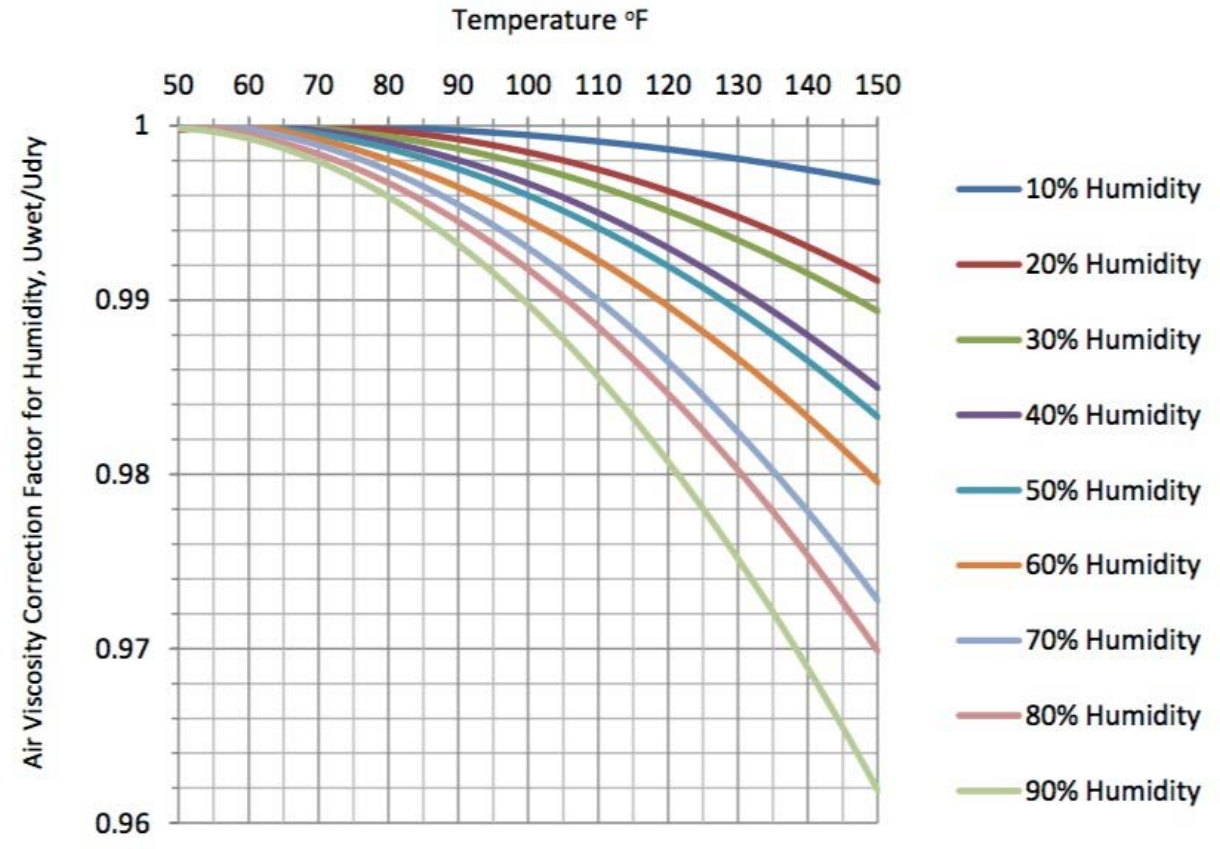

Figure A- 1 Relative humidity viscosity correction for air (Courtesy of [45])

This plot is then converted into a lookup table to calculate $\frac{\mu_{w e t}}{\mu_{d r y}}$ based on ambient temperature and relative humidity.

Table A- 1. Relative humidity viscosity correction factor

\begin{tabular}{|c|c|c|c|c|}
\cline { 2 - 5 } \multicolumn{1}{c|}{} & \multicolumn{4}{c|}{ Temperature ( ${ }^{\circ}$ F) } \\
\hline Relative & $\mathbf{6 0}$ & $\mathbf{7 0}$ & $\mathbf{8 0}$ & $\mathbf{1 0 0}$ \\
\hline Humidity (\%) & & 1 & 1 & 1 \\
\hline $\mathbf{0}$ & 1 & 0.9992 & 0.9987 & 0.9965 \\
\hline $\mathbf{4 0}$ & 0.9995 & 0.9987 & 0.9975 & 0.9930 \\
\hline 90 & 0.9992 & 0.9980 & 0.9957 & 0.9900 \\
\hline
\end{tabular}


Standard temperature and pressure correction factor is calculated using:

$$
\text { factor }_{T P}=\left(\frac{529.67}{459.67+T}\right) \cdot\left(\frac{29.9213}{P}\right)
$$

\section{(A. 5)}

in which $T$ and $P$ are ambient temperature and absolute pressure.

Density correction factor $\left(\frac{\rho_{w e t}}{\rho_{d r y}}\right)$ is obtained from Table A- 2 by having relative humidity and temperature.

Table A- 2. Density correction factor for humid air [45]

\begin{tabular}{|c|c|c|c|c|c|c|}
\cline { 2 - 7 } \multicolumn{1}{c|}{} & \multicolumn{6}{c|}{ Relative Humidity (\%) } \\
\hline $\begin{array}{c}\text { Temperature } \\
\left({ }^{\circ} \mathbf{F}\right)\end{array}$ & $\mathbf{0}$ & $\mathbf{2 0}$ & $\mathbf{4 0}$ & $\mathbf{6 0}$ & $\mathbf{8 0}$ & $\mathbf{1 0 0}$ \\
\hline $\mathbf{6 0}$ & 1 & 0.9986 & 0.9973 & 0.9960 & 0.9948 & 0.9934 \\
\hline $\mathbf{7 0}$ & 1 & 0.9984 & 0.9962 & 0.9944 & 0.9925 & 0.9907 \\
\hline $\mathbf{8 0}$ & 1 & 0.9974 & 0.9948 & 0.9922 & 0.9895 & 0.9870 \\
\hline $\mathbf{9 0}$ & 1 & 0.9964 & 0.9928 & 0.9892 & 0.9855 & 0.9818 \\
\hline $\mathbf{1 0 0}$ & 1 & 0.9951 & 0.9902 & 0.9854 & 0.9805 & 0.9756 \\
\hline
\end{tabular}

More details on LFE measurement can be found in [60]. 


\section{Appendix B}

\section{Steady-State Tests for Fuel Calculations}

Lambda sweep tests are performed at two different RPM's and the corresponding average values for injector PW, FRP and total injected fuel (300 cycles and 6 cylinders) are reported in Table B- 1. These data are used to fit fuel meter data to injector PW and differential injection pressure.

Table B- 1. Steady-state tests performed and corresponding PW, differential injection pressure, and total injected fuel in engine

\begin{tabular}{|c|c|c|c|}
\hline Test Condition & $\begin{array}{c}\text { Fuel flow meter } \\
\text { (Total Injected Fuel) } \\
\text { (gr) }\end{array}$ & $\begin{array}{c}\text { Average PW } \\
\text { (All } 6 \text { injectors) } \\
(\mu \mathrm{s})\end{array}$ & $\begin{array}{c}\text { Differential } \\
\text { Injection Pressure } \\
\text { (bar) }\end{array}$ \\
\hline 1500 RPM lambda=1 & 27.42 & 2402 & 17.38 \\
\hline 1500 RPM lambda=1.05 & 25.63 & 2279 & 17.36 \\
\hline 1500 RPM lambda=1.1 & 24.66 & 2192 & 17.03 \\
\hline 1500 RPM lambda=1.15 & 23.43 & 2083 & 17.03 \\
\hline 1500 RPM lambda=1.2 & 22.77 & 2053 & 16.80 \\
\hline 1500 RPM lambda $=1.25$ & 21.38 & 1924 & 16.40 \\
\hline 1500 RPM lambda $=1.3$ & 20.82 & 1870 & 16.40 \\
\hline 1500 RPM lambda $=0.95$ & 28.05 & 2438 & 17.64 \\
\hline 1500 RPM lambda $=0.9$ & 29.42 & 2527 & 18.16 \\
\hline 1500 RPM lambda $=0.85$ & 30.87 & 2591 & 18.93 \\
\hline 1500 RPM lambda $=0.8$ & 32.55 & 2662 & 19.87 \\
\hline 1500 RPM lambda $=0.75$ & 34.63 & 2685 & 22.30 \\
\hline 1500 RPM lambda $=0.7$ & 37.44 & 2730 & 25.30 \\
\hline
\end{tabular}




\begin{tabular}{|c|c|c|c|}
\hline Test Condition & $\begin{array}{c}\text { Fuel flow meter } \\
\text { (Total Injected Fuel) } \\
(\mathbf{g r})\end{array}$ & $\begin{array}{c}\text { Average PW } \\
\text { (All 6 injectors) } \\
\mathbf{( \mu s )}\end{array}$ & $\begin{array}{c}\text { Differential } \\
\text { Injection } \\
\text { Pressure } \\
\text { (bar) }\end{array}$ \\
\hline 1000 RPM lambda=1 & 18.48 & 1708 & 16.12 \\
\hline 1000 RPM lambda=1.05 & 17.41 & 1620 & 16.10 \\
\hline 1000 RPM lambda=1.1 & 16.49 & 1566 & 15.79 \\
\hline 1000 RPM lambda=1.15 & 15.94 & 1507 & 15.80 \\
\hline 1000 RPM lambda=1.2 & 15.48 & 1454 & 15.78 \\
\hline 1000 RPM lambda=1.25 & 15.13 & 1404 & 15.78 \\
\hline 1000 RPM lambda=1.3 & 14.54 & 1373 & 15.35 \\
\hline 1000 RPM lambda=0.95 & 19.42 & 1795 & 16.13 \\
\hline 1000 RPM lambda=0.9 & 20.37 & 1866 & 16.11 \\
\hline 1000 RPM lambda=0.85 & 21.26 & 1923 & 16.47 \\
\hline 1000 RPM lambda=0.8 & 22.12 & 2018 & 16.47 \\
\hline 1000 RPM lambda=0.75 & 23.74 & 2139 & 16.79 \\
\hline 1000 RPM lambda=0.7 & 25.56 & 2268 & 17.25 \\
\hline
\end{tabular}




\section{Appendix C}

\section{Final Steady-State Tables}

Table C- 1 includes all the calibration values for steady-state tests (61 total). Using an average value for parameters $h_{\text {constant }}, \alpha$ (over 3 cylinders) may cause deviation of estimated air charge form the cylinder experimental air charge:

$$
E(i)=\frac{\text { Air }(i)-\text { experimental air of } \operatorname{cyl}(i)}{\text { experimental air of } \operatorname{cyl}(i)} \times 100
$$

Air1, Air5, and Air6 are estimated air charge for cylinders 1, 5, and 6 when using the averaged parameters; the deviations of the estimated air charges from their corresponding experimental air charge are denoted by E1, E5, and E6.

Table C- 1 includes steady-state test conditions with different loads (IMEP's in kPa), engine speeds, intake cam timing (intake cam advance in deg CA) and lambdas. $h_{\text {constant }}$ is in $\left[\frac{W}{m^{2} \cdot K}\right]$, and $\alpha$ is in $\left[{ }^{\circ} \mathrm{CA} / \mathrm{m}\right]$. Also Air1, Air5, Air6 and LFE Air are in $[\mathrm{mg}]$ and error is in $[\%]$. 
Table C- 1 . Steady state test conditions and calibrated parameters

\begin{tabular}{|c|c|c|c|c|c|c|c|c|c|c|c|c|c|}
\hline Test & RPM & IMEP & $\lambda$ & Cam & $h_{\text {const }}$ & $\alpha$ & $\begin{array}{c}\text { Air } \\
1\end{array}$ & $\begin{array}{c}\text { Air } \\
5\end{array}$ & $\begin{array}{c}\text { Air } \\
6\end{array}$ & E1 & E5 & E6 & $\begin{array}{c}\text { LFE } \\
\text { Air }\end{array}$ \\
\hline 1 & & & 1.0 & 0 & 2.34 & 0.338 & 200 & 198 & 195 & 0.6 & 0.9 & -2.2 & 204 \\
\hline 2 & 1500 & 308 & 1.0 & 10 & 2.47 & 0.372 & 206 & 199 & 199 & 2.9 & -0.0 & -2.3 & 207 \\
\hline 3 & 1500 & 305 & 1.0 & 20 & 2.37 & 0.350 & 201 & 199 & 201 & 1.7 & 0.4 & -1.9 & 203 \\
\hline 4 & 1500 & 303 & 1.0 & 30 & 2.13 & 0.343 & 198 & 196 & 197 & 2.3 & 0.5 & -3.5 & 201 \\
\hline 5 & 1500 & 311 & 1.1 & 0 & 2.13 & 0.355 & 212 & 212 & 206 & 0.5 & 2.4 & -2.9 & 216 \\
\hline 6 & 1500 & 310 & 1.1 & 10 & 2.30 & 0.385 & 217 & 214 & 212 & 2.2 & 1.1 & -3.4 & 215 \\
\hline 7 & 1500 & 309 & 1.1 & 20 & 2.23 & 0.355 & 217 & 212 & 210 & 2.3 & 1.7 & -4.0 & 213 \\
\hline 8 & 1500 & 306 & 1.1 & 30 & 2.00 & 0.348 & 213 & 207 & 207 & 1.9 & 1.8 & -3.4 & 210 \\
\hline 9 & 1500 & 314 & 12 & 0 & 2.07 & 0.386 & 222 & 227 & 219 & 0.4 & 3.5 & -3.6 & 228 \\
\hline 10 & 1500 & 310 & 1.2 & 10 & 2.17 & 0.408 & 227 & 225 & 223 & 2.2 & 1.1 & -3.5 & 229 \\
\hline 11 & & & 1.2 & 20 & 27 & 0.372 & 230 & 226 & 224 & 20 & 1.5 & -4.5 & 229 \\
\hline 12 & 1500 & 306 & 1.2 & 30 & 1.80 & 0.368 & 224 & 222 & 221 & 1.5 & 1.6 & -3.4 & 226 \\
\hline 13 & 1500 & 318 & 12 & 0 & 1.63 & 0.410 & 238 & 236 & 229 & 3.3 & 2.7 & -5.5 & 245 \\
\hline 14 & 1500 & 312 & 1.3 & 20 & 1.60 & 0.382 & 239 & 238 & 237 & 3.7 & 0.6 & -4.2 & 247 \\
\hline 15 & 1500 & 309 & 1.3 & 30 & 1.20 & 0.363 & 240 & 236 & 236 & 3.4 & 1.2 & -4.7 & 247 \\
\hline 16 & 1500 & 520 & 1.0 & 0 & 2.50 & 0.940 & 313 & 315 & 314 & 2.6 & -0.2 & -1.8 & 322 \\
\hline 17 & 1500 & 510 & 1.0 & 20 & 2.10 & 0.810 & 315 & 308 & 314 & 4.6 & -1.8 & -3.0 & 319 \\
\hline 18 & 1500 & 507 & 1.0 & 30 & 1.83 & 0.840 & 310 & 302 & 306 & 3.9 & -1.8 & -2.4 & 313 \\
\hline 19 & 1500 & 515 & 1.1 & 0 & 1.97 & 1.090 & 327 & 332 & 330 & 1.4 & 0.4 & -1.8 & 339 \\
\hline 20 & 1500 & 510 & 1.1 & 10 & 1.53 & 0.853 & 334 & 324 & 327 & 1.8 & -1.9 & -4.3 & 337 \\
\hline 21 & 1500 & 511 & 1.1 & 20 & 1.97 & 0.807 & 338 & 332 & 333 & 5.5 & -1.6 & -4.1 & 335 \\
\hline 22 & & & & 30 & & 0.850 & 332 & 328 & 330 & 4.7 & -1.3 & -3.4 & 332 \\
\hline 23 & 1500 & 513 & 1.2 & 0 & 1.93 & 1.217 & 351 & 354 & 349 & 2.4 & 1.2 & -2.9 & 357 \\
\hline 24 & 1500 & 507 & 1.2 & 10 & 1.93 & 0.960 & 358 & 350 & 352 & 3.8 & -0.5 & -3.1 & 356 \\
\hline 25 & 1500 & 505 & 1.2 & 20 & 1.90 & 0.900 & 359 & 353 & 354 & 6.9 & -1.4 & -4.7 & 356 \\
\hline 26 & 1500 & 504 & 1.2 & 30 & 1.60 & 0.947 & 354 & 348 & 347 & 5.8 & -0.8 & -5.1 & 352 \\
\hline 27 & 1500 & 514 & 1.3 & 0 & 1.48 & 1.377 & 374 & 377 & 374 & 2.8 & 0.2 & -2.9 & 381 \\
\hline 28 & 1500 & 513 & 1.3 & 10 & 1.53 & 1.037 & 380 & 373 & 375 & 4.2 & -0.6 & -3.1 & 380 \\
\hline 29 & 1500 & 504 & 1.3 & 20 & 1.53 & 0.903 & 384 & 380 & 380 & 7.2 & -1.3 & -5.1 & 381 \\
\hline 30 & 1500 & 505 & 1.3 & 30 & 1.13 & 0.940 & 385 & 378 & 376 & 6.9 & -1.4 & -5.3 & 380 \\
\hline 31 & 1000 & 208 & 1.0 & 0 & 2.80 & 0.129 & 152 & 149 & 147 & 1.1 & 0.1 & -1.5 & 141 \\
\hline
\end{tabular}




\begin{tabular}{|c|c|c|c|c|c|c|c|c|c|c|c|c|c|}
\hline Test & RPM & IMEP & $\lambda$ & Cam & $\mathbf{h}_{\text {const }}$ & $\alpha$ & $\begin{array}{c}\text { Air } \\
1\end{array}$ & $\begin{array}{c}\text { Air } \\
5\end{array}$ & $\begin{array}{c}\text { Air } \\
6\end{array}$ & E1 & E5 & E6 & $\begin{array}{c}\text { LFE } \\
\text { Air }\end{array}$ \\
\hline 32 & 1000 & 209 & 1.0 & 10 & 2.73 & 0.162 & 151 & 149 & 151 & 0.2 & 0.1 & -0.8 & 141 \\
\hline 33 & 1000 & 207 & 1.0 & 20 & 2.57 & 0.187 & 149 & 147 & 148 & 1.1 & -0.5 & -0.6 & 139 \\
\hline 34 & 1000 & 214 & 1.0 & 30 & 2.80 & 0.194 & 150 & 145 & 147 & 2.7 & -2.6 & 0.4 & 139 \\
\hline 35 & 1000 & 209 & 1.1 & 0 & 2.53 & 0.137 & 160 & 157 & 155 & 0.3 & 1.6 & -1.5 & 148 \\
\hline 36 & 1000 & 209 & 1.1 & 10 & 2.43 & 0.170 & 159 & 155 & 158 & 1.1 & 0.3 & -1.0 & 149 \\
\hline 37 & 1000 & 214 & 1.1 & 30 & 2.63 & 0.212 & 163 & 157 & 161 & 1.6 & -2.5 & 0.6 & 150 \\
\hline 38 & 1000 & 212 & 1.2 & 0 & 2.43 & 0.132 & 168 & 165 & 162 & 1.3 & 1.4 & -3.1 & 156 \\
\hline 39 & 1000 & 212 & 1.2 & 10 & 2.37 & 0.165 & 168 & 163 & 164 & 1.8 & 0.9 & -2.5 & 156 \\
\hline 40 & 1000 & 212 & 1.2 & 20 & 2.30 & 0.180 & 165 & 163 & 164 & 1.6 & 0.7 & -2.0 & 156 \\
\hline 41 & 1000 & 211 & 1.2 & 30 & 2.20 & 0.227 & 182 & 170 & 170 & 5.3 & -0.9 & -2.3 & 161 \\
\hline 42 & 1000 & 216 & 1.3 & 0 & 2.43 & 0.134 & 177 & 175 & 170 & 1.6 & 3.1 & -4.6 & 165 \\
\hline 43 & 1000 & 217 & 1.3 & 10 & 2.37 & 0.167 & 177 & 175 & 173 & 2.1 & 2.2 & -3.9 & 166 \\
\hline 44 & 1000 & 216 & 1.3 & 20 & 2.30 & 0.187 & 178 & 177 & 176 & 1.3 & 0.8 & -1.9 & 168 \\
\hline 45 & 1500 & 213 & 1.0 & 0 & 2.30 & 0.152 & 140 & 138 & 137 & 0.7 & 0.2 & -0.6 & 141 \\
\hline 46 & 1500 & 218 & 1.0 & 10 & 2.47 & 0.205 & 151 & 145 & 146 & 2.7 & -2.2 & -0.6 & 148 \\
\hline 47 & 1500 & 218 & 1.0 & 20 & 2.40 & 0.200 & 145 & 139 & 143 & 1.0 & 0.2 & -0.6 & 144 \\
\hline 48 & 1500 & 217 & 1.0 & 30 & 2.07 & 0.173 & 141 & 134 & 138 & 1.6 & 0.9 & -2.0 & 141 \\
\hline 49 & 1500 & 604 & 1.0 & 0 & 2.13 & 1.527 & 357 & 360 & 353 & 0.5 & 2.8 & -3.3 & 374 \\
\hline 50 & 1500 & 608 & 1.0 & 30 & 1.70 & 1.243 & 357 & 354 & 354 & 2.7 & 1.8 & -4.1 & 374 \\
\hline 51 & 1500 & 607 & 1.2 & 10 & 1.30 & 1.567 & 405 & 401 & 403 & 1.9 & 3.3 & -4.4 & 426 \\
\hline 52 & 1500 & 598 & 1.2 & 20 & 1.23 & 1.400 & 403 & 398 & 400 & 2.4 & 3.2 & -5.1 & 422 \\
\hline 53 & 1500 & 603 & 1.2 & 30 & 0.93 & 1.507 & 410 & 402 & 400 & 4.4 & 1.3 & -5.4 & 426 \\
\hline 54 & 2500 & 332 & 1.0 & 0 & 2.80 & 0.415 & 212 & 202 & 199 & 5.4 & -0.7 & -4.0 & 215 \\
\hline 55 & 2500 & 332 & 1.0 & 10 & 2.60 & 0.452 & 215 & 200 & 198 & 5.3 & -0.3 & -5.2 & 218 \\
\hline 56 & 2500 & 333 & 1.0 & 20 & 2.43 & 0.503 & 212 & 199 & 198 & 4.6 & -0.3 & -4.6 & 215 \\
\hline 57 & 2500 & 331 & 1.0 & 30 & 2.17 & 0.458 & 210 & 196 & 196 & 3.8 & -0.2 & -3.2 & 215 \\
\hline 58 & 2500 & 333 & 1.2 & 0 & 1.73 & 0.527 & 232 & 219 & 216 & 4.5 & 0.2 & -4.8 & 242 \\
\hline 59 & 2500 & 332 & 1.2 & 10 & 1.47 & 0.543 & 232 & 215 & 216 & 3.2 & 0.6 & -4.1 & 244 \\
\hline 60 & 2500 & 333 & 1.2 & 20 & 1.50 & 0.543 & 234 & 221 & 219 & 4.2 & 1.0 & -5.1 & 244 \\
\hline 61 & 2500 & 328 & 1.2 & 30 & 1.20 & 0.490 & 228 & 216 & 217 & 2.1 & 1.3 & -3.4 & 240 \\
\hline
\end{tabular}


Appendix D

Letters of Permission 


\section{SAE International / letter of permission}

1 message

Nikole Aston <nikole.aston@sae.org >

Wed, Jul 27, 2016 at 4:19 PM

To: Arya Yazdani <aryay@mtu.edu>

Dear Arya,

Thank you for your patience.

Reproduction use of Figure 10 of SAE technical paper 2009-01-1505, is hereby granted, and subject to the following terms and conditions:

-Permission is granted for non-exclusive English language rights, and for the specific use as indicated in your email;

-Permission is required for new requests, or for further use of the material;

-The SAE material must be clearly identified and include the following statement "Reprinted with Permission from SAE International";

-We also request that you include a complete reference to the $S A E$ document in the reference section for each figure used;

-The permission does not cover any third-party copyrighted work which may appear in the material requested;

-Licensor's use of this material, in whole or in part, is entirely its responsibility, and SAE International does not warrant or is not responsible for any use of the material.

Best regards,

Nikole Aston

Copyright Administrator

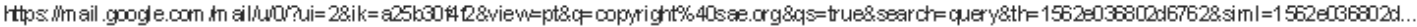




\author{
SAE INTERNATIONAL \\ 400 Commonwealth Drive \\ Warrendale, PA 15096 USA \\ o: +1.724 .772 .4095$ \\ e: nikole.aston@sae.org \\ unw.sae.org
}

From: Arya Yazdani [mailto:aryay@mtu.edu]

Sent: Tuesday, July 26, 2016 10:37 AM

To: copyright <copyright@sae.org>; Nikole Aston <nikole.aston@sae.org>

Subject: letter of permission

$\mathrm{Hi}$,

I need a letter of permission on this:

Here are the required information:

- Title, Publication number, Edition number, and Copyright year of SAE publication:

Fuel Injector Flow Rate Analysis for the Duratec 35 EcoBoost Engine, SAE Technical Paper 2009-01-1505, 2009

- Exact material, including page or figure numbers, for which permission is requested:

Figure 10. (Definition of SOI and EOI delay) on page 5

- Title of Thesis/Dissertation:

Air Charge Estimation for an SI Engine Using in-Cylinder Pressure Sensor

- Name of school:

Michigan Technological University

- Number of copies to be distributed, and to whom:

1, Arya Yazdani

- Format/media (print, electronic, etc.) If electronic, provide details on how it will be distributed:

Print/electronic. Electronic version will be distributed on "ProQuest" and "Digital Commons @ Michigan Tech".

- Expected publication date:

Aug. 2016

Please leave this text in your reply.

Thanks, 
$-$

Arya Yazdani

Mechanical Engineering

Michigan Technological University

1400 Townsend Drive

Houghton, MI 49931-1295

Linkedin: https://wuw. linkedin.com/in/aryayazdani

Nothing in this message is intended to constitute an electronic signature unless a specific statement to the contrary is included in this message. Confidentiality Note: This message is intended only for the person or entity to which it is addressed. It may contain confidential and/or proprietary material. Any review, transmission, dissemination or other use or taking of any action in reliance upon this message by persons or entities other than the intended recipient is prohibited. If you received this message in error, please contact the sender and delete it from your computer. 


\section{Letter of Permission for thesis}

Rich Angelino <rich@meriam.com>

Tue, Jul 26, 2016 at 8:59 AM

To: "aryay@mtu.edu" <aryay@mtu.edu>

Cc: Leo Buckon <lbuckon@meriam.com>, Jeff Ghilani <JGhilani@meriam.com>, Oneda Dixon <odixon@meriam.com>

$\mathrm{Hi}$

You have permission to use the bel ow Figure.

I am a master's student in Mechanical engineering at MichiganTech University. I am asking permission to use Figure 2. (Relative humidity correction factor for air viscosity) in "Meriam Laminar Flow Elements User Manual" for my thesis. It can be found at https://wwow meriam. com/assets/LFE-User-Manual. pdf.

Richard 0. Angelino | International Sales Manager

Meriam Process Technologies, a Soott Fetzer Company

10920 Madison Ave. Cleveland, $\mathrm{OH} 44102$

Main Line: $1+216.281 .1100$

Direct Line: $1+216.928 .2228$

Mobile: $1+216.650 .3051$

$\mathrm{Fax} 1+216.281 .0228$

Email: rich@meriam .com

Skype: roangelino

Web: whwweriam . com

From: Oneda Dixon

Sent: Monday, July 25, 2016 10:17 AM

To: Jeff Ghilani; Rich Angelino; Leo Buckon; Kim McLaughlin

Subject: FW: Letter of Permission for thesis

fyi 


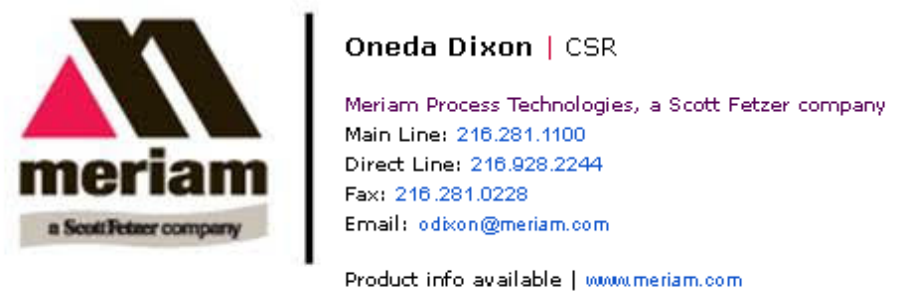

Providing Innovative, Reliable, Cost Effective Measurement \& Calibration Solutions Since 1911

Please ensure all returns are free of Hazardous Materials

From: Arya Yazdani [mailto:aryay@mtu.edu]

Sent: Monday, July 25, 2016 10:11 AM

To: return forms

Subject: Re: Letter of Permission for thesis 